\title{
Finding, developing and using indicators of behavioural determinants of children's health in Europe
}

Citation for published version (APA):

Alexander, D. (2015). Finding, developing and using indicators of behavioural determinants of children's health in Europe. [Doctoral Thesis, Maastricht University]. Maastricht University. https://doi.org/10.26481/dis.20151201da

Document status and date:

Published: 01/01/2015

DOI:

10.26481/dis.20151201da

Document Version:

Publisher's PDF, also known as Version of record

\section{Please check the document version of this publication:}

- A submitted manuscript is the version of the article upon submission and before peer-review. There can be important differences between the submitted version and the official published version of record.

People interested in the research are advised to contact the author for the final version of the publication, or visit the DOI to the publisher's website.

- The final author version and the galley proof are versions of the publication after peer review.

- The final published version features the final layout of the paper including the volume, issue and page numbers.

Link to publication

\footnotetext{
General rights rights.

- You may freely distribute the URL identifying the publication in the public portal. please follow below link for the End User Agreement:

www.umlib.nl/taverne-license

Take down policy

If you believe that this document breaches copyright please contact us at:

repository@maastrichtuniversity.nl

providing details and we will investigate your claim.
}

Copyright and moral rights for the publications made accessible in the public portal are retained by the authors and/or other copyright owners and it is a condition of accessing publications that users recognise and abide by the legal requirements associated with these

- Users may download and print one copy of any publication from the public portal for the purpose of private study or research.

- You may not further distribute the material or use it for any profit-making activity or commercial gain

If the publication is distributed under the terms of Article $25 \mathrm{fa}$ of the Dutch Copyright Act, indicated by the "Taverne" license above, 
Finding, developing and using indicators of behavioural determinants of children's health in Europe

\section{Paula Denise Alexander}





\title{
Finding, Developing and Using \\ Indicators of Behavioural Determinants \\ of Children's Health in Europe
}

\author{
Dissertation \\ To obtain the degree of Doctor at Maastricht University \\ on the authority of the Rector Magnficus, \\ Prof. dr. L.L.G. Soete in accordance with \\ the decision of the Board of Deans, to be defended in \\ public on Tuesday, 1st December, at 14.00 hours
}

by

Paula Denise Alexander 


\section{Supervisors}

Prof. dr. H. Brand

Prof. M.J. Rigby, Nordic School of Public Health, Gothenburg, Sweden

\section{Co-supervisor}

Dr P. Schröder-Bäck

\section{Assessment Committee}

Prof. dr. L.M.G. Curfs. (Chair)

Prof. P. Achterberg

Dr. P.A. Wiegersma

Prof. dr. J. van der Zee 


\section{Table of contents}

Part 1 Introduction 5

Chapter $1 \quad 6$

Methodology 8

What is so special about children? 11

Measuring 14

Why do we need to measure? 14

What do we mean by upstream? 15

How can we measure? Finding and creating $\quad 17$

indicators

Existing indicator sets 18

International indicators and data comparability 19

Outline of this thesis 21

Part 2 Finding indicators 24

Chapter 2 Challenges and Findings in Measuring the 25

Behavioural Determinants of Obesity in Children in

Europe: Introduction: purpose, origins and method

Chapter 3 Nutrition policy measures in European Countries. 38

Part 3 Developing indicators 66

Chapter 4 Challenges in finding and measuring behavioural 67

determinants of childhood obesity in Europe.

Chapter 5 Measuring behavioural determinants of child 89 maltreatment - an alternative viewpoint focusing on preventive and risk factors.

$\begin{array}{lll}\text { Part } 4 \text { Using indicators } & 109\end{array}$

Chapter 6 The challenges of compiling data profiles to 110

stimulate local preventive health action - a

European case study from child safety.

Chapter 7 The RICHE taxonomy - an innovative means of classification of child health research. 
Part 5 General discussion 149

Chapter 8 Characteristics of the problems identified 150

The environment as a determinant of health $\quad 150$

Lack of accessible data for indicators describing 152

determinants of health

Subnational data 152

Lack of standardisation and definitions across 153

Europe

Finding the most appropriate measures 154

Appropriate age groups - life course influences 154

Unmanageable number of indicators 155

Common themes that emerge 156

Utilising indicators into behavioural 156

determinants of health

Reliance on survey data 157

Lack of routine behavioural indicators about $\quad 158$ children

Strengths and limitations $\quad 160$

Recommendations for the future 161

References 164

Chapter 9 Summary, Samenvatting, Acknowledgements, 171

About the Author, List of Publications, List of EU

Projects

Valorisation $\quad 171$

Summary $\quad 176$

Samenvatting $\quad 180$

Acknowledgements $\quad 184$

About the Author 185

List of Publications 186

List of EU Projects 187 
Part 1: Introduction 


\section{Chapter 1:}

Good health is one of our most valuable resources, and good health in childhood is essential for future economic and social prosperity (World Health Organisation Regional Office for Europe, 2013). This thesis focuses on the challenges in finding appropriate indicators to measure the behavioural determinants of children and young people's health. Although at first glance this seems a simple prospect, and possibly even a task that contains nothing new to discover, the reality is very different. Children are recognised as a vulnerable population alongside other vulnerable populations, such as the elderly, the sick, migrant groups or other marginalised persons and so on; but they are unique in the characteristics that make them vulnerable for biological, developmental and environmental reasons. In addition to this, the effects of adverse health determinants on children are the longest lasting of any population group, because they can last a lifetime; determinants of poor health in childhood may also have a cumulative effect leading to worsening health as a child matures and develops, for example in the case of exposure to an obesogenic environment as a baby, leading to a struggle with obesity during childhood, and consequent health issues throughout life. These reasons necessitate a specific focus on children's health and measurement of its determinants. The specific characteristics and needs of children are discussed in more detail in the thesis.

Behavioural determinants of health are increasingly recognised as important to public health, as the evidence grows for the benefits of taking a holistic approach to many aspects of health, in particular children's health (Cattaneo et al.,2012; Institute of Medicine, 2011). Children's health is deeply rooted in the family, educational, societal and policy support that surrounds them as they grow up. Good health does not just 'happen' - it must be fostered. Many aspects of health are determined or influenced by personal choices and actions, and in the case of children, their own, parental and other adults' behaviours are involved, examples of this are breastfeeding, smoking, diet and physical exercise and recreation. Many of the determinants of good health, and of good health behaviour are interrelated.

This thesis critically examines a series of issues in order to propose a means of measuring children's health determining behaviours in their real life settings, using routine measures where possible and attempting to use measures that already exist, or could be collected in as easy and as 
practical manner as possible in today's Europe. This project primarily focuses on countries in the European Union (EU) and the European Economic Area (EEA).

My hypothesis is twofold: firstly, measuring children's lives, not just the negative health outcomes, will help to promote and protect population health; and secondly, to give effect to this, the collection and data about children's lives if undertaken cohesively will inform policies and preventive actions to provide an evidence-base for effective interventions.

Meaningful indicators need to be precise and specific and grounded in research evidence which demonstrates the relationship between what it measures and a health outcome. They should also be descriptive and imaginative in their function of describing the health and influences on health of children. The challenges of finding, developing and using indicators of children's health are considerable. Not only are children a vast and diverse population, differing in their health needs and actions according to age, development, social factors and so on; but Europe is a large continent, rich in variety of culture, language and lifestyles. For these reasons, specific subjects were identified that focus on the utility, potential and difficulty in using upstream behavioural determinants of health. Other concerns are how the indicators are populated with data and how they can be used. All of these subjects are of particular concern to the child population in the EU and EEA. They are childhood obesity, child maltreatment and child injury, and were the object of investigation in four large EU scientific research projects - the Scientific Platform on Lifestyle Determinants of Obesity (project no: 2005111); Tools to Address Childhood Trauma, Injury and Children's Safety TACTICS (project no: 20101212); Public Health Action for a Safer Europe (project no: 2006123); and Research Inventory of Child Health in Europe (project no: 242181).This thesis condenses, critically reflects and synthesises the outcome of these projects.

There is a dichotomy in attempting to apply a focussed scientific objectivity to a multi-faceted subject as the determinants of children's health behaviour. The introductory discussion that follows describe the methodologies used in this project; and goes on to outline what is so special and challenging about describing children's lives; the challenges 
of measurement; and the particular benefits and challenges of working in Europe. Finally, an outline of the thesis is described.

\section{Methodology}

The research framework in this thesis is primarily epidemiological. The focus recognises the importance of the influences there are on people to make choices about their health; and what elements make it easier or harder to behave in a health-promoting way. The question of how to measure these constructs is addressed through biomedical and public health science, using behavioural and sociological standpoints. There is great value in measuring children's 'real lives' without intrusion, or compromising a child and family's autonomy. This is because of the danger of the influence of the research itself, known as the Hawthorne effect (Saks and Alsopp, 2007), where the act of observation or measurement can distort behaviour leading to bias in findings. This can be used to advantage in terms of indicator creation; as anticipated in the terms of injury prevention for example. Simply measuring the safety elements of a community can actually focus efforts to improve them, which Chapter 6 of this thesis demonstrates; but in general, research needs to remain as impartial as possible to produce robust and reliable results. Achieving this is a considerable challenge. A traditional scientific approach, originating from natural sciences, which strives to measure phenomena in a considered and objective manner is not, at first glance, ideal to measure the often random, messy and unpredictable life of the average healthy and happy child in the European Union, let alone those experiencing adverse circumstances such as poor health, disadvantaged circumstances, disability or marginalisation. Nor is it possible, on an international scale, to use primarily qualitative research methods of inquiry, because of difficulties in generalisability across an entire continent; and the ethical and developmental obstacles inherent in interviewing and researching children. The potential clash of ideologies in undertaking a project such as this, to determine how to create indicators that measure the determinants of children's health behaviour has been interesting and rewarding, thus a mixed methods approach to the topic was taken, combining literature reviewing, qualitative inquiry and quantitative reasoning.

To attempt to measure any aspect of life from a holistic viewpoint primarily originates from a positivist paradigm; in that an attempt is made to find objective measures that will describe a scientific reality. 
However, in practice, there is a need for a more interpretivist viewpoint, to enable measurement of the wider factors that influence children's health and determinants of their health behaviour. Children are a diverse population, and their actions and needs are influenced by a myriad of factors, including personal ones such as age and development; and family, school and social circumstances. Thus, quantitative methodologies are used in this research in terms of identifying and using indicators, for example in the attempted creation of an index of child safety; but in addition, more qualitative methodologies were also used, for example in the discussions with experts and professionals that identified the most useful topics for indicators and the primary influences on children's lives. From this exploratory research, quantitative methods were used to provide a means of ultimately gathering descriptive statistics. Another example comes from the collection of much additional information about the measurement and attitudes to childhood obesity by the country sub-contractors in the Scientific Platform Project on Lifestyle Determinants of Obesity; this information added greatly to the richness of knowledge gathered in the research, although it did not contribute to the original quantitative project aims.

There is an ever-increasing range of influences on children's lives. This is for a number of reasons, not least because ideas and trends from across the globe are transmitted via fast and personal communication through social media or other forums. The influences of social and other forms of media are potent and provide another dimension to the influences of family, school and community that exist. These changes call for a new way of measuring children's lives. It is not enough to measure disease once it has occurred. New ways of facilitating prevention of poor health must be highlighted, and upstream influences on behavioural determinants must be identified and measured in order to empower children, their families and communities. In short, it is essential to move to a more holistic approach towards children's health; one that takes into account the importance of the family and wider environment, as it is the decisions made within the family that determines health and health outcomes in many aspects.

The methods used throughout this research, in terms of identifying and using indicators are inspired by those used in the Child Health Indicators for Life and Development (CHILD) project (Rigby et al., 2002). Firstly, for each specific example (such as obesity, injury or child 
maltreatment), a broad picture of the issues involved was first determined. Therefore, in the instance of childhood obesity it was the influences on the two immediate causal factors of obesity - namely nutrition and physical activity - which were investigated. These main issues formed a framework for further work. A review of the literature was conducted on each of these potentially influential elements, and those aspects that were capable of being measured were then identified. In the projects described here, further processes narrowed down the indicator list. Firstly it was considered whether these indicators would potentially be relevant in the different countries of the European region; and secondly the issue of whether it was possible, or even potentially possible, to find data to populate the indicator. In the Lifestyle Determinants project (Chapters 2,3 and 4) this work was a central theme as the indicators were tested to see what data were available in the countries of Europe about childhood obesity; In Chapter 6 in terms of the feasibility of the injury indicators, data availability played a large part in the outcome of the project, and Chapter 5, when proposing measures of child maltreatment, sought to find indicators where data could be developed or found via routine sources. This process of narrowing down the wider issues to more specific and informative elements was also used on a macro scale in Chapter 7 , to systematically catalogue and make sense of the enormity of elements that influence children's health outcomes.

Alongside this process, the elements of a model indicator were also considered (Rigby et al., 2002). In an ideal world, an indicator should have the following qualities:

- It should be valid in terms of face validity (can it measure what it claims to measure?); content validity (does it take into account the qualities that its definition implies); and construct validity (does it demonstrate an expected empirical relationship with other related indicators?)

- It should be consistent (is it reliable in measurement, so that variations in data are true variations, not random errors?)

- It should be sensitive (so that appropriate change is registered)

- It should be feasible (is a data source, or potential data source available?) 
- It should be defined (is it unambiguous in its construct?) This is in terms of topic definition; measure definition; measurement definition; and data capture definition.

It is not always possible to include all these elements in an indicator particularly when measuring children's lives. Nevertheless, the notion of an indicator that is ambiguous and able to show changes in a phenomenon or element of a child's lifestyle that influences health is vital. In terms of children's health, proxy and contextual measures are essential inclusions, particularly in the case of young children who cannot answer or speak for themselves. For example, determinants such as breastfeeding incidence must be reported by the mother; and the presence of baby friendly hospitals can be regarded as indicators of how the governmental system is protecting early child health. For slightly older children, food surveys provide accurate data, but they are expensive to carry out and are not necessarily transferrable to other regions or countries; whereas records of food purchases, although not ideal, have the potential to tell us who may or may not have access to fresh food within a household. A generic issue across this entire thesis is that of finding appropriate measures relevant to each topic under consideration; the influence of the life course on health decisions and health determinants and how close to the topic does an indicator need to be?

\section{What is so special about children?}

The United Nations Convention on the Rights of the Child, to which all European nations are signatories defines children as "every human being below the age of eighteen years" (United Nations General Assembly, 1989). As part of the Convention, every state is required to ensure "the right of the child to the enjoyment of the highest attainable standard of health and to facilities for the treatment of illness and rehabilitation of health". Thus, measuring children's levels of health, and the influences upon health is a vital action in order to improve health to the highest standard.

Children are a diverse population, and one that is uniquely vulnerable in terms of risks to health. They merit scientific attention and health protection in the same way as other vulnerable groups, such as the elderly or chronically ill, but over and above this, they are uniquely and specifically different to adults in terms of their health and risks to health 
and as such merit a specific approach to measurement and health surveillance.

Children's particular vulnerability to determinants of health manifests in many ways. Biologically, children are extremely sensitive to environmental stressors. They can be profoundly affected by external influences in utero and during the first years of life, but this vulnerability remains the case throughout childhood (Kuh \& Shlomo 2004). In addition to this, children's lifestyles can increase the risks to their health as they interact with the adult world and the domination of adults upon their lives. A child's habits of life, lack of awareness, size and metabolism mean that he or she receives greater exposure to environmental toxins, such as traffic pollution, per kilogramme of body weight than an adult would, for example (Bolte et al., 2009).

Childhood is where prevention of many adult diseases can take place. An increasing body of research indicates that childhood physical status, and childhood experiences have an important effect on adult health for example low socioeconomic status or adverse childhood experiences have been linked to poorer mental health (Cabaj et al., 2014; Lindström et al., 2014); and maltreatment in childhood is known to cause poor mental health in adulthood as well as other issues surrounding violence and perpetuation of maltreating behaviour (Godinet et al., 2014; Beach et al., 2013; Smith et al., 2008; Gilbert et al., 2009; World Health Organisation, 2014). Low socioeconomic status and social disadvantage during childhood has been linked to higher rates of cardiovascular disease (Non et al., 2014), increased risk of myocardial infarction (Morton et al., 2014); and even other adult diseases have been linked to childhood disadvantage, including multiple sclerosis (Briggs et al., 2014) and obesity (Boylan et al., 2014). The difference between a child and an adult is that children cannot usually express themselves and represent their own interests as effectively as an adult. For much of childhood, a person is dependent on the care-givers who surround them. They are vulnerable to the actions or inactions of others, and to the effects of adverse social or physical environments. A child's surroundings therefore have a profound influence on health and habits for future health. Despite this, children are sometimes ignored when important policy decisions are made. These can have profound influences on a child's health behaviour and health. If a policy does not take into account of children's lives it can prove very difficult for a child or family 
to act in a health promoting way, for example if town planning does not allow for safe play or a safe means of walking or cycling to schools, shops and leisure areas this can directly impact on a child's health. As the World Health Organization states, if it were possible to replicate the socio-economic conditions of the most privileged across the whole of the European Union there would be a massive improvement in the health of young people, simply by the improvement of physical, mental and emotional lifestyle (WHO Europe, 2005).

Children's autonomy changes as they grow up, and the behavioural determinants of health change from it being the behaviour of the parent and family environment that impacts upon a very young child; to behavioural determinants in the form of family and community norms, peer pressure and the environment in which a child lives. The World Health Organization Europe (WHO Europe 2005), together with most modern researchers into children and children's health, agree that a 'life course' approach is essential when collecting and analysing data about children. This concept is simple. From birth to young adulthood, a child undergoes enormous physical, emotional, cognitive and social changes; we can see that infants are clearly very different from adolescents. In terms of collecting data, using a life-course approach allows for the fact that each stage in development, and thus in choices and lifestyles; lays the foundations for the next stage, and that its effects can be cumulative. Actions begun in babyhood, such as eating too many calories or being consistently exposed to cigarette smoke, traffic pollution or to violence, have enduring effects as a child grows up (Alexander et al., 2010; WHO Europe, 2005). In this thesis, the example of nutrition and physical activity is used to demonstrate how indicators could be created with a life-course perspective as a background principle; but this could apply to a number of issues. It is impossible to devise one measure or indicator that is relevant and meaningful for all ages, a fact that is recognised by a number of agencies, including the United States Centers for Disease Control and Prevention (CDC) and the US Institute of Medicine (IOM). The CDC monitor the population health of children by health outcome by life stage (Roy et al., 2009), and the IOM recognises that each indicator it uses must be regarded from a life course perspective (Institute of Medicine, 2011). This allows changes over time to be taken into account when looking at data, so that valuable and accurate intelligence about the health of the child population can be identified. 
The Child Health Indicators of Life and Development (CHILD) project (Rigby and Kohler, 2002) and the Scientific Platform on Lifestyle Determinants of Obesity project (Wolfram et al., 2008; Alexander et al., 2010) aim for the life course to be applied in indicator data collection and analysis, but this is not yet wholly achieved in many projects, and as a matter of course in many European routine statistics.

Thus, it makes sense that to measure children's health accurately; we must look upstream at the physical and social environments in which children live, learn and play including the family, community, school and wider environment. In the case of childhood obesity, for example, the availability of fresh fruit and vegetables in a household with children could give us information about the ease of finding such food, its affordability, and family culture. This information may well, in turn, have a direct correlation with the presence or absence of obesity (Alexander et al., 2010).

Finally, it is important to remember that most children in Europe are well, and enjoy good health; they are active, intelligent and provide a vitality and enthusiasm that is essential for Europe's future. Respecting the value of these children, and wanting the best and most healthy future possible for them must underpin any work to measure and improve the lifestyles and health behaviour of children and young people.

\section{Measuring}

\section{Why do we need to measure?}

In order to tackle a problem effectively, one of the first things to do is to measure its scale. Only then can public health practitioners and policy makers take evidence-based action that really benefits the child population. Accurate data allows proper targeting of public health work, and evaluation of the success or failure of health interventions. As the European Community Health Indicators Monitoring (ECHIM) project states, a health system needs to be a "dynamic and flexible infrastructure for monitoring health activities and population health outcomes that is active at the national or subnational level ... It covers a wide range of information relevant to different user groups" (Kipeläinan et al., 2008). Health and health-related indicators are an important way of quantifying the state of children's health and the actions of the environment and 
other determinants of health on the child population of Europe. Although, by definition, they cannot provide the whole picture, good indicators give an interesting and informative indication of the health status, trends and determinants of the children of Europe. In addition to measuring children's health, indicators and the data they contain can identify successes, which can be sources of learning; and also shortcomings where health needs to be improved. It is also recognised that there are a number of existing statistics and catalogues of information that may contain information of great utility to child health practitioners, policy makers and researchers but have not yet been analysed in a way that draws out the important information about children's health and wellbeing that already exists in Europe (Rigby and Köhler, 2002).

\section{What do we mean by upstream?}

The World Health Organisation (WHO) describe upstream indicators as: "a series of causes, some of which are immediately reflected in behaviour patterns, while others are more distant and shape the context for behaviour rather than behaviour itself' (2006). This type of measurement lends itself to children's health because it is difficult to measure directly the physiology and behaviour of children for a number of practical reasons. Invasion of children's privacy, intrusion and other ethical concerns are important considerations. Although some information can be obtained from circumstantial evidence, such as parental food purchasing, this information is not ideal, as there is no indication of the proportion of food actually eaten by the children. Other measurements, such as hospital admissions only give us information about adverse outcomes. It makes sense, when measuring a generally well population, to seek to measure the upstream behaviour determinants and to focus on salutogenic factors in as accurate a manner as possible. It is particularly important to look further afield than health outcomes and their immediate causes when measuring children's health behaviour to create clear picture. Factors such as town planning priorities, economics, food labelling and advertising, policy related to education, access to sports facilities and so on can give us important practical information about what directly impacts upon children's lives (Alexander et al., 2010). We all start life with a lack of autonomy and are heavily influenced by outside agents such as parents, authority figures and peers throughout childhood to varying degrees. Thus, measuring the 
number of children who use a 'walk to school' scheme can be a more rewarding indicator of children's physical activity than an indicator that describes the number of children who play competitive sports. Eurostat (2015) note the importance of being able to analyse how the environmental and cultural influences of the different countries in Europe in terms of how they influence health behaviour and outcomes.

There has been an increase in interest in measuring health and wellbeing of children in Europe for the past twenty years, as opposed to concentrating on child survival and on disease. The ChildONEurope project (2009) described a shift in perspective that occurred in Europe in the 1990s, where indicators began to focus less on basic needs of development and deviance from health norms towards indicators that promote healthy child development. Positive, protective factors are increasingly identified as a primary influence on children's lives. As a result, indicator development moved into potential new areas, such as children's life skills, children's civic involvement and participation and children's culture, and become closely related to children's rights agendas. This has also been echoed in other parts of the world. The Institute of Medicine (IOM) (2011) proposed new child indicators drawn from US National sources such as Healthy People 2010 and Healthy People 2020 (www.healthypeople.gov/2020/default.aspx) and includes goals for health and health promotion in the United States. Similarly to the ChildOnEurope group, the IOM recognised the need to look beyond a traditional focus on mortality, morbidity, and chronic and acute conditions in children. They include certain priority areas that complement these traditional indicators, such as functional status, preventable common conditions, including mental and behavioural health, social determinants of health and health inequalities. This is not to say that survival indicators such as $>5$ mortality rates are unnecessary as a basic indicator of a population's health, they remain important but need to be complemented with indicators that represent current child populations. What is increasingly regarded as important is the influence on health behaviour that a child's environment and social circumstance wields. Measuring these influences can provide us with a more complete picture of why health outcomes occur; and as a result help in preventive actions.

The Health Behaviour in School-Aged Children (HBSC) study uses upstream indicators as part of its survey. The HBSC survey is carried out 
in conjunction with the World Health Organization of children aged 11, 13 and 15 years of age every four years. It is very informative and gives a greater understanding of children's lives and the influences on children's health and wellbeing. The HBSC study does not just focus on traditional health questions, but contains indicators for social, socio-economic, environmental and other lifestyle factors, which are standardised to enable data to be compared across nations, languages and cultures (Currie et al., 2008). This standardisation is a great strength of the study; but it is nevertheless a survey, and it is not normally possible to analyse results by special population subgroup, or to use the source data for secondary use (www.hbsc.org/data/index/html). In terms of this thesis, and the future measurement of the behavioural determinants of children's health, the upstream indicators used by HBSC, are an exciting and easily understood way of identifying and tackling public health problems that affect children.

\section{How can we measure? Finding and Creating Indicators}

In an ideal world, to measure the many and disparate elements that influence children's lifestyles and health, we use a variety of indicators, to which data is compiled and the results analysed. An indicator is a means of demonstrating in a concise way the status of a particular situation, whether this is a health issue, a service performance, population status or similar. Such indicators are, whenever possible, based on previously recognised and scientifically validated measures of the phenomenon concerned. There is a fundamental symbiosis and distinction to be noted here between international comparative research on the behavioural determinants of child health, and the construction of sets of indicators that are suitable for monitoring health and policy making. This thesis focuses on comparative research in the sense that we must know what issues contribute to children's poor or good health; but it majors on the challenges of addressing the need for indicators.

There are a number of issues to be taken into account when setting out to measure children's health, because finding appropriate indicators and a pragmatic means of collecting data is not simple. Indicators are complex to develop. They need to provide a glimpse of a much larger health issue or health determinant than they describe in the measurement. For example, the REPROSTAT project developed indicators to monitor and describe reproductive health in Europe (Temmerman et al., 2006). The initial indicator set was developed from a 
literature review, but this set was then discussed and refined by 200 health experts throughout Europe. The resulting list contained 13 indicators, which were piloted in Germany and Italy. Even after this process, data from the indicators were harmonized so that true comparability across European countries was achieved, and the benefits of the indicators can be used by all countries concerned (Temmerman et al., 2006). The related EURO-PERISTAT project discussions about indicators for the perinatal health of migrants concluded that as well as including "country of birth" in their list of indicators, it was important to ask about the "length of time in present country" which would complement routine data collection about immigrant status, language and so on (Gagnon et al., 2010). A related and subsequent discussion about the applicability of the "country of birth" indicator for ethnicity and health concluded that this would have limitations and articulation of ethnic background may be more informative. Similarly, Stronks et al. (2009) concluded that using a country of birth as an indicator is only useful if it is complemented with additional indicators that describe culture and ethnic identity in the host country. Thus, creating indicators is not as simple as it first seems.

\section{Existing indicator sets}

There is a vast amount of indicator sets that describe children's health, and this thesis seeks on the whole to make better use of those that exist and are relevant for health even though they may not be from traditional health contexts. Many of these indicators are perhaps not utilised to their best advantage, or are not disaggregated by life course age groups or other determinants of health. European indicator sets provide us with an enormous amount of information about children and childhood, but arguably it is not always in a clear and easily accessible form or that gives a true picture of the risk and protective factors that act to influence children's health. Indeed the sheer volume of indicators can sometimes seem overwhelming. Examples of indicator sources are the CHILD project (Rigby and Kohler, 2002), EURO-PERISTAT (Gissler et al., 2010; Hjern et al., 2011), ECHIM (Kipeläinan et al., 2008), World Health Organisation (2011) CEHAPE (2004), ENHIS (WHO Europe, 2012), WHO Geneva (2015), University of Washington Health Metrics (Institute of Health Metrics and Evaluation, 2015), OECD (2015), and UNICEF (2015) as well as the international scientific literature (Alexander, 2011). In 2005, the European Health Report used many 
childhood indicators to focus upon child health and development in Europe. The Report used CHILD indicators among others to give us an important snapshot of the health of European children. Even though it is now over a decade old, it is still one of the few reports that focuses on children and the indicators that measure them. What is new in this thesis is the identification of indicators in combination with each other, and from an upstream perspective. What is needed are indicators to measure child health in terms of children's good health, and measurement of the threats and benefits to their health. This enables preventive actions to take place before any adverse consequences occur. Of particular note is that some of the adverse consequences related to poor health choices or exposures may not occur until many years later.

\section{International indicators and data comparability}

The WHO European Health Report (2005) looked at public health action for healthier children and populations across the countries of the WHO European region, an area encompassing the countries of the EU, EEA as well as 22 other countries including the Russian Federation, Serbia, Bosnia and Herzogovina, and Turkey (World Health Organisation, 2015). This report stated that this is a geographical region where children's health is polarised; and this has not fundamentally changed in the subsequent decade (UNICEF, 2015; Hjern 2012, WHO 2013):

"On the one hand [Europe's] most developed countries are amongst the healthiest on the planet in terms of longevity, late onset of disease and disability ... on the other hand, the Region also contains poor countries that are still struggling with severe ill health among younger groups in their populations. ... Further, all countries, even the most affluent, have vast and growing inequalities in health between the richest and poorest people". (WHO 2005)

Using international indicators can help reduce the inequalities in health that exist across the continent, by increasing knowledge and identifying areas of success and of need. In a sense, therefore, comparable international indicators can facilitate better health. They not only draw attention to the elements that most directly influence risk or protective factors but also identify those countries that have good practice and can 
provide lessons by example to countries with less healthy child populations or specific public health challenges (Hjern 2011).

Nevertheless, the ideal of comparable international indicators is not yet realised. Comparable data, even from the same indicator remains a major issue even in well-established indicator sets and subjects. Gissler et al. (2010) found that "there is no common approach in Europe" to data about deliveries, births, mothers and newborn babies, and no standard definition of stillbirth.

Ideally, international indicators give comparable information at the national level, and may be compiled for a global region of affinity such as Europe, or for the whole world. This information is increasingly vital in Europe as the European Union enlarges, encompassing new countries with very different histories, cultures and living conditions. Health information in Europe has existed in many countries for over 100 years, but each country has developed its own information systems and preferences for recording information in order to measure its population's health. It is unsurprising therefore that there is great disparity in statistics and a lack of comparability in existing systems across Europe (Kipeläinan et al., 2008). Creating internationally comparable indicators in Europe is an extremely challenging task, but is an important exercise in developing children's health in a continent where globalisation, international travel and international cooperation is increasing every year. As Eurostat states, European health policy needs solid health information derived from valid and comparable sources (2015). Currently, key issues are lack of data for key indicators and the poor comparability between countries and regions within them. Eurostat consolidate national data and harmonize methodology as far as possible to allow country comparisons, however, data that describe upstream influences on children's lives are scarce in the Eurostat indicators.

To be taken seriously as a fundamental element in health surveillance on a European scale, indicators need to measure consistent elements across nations, and take into account differences between countries. Cultural and geographical influences can have profound influence on future social development, and perhaps ultimately on health - although this is debatable because it seeks not to state whether any culture is 'better' or 'worse' than another. However, it is clear that lifestyle indicators that are relevant in Scandinavia may not be so applicable to Mediterranean 
populations, and hereby the challenges lie. Cultural meanings tend to affect data collected and the function of the data. As Saks and Allsop (2007) state: health care is "a complex process requiring translation of both words and meanings, and an acknowledgement of social construction of concepts". As an example, Sweden experienced difficulty with an apparently straightforward indicator of neonatal mortality. The country has reported some of the lowest neonatal mortality rates in Europe, primarily because in Sweden a foetus was classed as a 'child' at 28 weeks gestation, which was later than many other European countries. When Sweden changed its definition of when a foetus became a child to ensure international comparability the apparent rise in stillbirth rates in the country caused concern among the population, despite the fact the results were an artifact in the data (Hjern, 2012). Cultural differences may mean that some indicators become irrelevant to certain populations or sub-populations. This became apparent in studies carried out in Australia. Work has been carried out to find suitable indicators to measure the Aboriginal population's health status; a population which is more rural and considerably more socially disadvantaged than the dominant settler population. Peiris et al. (2010) found that existing indicator quality and breadth was limited by 'under-enumeration of Aboriginal status, small samples... and few primary health care indicators'. Steenkamp et al. (2010) noted that very few indicators were designed around remote maternal and infant health services in Australia and those that were present were unclear. This is despite known poorer care in this setting than in urban settings. Only seven indicators, out of 42 indicator sets, were found to be directly relevant to Aboriginal health, which stresses the importance of establishing relevant indicators for sub-populations, and the difficulty of creating a general indicator set that accounts for cultural differences between and within nations. Although outside European borders, the message from this research is transferable in that indicators should be applicable to even the most marginalised sectors of the population, in order for the indicators to properly play their part in improving child population health.

\section{Outline of this thesis}

Part 2 focuses on the issues surrounding finding indicators that accurately, sympathetically and intelligently measure children's health. The chapters are extracts from a book commissioned after the 
conclusion of a major EU-funded project into obesity, physical activity and nutrition (Alexander et al., 2010). The book was written by myself and edited by the project team from the Scientific Platform Project on Lifestyle Determinants of Obesity (project no: 2005111). The childhood obesity aspect of the project was originally intended to be a simple reworking of the identified adult indicators of obesity; but the identified challenges in measuring the determinants of children's obesity merited particular focus and interest as an important outcome of the project. This is an example of the particular issues involved, and the need for specifically child-focused effort, in finding indicators of behavioural determinants of children's health. Chapter 2 describes the aims and methodology used by the project to gather information about what indicators were collected by 31 countries in Europe to describe children's nutrition and physical activity behaviour throughout the life course. In this chapter, the particular aspects of measuring children are described, and an explanation of why this work is needed above and beyond measuring determinants of adult obesity. Chapter 3 discusses the findings of one particular aspect of this project, the policy measures that describe children's nutrition at various stages of children's lives in 31 European countries. Within the book, a similar discussion of physical activity determinants and indicators is given. It is here that we can see how difficult it is to find internationally comparable measurements, and how few data many countries in Europe collect that describe their child populations, despite this being perhaps their most valuable resource for the future.

Part 3 focuses on developing indicators of determinants. Chapter 4 leads on from the indicators of childhood obesity that were described in chapter 2. Here, a paper published in the Journal of Public Health describes the original Lifestyles project and the indicator development process and results that were obtained in 2007. These are then compared with what results could be found using a literature search in 2014. It seems that these indicators are still, as yet, not collected and analysed in many countries of Europe. Thus, the obesity epidemic is not yet measured in a systematic and comparable way across the continent. This paper illustrates the challenges to be found in collecting comparable international data about childhood obesity, despite it being a recognised important public health concern in the $21^{\text {st }}$ Century. 
Further to this, Chapter 5 extends the concept of behavioural indicators of health to another very important public health issue; that of child maltreatment. The issues of measuring such a covert and complicated phenomenon are discussed, alongside the utility of upstream determinants as preventive measures as well as a means of early detection of the increased risk of child maltreatment on a community, regional and population scale.

Part 4 focuses on using indicators of the behavioural determinants of health. Chapter 6 was originally published in the International Journal of Public health. It looks at how upstream indicators of child injury, specifically outcome and environmental indicators could potentially be used as important local preventive tools for action - yet the data are not present for an index of child injury risk to be created.

Chapter 7, originally published in Child: Care, health and development, looks at how the enormous range of indicators that are potentially available to researchers, health professionals and policy makers can be classified in order to gain some sense of the diversity of influences on children's health. This is an extremely important addition to child public health, in that at present there is so much diverse and disparate information it becomes impossible for many policy makers to find and use robust scientific evidence to support their policies of children's health. 
Part 2: Finding indicators 


\section{Chapter 2:}

\section{Challenges and Findings in Measuring the Behavioural Determinants of Obesity in Children in Europe: Introduction: purpose, origins and method}

Extract from: Alexander D, Rigby M, Sjöström M, Frazzica RG, Hillger C, Neumann G, Kirch W. (2010) Challenges and Findings in Measuring the Behavioural Determinants of Obesity in Children in Europe. Huber, Bern.

This extract comes from the introduction to a book that originated from a European Commission funded project, the Scientific Platform Project on Lifestyle Determinants of Obesity (project no: 2005111), and commissioned by Huber press after the project had delivered the final report to the European Commission. The book was written by myself, Denise Alexander, along with Professor Michael Rigby, and edited by the Lifestyles project team: Christiane Hillger, Grit Neumann, Anja Zscheppang and Professor Wilhelm Kirch.

This extract describes the methodology that was used to gather the indicators and to determine what countries collected data to these indicators, or alternatively, collect data to indicators that are similar to those proposed by the Scientific Platform Project on Lifestyle Determinants of Obesity project. 


\section{Challenges and Findings in Measuring the Behavioural Determinants of Obesity in Children in Europe: Introduction: origins, purpose and method [extract]}

Children are a unique group in society because of their initial dependence on others for their health, development, and well-being, and this is followed by their continuing and increasing desire for independence. Not least but too often conveniently overlooked, this includes nutrition and exercise opportunities, and thus the determinants of obesity. There is general alarm about a "childhood obesity epidemic" in Europe, with an implicit but ill-defined recognition that this is a societal issue with regard to causes and determinants.

However, the statistics defining and supporting the concern, and the potential data sources for monitoring the battle to prevent and address the problem, are not in general scientifically optimum, accurate or consistent across the European Union. This is particularly true about measurement of behaviour and expression of choice, as the upstream determinants of many aspects of overweight and obesity. The aim is to report the key findings of a project to discover the range of monitoring and data collection on these aspects across the European Union in order to identify best practice, to establish where there are undesirable gaps in the data, and thus to stimulate more effective and informative data collection across Europe with a view to providing evidence for policy makers and commentators on a locally useful yet internationally comparable basis.

This project was carried out in the calendar year 2007, and is the childfocussed follow-on to the previous year's study on Nutrition and Physical Activity: Health Information Sources in EU Member States, and Activities in the Commission, WHO, and European Networks (Wolfram et al., 2008) which dealt with the overall cataloguing of routinely available data in each Member State on nutrition and on physical exercise in the general population. This focussed principally on adults, together with an overview of the wider issues. This later volume reports on the study to address the specific and even more challenging issues regarding the equivalent information for children. During the period of the work the European Commission published a White Paper on a Strategy for Europe on Nutrition, Overweight and Obesity related Health 
Issues (European Commission, 2007). This publication underscores the importance of the work done by the project, and published here.

Part 1 of this child-specific report on The Public Health Challenge of Measuring the Nutritional and Physical Activity Behaviour of Children and Adolescents focussed on the conceptual and technical challenges of measuring the primary determinants of obesity and overweight in children. Part 2 assesses the current state of application of these concepts in practice across the nations of Europe, and in it the available information is presented and the limitations and advantages of the data are discussed. It will report on the identification of a suggested set of key indicators as comparative measures of determinants, and on the availability of data to populate those indicators; also on the updating of the database of routine scientific measures.

Identifying information that has a purpose is the primary focus of any data gathering exercise. However, the complexity of the obesity determinant scenario can be overwhelming. Figure 1.1 illustrates the owners of the policy areas involved in combating obesity and the many agencies involved. 
Figure 1: National and related bodies with a potential role in combating obesity

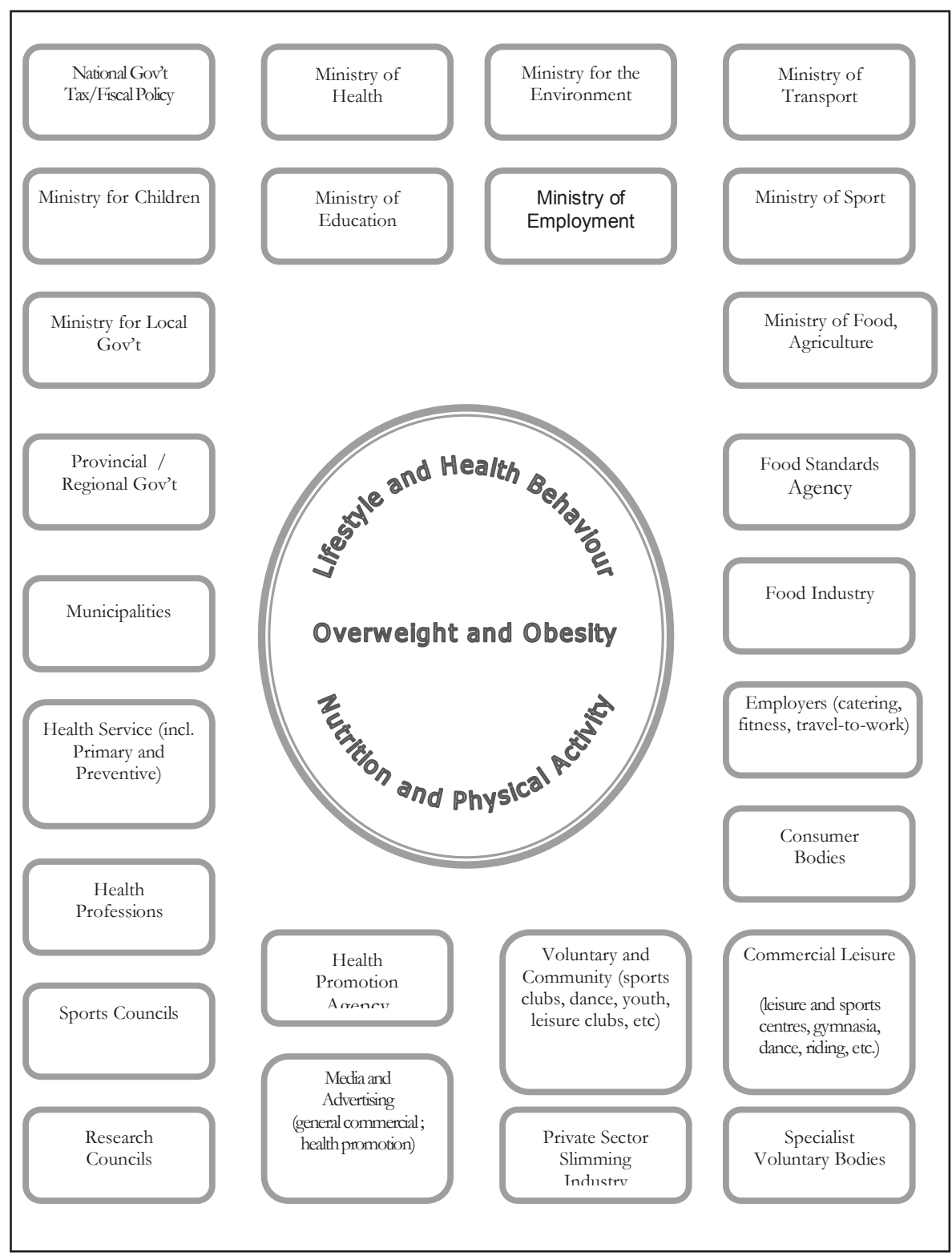

Developed by Rigby and Alexander, after National Audit Office, 2001.

Given this complexity, there were initial challenges faced by this project in determining how to define a child, which behaviour should be 
measured and how it should be monitored on a national scale. The challenges addressed were, specifically:

- Defining "children" and the stages of childhood - overall, it was seen as desirable that "children" should be defined according to the definition in the United Nations Declaration on the Rights of the Child (United Nations Office of the High Commissioner for Human Rights, 1989), namely persons from birth up to their $18^{\text {th }}$ birthday, but it was also acknowledged that for practical purposes alternative age-bands such as 0-14 and 0-19 would have to be used on occasions as determined by data availability. However, as children are not homogenous, but go through radical stages of development from infancy to adolescence; the Life Course approach promoted by the World Health Organisation (WHO, 2005) was followed. As described, from birth to adulthood a child undergoes enormous growth and physiological changes; although the aims of a balanced diet and regular exercise remain constant, it is impossible to have one measure of nutritional intake and exercise taken that is relevant both in data requested, and in interpretation, throughout childhood. Five broad developmental stages, reflecting not only physiological stages of nutritional and physical activity patterns, but also the progression from total dependence on parents through to a high degree of autonomy, were adopted.

- Direct or circumstantial measurement - as discussed in Part 1 , when determining data to describe children's lives intelligently, it is necessary to use a mixture of circumstantial evidence as well as direct measurements.

- Focussed and upstream determinants - again, as discussed in Part 1, it is imperative to use a mixture of focussed determinants - such as the number of babies' breastfed, as well as more upstream measures - such as those describing the presence of playgrounds and playing fields, or the number of families that purchase fresh fruit and vegetables regularly.

These challenges had significant implications, necessitating an approach that considers aspects of childhood obesity that ultimately fell beyond the resources of the project. Nevertheless, it was apparent that if the 
boundaries of data collection were drawn too narrowly, or too simplistically, the project would have limited and compromised value.

It should also be re-emphasised that the purpose of the project was not to measure the incidence of childhood obesity itself, but to facilitate effective preventive action by measuring the determinants of that obesity. Thus the project needed to look at societal, familial, cultural, commercial, legal, and health system contexts that influenced nutritional and exercise behaviour, in ways which could make meaningful comparisons across Europe.

\section{Methodology}

This phase of the project was led from the former Centre for Health Planning and Management, Keele University, UK, by Professor Michael Rigby, with Denise Alexander as the dedicated researcher. The overall project main contractor, the Technical University of Dresden, and the other two partners - CeFPAS from Italy and the Department of Preventive Nutrition of the Karolinska Institute, Sweden, took a full part in the design of the study. The partners, the responsible individuals, and the identity of the data-gathering sub-contractors, are reported in Chapter 2.

\section{Literature Search}

A literature search was carried out to determine the type of data collection that could be used to describe effectively the determinants of obesity and overweight in the children of Europe. Current research was identified using PubMed searches of peer reviewed research papers; papers retrieved were read, and relevant references followed up. In addition, consultation with identified experts in the fields of nutrition, exercise, and obesity was sought and methodological recommendations acted upon. From the literature search, topics and measures were derived, discussed by the four partners in the project during a two-day workshop, and then refined into formal data definitions.

This literature review, and analytic discussion, led to the conclusion that the initial task, solely of updating the previous year's database of routine national surveys and data sources to now include those sources related to children's behaviour, would be far too restricted. It would not give national policy makers adequate evidence of behavioural determinants for all life course stages within childhood. Therefore, it was agreed also 
to seek to determine a key indicator set, separately for nutrition and for physical activity, for each of the stages of childhood, and to seek to populate those measures on a one-off basis.

\section{The Indicator set}

Through careful consideration of the measurement issues and challenges as detailed in Part 1 of this volume, identification of key issues in the measurement of nutrition and physical activity behaviour and their determinants, and the evidence from study of the scientific literature, a set of indicators was specified which were seen to provide an adequate subject and life-stage spread, be clear and purposeful, capable of unambiguous definition, likely to be available, and be meaningful to policy makers and public health practitioners. A workshop of the partners in this project considered and unanimously agreed the indicator sets. The principles adopted for the CHILD indicators project (Rigby and Köhler, 2002) were taken as the underlying principles for selecting and defining these indicators.

The resulting data items to be sought were a mixture of "ideal" measurements, and pragmatic items that were more likely to be easily, and cheaply, collected at a national level. The study determined two types of indicator:

- Legal and Policy Items: these are indicators which describe the regulatory and service environment in which the child grows up; they are measured not just by presence or absence, but by degree of enforcement or application.

- Population Level Statistical Items: these give a statistical indication of key phenomena for the population.

The two indicator sets are presented in full in Appendices 1 and 2. Not only were they used for the work in this project, but they are commended for addition to European health indicator sets. The current availability of data in these indicators for each country is reported in the next four chapters.

The challenge of producing robust definitions and data sources of otherwise very important issues was considerable. Not all measures are scientifically ideal, but the intention was that those used would all be clear and unambiguous, and be capable of local collection. However, 
three key topics proved too difficult to define and collect, and thus reluctantly had to be omitted:

- Percentage of children eating junk food every day - though used in the HBSC, the term "junk food" is not a precise term, despite being in common use. (A commonly used definition is "food that is high in calories but low in nutritional value", and this is the definition that appears in the Merriam-Webster dictionary (2007), but there is no standard definition of what "high in calories" means nor "low in nutritional value", making it very difficult to be precise on a population basis.) Therefore the indicators regarding sweets and soft drinks were used as a proxy for this question.

- Percentage of children who own a bicycle or have access to a bicycle - this is recommended by the World Health Organization, but there are too many difficulties in defining "ownership" or "access to" a bicycle to make it a reliable indicator on a population level.

- Family access to affordable food; Access to affordable healthy food at school: it was difficult to find a workable definition for this. In its place, a policy indicator "Existence and enforcement of legislation to support availability and access to healthy food, including school meals" as used by the World Health Organization (2005) was used.

\section{Country-based data sources, studies, and projects}

Complementary to seeking the availability of the data to populate the two sets of indicators, this project sought to extend the database of national studies in this field compiled in the first (adult-oriented) phase of work (Wolfram et el, 2008), to accommodate inclusion of studies related to children's behaviour and its determinants. Three types of data were sought for entry into the pre-existing database:

- Country-level Routine and Repeated Data Collection: as with the preceding year's study on the general population, this catalogues the routine and repeated studies, censuses, and other sources which collect specific data items relevant to nutrition and physical activity behaviour. These are very important in that they are published - and thus available widely to policy makers 
and commentators, and they are repeated - thus enabling trends to be identified.

- One-off Research Studies and Initiatives: unlike the previous year's adult-orientated phase of the study, this later work related to measurement of children's behaviour determinants took account of the paucity of robust studies regarding children's behaviour and therefore decided also to seek details of any published one-off or research studies. Though these have much less population health value in terms of problem and trend analyses, because of the challenges of measurement in this arena and the consequent current limitations on data availability it was felt beneficial to collect and publish relevant one-off initiatives with the aim of stimulating further study and the development of routine measures.

- National Issues and Policies: in order to give a very broad picture of each Member State's current awareness and activity in this area, structured country profiles were sought.

The results of this component of data gathering, in the form of details of every identified project and data sources, are to be found in the Online Data Repository at http://www.public-health.tudresden.de/dotnetnuke3/eu/Propjects/PresentProjects/

ScientificPlatformoftheWorkingParty/tabid/880/Default.aspx.

An analysis of issues in the country profiles is presented in Chapter 7.

\section{Country-level indicator data availability}

Appendix 1 describes the Legal and Policy items that ideally could be used to describe policy determinants affecting childhood obesity throughout the life-course of childhood. For each data item or measure, country researchers were asked to state:

- Whether the policy exists, its type, for example law, government policy, professional body guidance;

- Whether the data are available from a national contact point or routine source;

- Any comments, including the source of policy application data.

- A presentation and discussion of the findings relating to these items is in Chapters 3-5. More detailed findings are in the Online Data Repository. 
Appendix 2 similarly presents the empirical population level measures derived from the literature review as items which specifically described an aspect of the behavioural issues which affect childhood obesity. The database entries for these items can be seen in the On-line Data Repository, and a discussion surrounding the findings is in Chapter 6.

\section{The Project Database}

The project database was completed by the country subcontractors and contains the information that could be found in each country relevant to behavioural determinants of overweight and obesity. The database is available online at: Working Party on Information on Lifestyle and Specific Subpopulations. www.public-health.tu-dresden.de/ dotnetnuke3/eu/Projects/PresentProjects/ScientificPlatformoftheWork ingParty/tabid/880/Default.aspx.

\section{Criteria for inclusion into the Project Database}

Health information activities in this report are published activities, projects, surveys etc., that collect data on children and adolescents $(0-17$ / 0-19 years old) with special focus on nutrition and levels of physical activity as determinants of obesity. Available health information activities inclusion criteria were defined as data which:

- related to physical activity and/or nutrition as determinants of obesity;

- focus on children and adolescents;

- included data collection projects with regional, national, and European scope (first priority being on data collection projects on national and European level);

- started by 1990 or later, were still running; or approved (but not yet started).

- Criteria for exclusion were activities:

- that do not produce data, that promote and implement projects;

- that are prevention and intervention programmes;

- that are part of textbooks.

\section{Definition of routine data sources}

Primarily, the project wished to determine the routine data sources that were available nationally in the European Union. The definition of "routine data source" used by the project was: 
- all people can get this information regularly;

- regular, periodic gathered data;

- routine data sources can be defined as information systems in which data are recorded or collected continuously or periodically for several reasons (for example, for legal, operational, or reimbursement reasons);

- Examples: vital statistics, census data, hospital care statistics, ambulatory care statistics;

- Surveys would be classifiable as "routine" under reasonable assurance of periodic data collection (such as the Health Behaviour in School-aged Children study).

\section{The role of the country subcontractors}

The Country Subcontractors were the means to data collection. They were not experts on childhood obesity, but were tasked to find information that is readily available to the informed layperson. Most of these subcontractors worked over and above their normal employment duties to provide the project with its information. The tasks for each subcontractor were to:

- provide a one-page Country Profile detailing the health surveillance activities and the priority childhood obesity is given by government, health services and the mass media;

- complete the two agreed schedules of data availability of legal and policy items and desirable behaviour measures;

- update the pre-existing project database regarding projects with children within the included age-group, adding in information about age groups, gender, the data collected and behaviour measures data availability.

- In addition, the national subcontractors:

- updated the project database with new entries for projects that were not included in the earlier project, because they involved only children;

- supplied key information about any published or formally reported innovative and successful behaviour-measuring initiatives or pilots (which can include data-gathering as part of an intervention study or evaluation) to a maximum of three items per country. These initiatives may be about the general 
child population or about a special subgroup, such as an ethnic minority;

- provided information about Bulimia and Anorexia Nervosa if it was available nationally, including the type of source, and whether the data reports incidence, prevalence, or special treatment attendance;

- included significant "grey literature" surrounding the topic of measuring childhood obesity.

\section{References}

European Commission (2007). White Paper on A Strategy for Europe on Nutrition, Overweight and Obesity related Health Issues (COM(2007) 279); Brussels.

Gabhainn, S, N. (2004) Young People's Health and Health Related Behaviour in Currie et al (ed) Young people's health in context: Health Behaviour in School-aged Children (HBSC) study: international report from the 2001/2002 survey. World Health Organization, Geneva [available online www.euro.who.int/document/ e82923_part_3.pdf]

Merriam-Webster online (2007) Junk Food definition [available online http://m-w.com/dictionary/junk+food]

National Audit Office (2001) Tackling Obesity in England: Report by the Comptroller and Auditor General. The Stationery Office, London. [available online: http://www.nao.org.uk/publications/nao_reports/0001/0001220.pdf]

Rigby, M \& Köhler, L (2002) Child Health Indicators of Life and Development: Report to the European Commission. European Commission, Luxembourg. [available online: www.europa.eu.int/comm/health/ph/programmes/monitor/fp_monit oring_2000_frep_08_en.pdf]

Wolfram N, Rigby MJ, Sjostrom M, Frazzica P, Kirch W (eds) (2008) Nutrition and Physical Activity: Health Information Sources in EU Member States, and Activities in the Commission, WHO, and European Networks. Springer, New York. 
World Health Organization Regional Office for Europe (2005) European Strategy for Child and Adolescent Health and Development. Copenhagen [available online: http://www.euro.who.int/document/E87710.pdf] 


\section{Chapter 3:}

\section{Nutrition policy measures in European Countries}

Extract from: Alexander D, Rigby M, Sjöström M, Frazzica RG, Hillger C, Neumann G, Kirch W. (2010) Challenges and Findings in Measuring the Behavioural Determinants of Obesity in Children in Europe. Huber, Bern.

This extract chapter comes from a book that originated from a European Commission project, the Scientific Platform Project on Lifestyle Determinants of Obesity, and commissioned by Huber press after the project had delivered the final report to the European Commission. The book was written by myself along with Professor Michael Rigby, and edited by the Lifestyles project team: Christiane Hillger, Grit Neumann, Anja Zscheppang and Professor Willhelm Kirch.

This extract gives the findings of the project after attempting to populate policy indicators of children's nutrition in 31 countries from the EU, members of the European Economic Area, Croatia, Macedonia and Turkey. This chapter was accompanied in the final report of the project by chapters describing whether countries in Europe were able to populate identified statistical indicators of nutrition and physical activity factors. 


\section{Nutrition policy measures in European countries [extract]}

This chapter summarises the findings of this project about the availability of data and policies concerning the determinants of nutritionrelated behaviour of children in the countries in Europe.

Information was obtained by researchers in each country, acting as "informed lay persons" rather than experts in the field. This, it was felt, showed the availability of data to researchers and policy makers in general, who would find accessibility of accurate and pertinent data important in their working lives addressing the challenge of combating obesity. Thus, the data obtained give a picture, not necessarily of the highest specialist scientific data available in each country, but that which is most easily available, the key issue being that high quality data is only useful if it is also available and accessible.

Given the limited resources of the project, and the large number of countries covered, the request to the data-gathering sub-contractors for each country was fairly modest - to provide simple indicator information as to numbers, percentages, or the presence or absence of specific policies. In the event, many contributors extended well beyond that narrow remit, and included more detailed information on policies and initiatives, their origins, and attitudes to them. This has enabled a much fuller analysis, which cannot claim scientific comparability because of the fact that many of the details were reported spontaneously, but it has created a much richer picture of situations, initiatives, and challenges that had been envisaged initially in this project.

The chapter is divided into a number of sections based on the lifecourse of a child: Babies and Infants, School Age Children, and Adolescents. 


\section{Babies and infants aged under 1}

The key indicator questions here were:

- Number of baby friendly hospitals (and as percentage of all maternity hospitals)

- Existence and enforcement of legislation to protect breastfeeding mothers who work.

- Does the Member State apply the International Code on Marketing of Breastmilk Substitutes (World Health Organization, 1981)?

Most countries answered these questions, but not many gave any figures for the first one. This is interesting as it suggests that the data is not readily available, and therefore difficult for member state to accurately assess whether the baby friendly hospital policy is successfully applied. A summary of the data received is outlined in table 2.1.

\section{Number of Baby Friendly hospitals (and as percentage of all maternity hospitals)}

The Baby Friendly Hospital Initiative was launched by WHO and UNICEF in 1992. Its aim was to strengthen maternity services to provide greater support for breastfeeding. Worldwide, there are around 16,000 Baby Friendly Hospitals in 171 countries. The answers given for each country for this question are given in Table 2.2.

Of the countries that replied to the survey, only one stated that there was no Baby-friendly policy - Liechtenstein. However, how this affects breastfeeding rates in such a small population, where it is likely that many babies will be born over the border in Switzerland, is unknown. It is unclear if a policy surrounding Baby Friendly accreditation exists in Greece, but according to the World Health Organization, there are no accredited hospitals in the country. Estonia (which has one Baby Friendly hospital) states that almost all maternity hospitals implement the criteria for the award but have not been awarded, or perhaps applied for, the award. Malta stated that there were no Baby Friendly Hospitals, but it is unclear if there is no policy or presence of the Baby Friendly Initiative in the country. 
Table 2.1: Breastfeeding indicators

\begin{tabular}{|l|l|l|l|}
\hline & $\begin{array}{l}\text { Number of } \\
\text { Baby Friendly } \\
\text { hospitals }\end{array}$ & $\begin{array}{l}\text { Legislation to } \\
\text { protect } \\
\text { breastfeeding } \\
\text { mothers at work }\end{array}$ & $\begin{array}{l}\text { International Code } \\
\text { on Marketing of } \\
\text { Breastmilk } \\
\text { Substitutes applied? }\end{array}$ \\
\hline Austria & No data & Yes & Yes \\
\hline Belgium & $10(6 \%)$ & Yes & Yes \\
\hline Bulgaria & No data & Yes & Yes \\
\hline Croatia & $15(46.9 \%)$ & Yes & No \\
\hline Cyprus & $\begin{array}{l}\text { (possibly } 100 \\
\%)\end{array}$ & Yes & Yes \\
\hline Czech Republic & $64(63.3 \%)$ & Yes (limitation $)$ & Yes \\
\hline Denmark & $12(37.5 \%)$ & Yes & Yes \\
\hline Estonia & 1 & Yes & Yes \\
\hline Finland & 2 & Yes & Yes \\
\hline France & 5 & Yes & Yes \\
\hline Germany & No data & Yes & Yes \\
\hline Greece & 0 & Yes & Yes \\
\hline Iceland & & & \\
\hline Ireland & $6(28 \%)$ & Yes & Yes \\
\hline Italy & 13 & Yes & Partially \\
\hline Latvia & $13(22.4 \%)$ & Yes & Yes \\
\hline Liechtenstein & 0 & Yes & Yes \\
\hline Lithuania & No data & Yes & Yes \\
\hline Luxembourg & No data & Yes & Yes \\
\hline Macedonia & $28(96.5 \%)$ & Yes & Yes \\
\hline Malta & 0 & No & No \\
\hline Netherlands & No data & Yes & Yes \\
\hline Norway & $40(80 \%)$ & Yes & Yes \\
\hline Poland & $62(16.5 \%)$ & Yes & Yes \\
\hline Portugal & & & \\
\hline Romania & 22 expressed & Yes & No \\
\hline interest & $10(71 \%)$ & Yes & Yes \\
\hline Spain & $13(1.4 \%)$ & Yes & Yes \\
\hline Sweden & 63 & Yes & Yes \\
\hline Turkey & $546(90 \%)$ & Yes & Yes \\
\hline United Kingdom & $132(41.6 \%)$ & Yes & Yes \\
\hline & & & \\
\hline & & & \\
\hline
\end{tabular}

In contrast, Turkey actively promotes baby friendly hospitals. The Turkish Ministry of Health trains health professionals on educating new 
mothers about breastfeeding as part of its programme to promote breastfeeding and the baby friendly hospital initiative. This is reflected in the data, as there are 546 baby friendly hospitals in Turkey; 67 out of 81 provinces are baby friendly and around $90 \%$ of births in Turkey are delivered in a baby friendly hospital. Macedonia states there are 28 maternity hospitals that are registered as Baby-Friendly, and only one has not got the award, a coverage of $96.5 \%$. In the Czech Republic the National Institute of Public Health (www.szu.cz) and National Lactation Centre implement government policy encouraging Baby Friendly accreditation in the nation's maternity hospitals, $63 \%$ of the country's hospitals are accredited Baby Friendly. In Belgium, $6 \%$ of hospitals are currently Baby Friendly, with the total aiming to rise to $15 \%$ in May 2008. Belgium has an objective of having $50 \%$ of maternity hospitals designated Baby Friendly by 2010. Spain has only $1.4 \%$ of its maternity hospitals classed as Baby Friendly.

Nearly half of Croatian maternity hospitals were designated Baby Friendly (46.9\%), and this is accompanied by a national programme to promote breastfeeding in Croatia that has been in existence since 1992 and the Breastfeeding Support Act, which is currently being debated by Government. However, despite these initiatives, the Ministry of Health introduced the Happy Baby pack as a gift for mothers after delivery in 2004. This pack contains a bottle and commercial baby feeding leaflet, meaning that the Baby Friendly Hospitals are likely to lose their accreditation at the end of 2007, despite the good work that has been undertaken so far. This is perhaps an example of the lack of understanding at the highest level of the importance of consistent and continued support of breastfeeding mothers from the moment they give birth.

Of the other countries, actual percentages of Baby Friendly hospitals were not given routinely. Austria, Bulgaria, Germany, Luxembourg and the Netherlands gave no data. Although Austria gave no figures, they indicated the presence of an initiative about breastfeeding-friendly and mother-friendly hospitals (Ten Steps towards a mother friendly hospital, Coalition for Improving Maternity Services) in the country. Bulgaria, similarly, gave no data, but stated that hospitals are encouraged to acquire the Baby Friendly accreditation. Out of Romania's maternity hospitals, 22 officially declared their interest in Baby Friendly status in 2002 , but there is no indication as to whether any of them have gained 
full accreditation or what percentage of the nation's hospitals they represent. However, the country is making a concerted effort to attain Baby Friendly status in its maternity hospitals.

\section{Table 2.2: Number of Baby Friendly hospitals (percentage)}

\begin{tabular}{|l|l|}
\hline & Number (percentage) \\
\hline Austria & No data \\
\hline Belgium & $10(6 \%)$ \\
\hline Bulgaria & No data \\
\hline Croatia & 15 out of $32(46.9 \%)$ \\
\hline Cyprus & 4 (possibly $100 \%)$ \\
\hline Czech Republic & 64 out of $101(63 \%)$ \\
\hline Denmark & 12 out of $32(37.5 \%)$ \\
\hline Estonia & 1 \\
\hline Finland & 2 \\
\hline France & 5 \\
\hline Germany & No data \\
\hline Greece & 0 \\
\hline Iceland & \\
\hline Ireland & 6 out of $21(28 \%)$ \\
\hline Italy & 13 \\
\hline Latvia & $13(22.4 \%)$ \\
\hline Liechtenstein & 0 \\
\hline Lithuania & No data \\
\hline Luxembourg & No data \\
\hline Macedonia & $28(96.5 \%)$ \\
\hline Malta & 0 \\
\hline Netherlands & No data \\
\hline Norway & $40(80 \%)$ \\
\hline Poland & $62(16.5 \%)$ \\
\hline Portugal & \\
\hline Romania & 22 expressed interest \\
\hline Slovenia & 10 out of $14(71 \%)$ \\
\hline Spain & $13(1.4 \%)$ \\
\hline Sweden & 63 \\
\hline Turkey & $546(90 \%)$ \\
\hline United Kingdom & 132 out of $317(41.6 \%)$ \\
\hline & \\
\hline
\end{tabular}

A National Committee for Breastfeeding Promotion was established in 2002, tasked with encouraging Baby Friendly accreditation. This 
Committee is developing a reporting system around breastfeeding rates, rooming in and training for medical and nursing staff in the importance of, and how to encourage, breastfeeding. In Italy, 13 hospitals are accredited with the Baby Friendly award, but there is no indication of the percentage of total hospitals in the country. Similarly, in Belgium, six hospitals are Baby Friendly, but there is no indication of whether this is a large or small proportion of maternity hospitals in the country. Lithuania gave no data as to numbers of hospitals, but states that there is a national committee that is working towards encouraging and helping hospitals to obtain Baby Friendly status. France reported five Baby Friendly hospitals, and although there is no indication as to percentage of the total number of hospitals, it seems that this is likely to be a small proportion of maternity hospitals in such a large country. Poland, for example, has 62 baby friendly hospitals, covering around $16.5 \%$ of the maternity units in the country.

While this is only one aspect of the determinants of healthy child nutrition, the findings of this project are of concern. Given that the importance of breastfeeding is well-established, and it is 15 years since the start of the Baby Friendly Hospital programme, the findings here suggest that it has had disappointingly low impact. In most countries, either only a small proportion of maternity hospitals have obtained accreditation, or else the recognition is so low profile an issue that there is very limited awareness of Baby Friendly status. With this low level of commitment to a validated, non-controversial, and internationally backed programme, the prospects of tackling more challenging aspects of nutritional behaviour determinants do not auger well. For some countries it was also possible to determine the proportion of babies born in Baby Friendly hospitals (this is an example of a measure which could be more readily available were it to become a statistical reporting standard). The data received by this project - where available in percentages - can be seen in Figure 2.1. Where data exist, they show countries' reported success in achieving Baby Friendly hospital recognition.

\section{Existence and enforcement of legislation to protect breastfeeding mothers who work.}

Table 2.3 summarises the answers given by the relevant countries. Of the countries that replied, all except Malta stated that working breastfeeding mothers were protected by law. Some countries express 
the law as paid maternity leave; others have structured time during the working day for breastfeeding or expressing milk. In some cases, it was unclear what the legal provision is, although its presence is clear.

In Cyprus, mothers can take two hours off from their work to breastfeed for six months. In Luxembourg, there are national recommendations from the Ministry of Health that include eight weeks postnatal leave and a further four weeks if breastfeeding. In addition, a breastfeeding break of 45 minutes a day is in existence. In Spain, maternity leave is up to four months, with the possibility for reduced working hours in the subsequent year. In Turkey, there are several legal supports to nursing mothers who work. They have three hours a day where they can breastfeed for the first six months, and a further 1.5 hours a day until the infant reaches 12 months. In addition, employers have to supply a room for breastfeeding if they employ more than 100 women and a crèche if there are more than 150 female workers. In Croatia, a bylaw gives women a right for a breastfeeding break during the working day, and women also have the right to maternity leave or to have leave while breastfeeding.

\section{Figure 2.1: Percentage of births in Baby Friendly Hospitals}

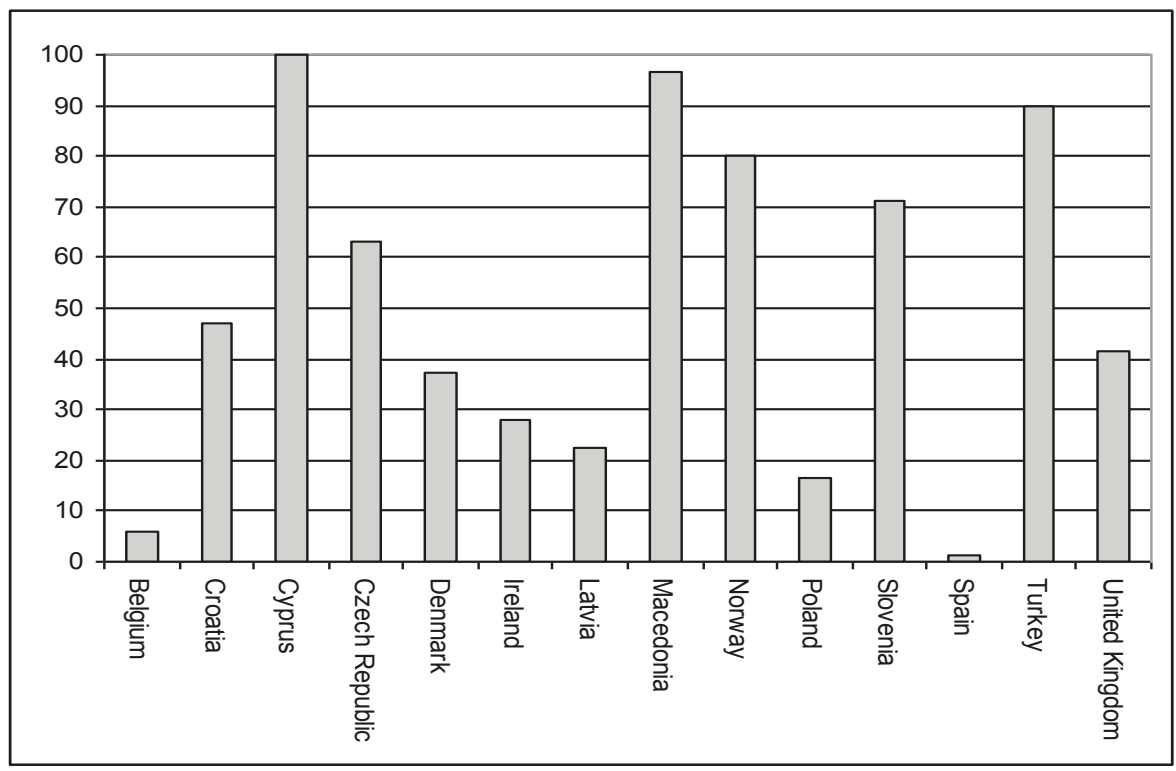


Table 2.3: Existence of legislation to protect breastfeeding mothers who work

\begin{tabular}{|c|c|}
\hline & Presence of legislation \\
\hline Austria & Yes \\
\hline Belgium & Yes \\
\hline Bulgaria & Yes \\
\hline Croatia & Yes \\
\hline Cyprus & Yes \\
\hline Czech Republic & Yes (limitation) \\
\hline Denmark & Yes \\
\hline Estonia & Yes \\
\hline Finland & Yes \\
\hline France & Yes \\
\hline Germany & Yes \\
\hline Greece & Yes \\
\hline \multicolumn{2}{|l|}{ Iceland } \\
\hline Ireland & Yes \\
\hline Italy & Yes \\
\hline Latvia & Yes \\
\hline Liechtenstein & Yes \\
\hline Lithuania & Yes \\
\hline Luxembourg & Yes \\
\hline Macedonia & Yes \\
\hline Malta & No \\
\hline Netherlands & Yes \\
\hline Norway & Yes \\
\hline Poland & Yes \\
\hline \multicolumn{2}{|l|}{ Portugal } \\
\hline Romania & Yes \\
\hline Slovenia & Yes \\
\hline Spain & Yes \\
\hline Sweden & Yes \\
\hline Turkey & Yes \\
\hline United Kingdom & Yes \\
\hline
\end{tabular}


Denmark recommends that all children should be exclusively breastfed until 6 months of age. To this end, maternity leave is paid by law, although it is not clear how long maternity leave lasts (presumably at least six months), and there is no indication of legal protection for women who have returned to work and who want to breastfeed. In Liechtenstein, the Mutterschaftsschutz, law provides maternity protection. This includes regulations for the protection of pregnant and breastfeeding women. Breastfeeding women can only be employed with their agreement, and the employer has to make sure that there is free time for breastfeeding. In Sweden the policy is to breastfeed infants for the first six months. There is parental leave for 18 months, which can be divided among the parents; at least three months' parental leave is taken by the father. In Ireland, the Maternity Protection (Amendment) Act 2004 entitles breastfeeding mothers to a number of rights at work, including paid time off to breastfeed or express breast milk, regular breaks (either one 60 minute break, two 30 minute breaks, three 20 minute breaks or a period agreed by the employee and employer, every working day) to sustain breastfeeding. In the United Kingdom, similarly, there are a number of laws to protect breastfeeding women. These include the Management of Health and Safety at Work Regulations 1992 and Employment Rights Act 1996. There is no time limit to the right to claim time off for breastfeeding, as it is felt that breastfeeding should continue until the woman and baby decide to stop. In the United Kingdom, women are allowed six months paid maternity leave and another six months unpaid leave without affecting their job or status at work. This is to be increased to nine months paid maternity leave from April 2008. In Austria, the Mutterschutrgesetz, protects expectant and nursing mothers, similarly, the Lithuanian Labour Code (article 278 maternity protection) exists to protect pregnant and breastfeeding women and in Germany the Mutterschutagesetz law protects expectant and nursing mothers. In Italy, there is provision for paid maternity leave (three months post-delivery) and for special working hours' arrangements for breastfeeding mothers.

In the Czech Republic, there is a limited protection whereby nursing mothers can receive financial compensation if the working environment is unsuitable for breastfeeding, and the employer cannot transfer the woman to an arena that is unsuitable. Issues that arise may be resolved in negotiation with the woman's gynaecologist. 
Does the Member State apply the International Code on Marketing of Breast-milk Substitutes (WHO, 1981)?

The International Code on Marketing of Breast-milk Substitutes (World Health Organization, 1981 provides detailed information about how artificial baby formula can be marketed and the claims that manufacturers can make about its contents. Statements such as "closer than ever to breastmilk" are not encouraged and actively advertising formula milk is banned. Table 2.4 summarises the information given by the member states.

Again, almost all countries who replied stated that the International Code was adopted, although some, such as Italy, have only partially adopted it. In the Czech Republic the code is not legally enforced, but it is observed throughout the health care system and in pharmacies. Similarly, in Turkey, the Code has been adopted, but national legislation to enforce its principles is not yet in place. Liechtenstein applies the code in conjunction with Switzerland because of the close connections between the two countries due to the Customs Treaty (1924) in which currency and commerce are linked.

Adopting the code has had positive effects in some countries. In Macedonia, the percentage of exclusive breastfeeding up to 4 months has increased from $8.1 \%$ in 1994 to $45.3 \%$ in 1999 and the exclusive breastfeeding up to 6 months from $26.6 \%$ in 1999 to $64.7 \%$ in 2001 .

Croatia has not formally adopted the code, but it is included in the forthcoming Breastfeeding Act that is currently being discussed by government. Romania has not officially adopted the code. In the United Kingdom, a number of loopholes in the code are exploited by the manufacturers, whereby "follow-on" milks are advertised in a way that makes it very difficult to distinguish them from infant formula. This is currently being investigated by the national Food Standards Agency. 
Table 2.4: International Code on Marketing of Breastmilk Substitutes applied

\begin{tabular}{|l|l|}
\hline & Code applied? \\
\hline Austria & Yes \\
\hline Belgium & Yes \\
\hline Bulgaria & Yes \\
\hline Croatia & Not yet \\
\hline Cyprus & Yes \\
\hline Czech Republic & Yes \\
\hline Denmark & Yes \\
\hline Estonia & Yes \\
\hline Finland & Yes \\
\hline France & Yes \\
\hline Germany & Yes \\
\hline Greece & Yes \\
\hline Iceland & \\
\hline Ireland & Yes \\
\hline Italy & Partially \\
\hline Latvia & Yes \\
\hline Liechtenstein & Yes \\
\hline Lithuania & Yes \\
\hline Luxembourg & Yes \\
\hline Macedonia & Yes \\
\hline Malta & \\
\hline Netherlands & Yes \\
\hline Norway & Yes \\
\hline Poland & Yes \\
\hline Portugal & \\
\hline Romania & No \\
\hline Slovenia & Yes \\
\hline Spain & Yes \\
\hline Sweden & Yes \\
\hline Turkey & \\
\hline United Kingdom & Yes \\
\hline & \\
\hline
\end{tabular}




\section{School nutrition}

Indicators in this section were divided into age groups. They are detailed below:

- Pre-school children aged 1-4 years

- Percentage of pre-schools with a school food policy

- Percentage of pre-schools offering school meals consistent to dietary guidelines

- Percentage of pre-schools offering healthy food options

- Are nutrition standards of school meals included as part of regulatory kindergarten / pre-school care facility inspection process?

- Primary school aged children aged 5-9 years

- Percentage of primary schools with a school food policy

- Percentage of primary schools offering school meals consistent to dietary guidelines

- Percentage of primary schools offering healthy food options

- Is there legislation, or effectively enforced national policies, against advertising (unhealthy) food to children?

- Is there legislation, or an effectively enforced voluntary code of conduct, against promoting or "placing" unhealthy food in television programmes likely to be viewed by children?

- Existence of legislation to support availability and access to healthy food, including school meals.

- Secondary school-aged children aged 10-14 years

- Percentage of secondary schools with a school food policy

- Percentage of secondary schools offering school meals consistent to dietary guidelines

- Percentage of secondary schools offering healthy food options

- Percentage of secondary schools with school nutrition policy incorporated into education curriculum.

- Adolescents aged 15+

- Percentage of schools with a school food policy

- Percentage of schools offering school meals consistent to dietary guidelines

- Percentage of schools offering healthy food options 
- School nutrition policy incorporated into education curriculum

- Restrictions on advertising of snack foods to adolescents.

The key indicators in this section, dealing with nutrition policy for children throughout their school careers, were all similar. However, for each age group subtle differences in interpretation by the children and the institution makes the data for each age group different. The primary focus of children's nutrition is the provision of affordable, good and healthy food at schools. This can take the place in a range of ways, principally whether the school or institution has a recognised policy about the standard and composition of school food, and whether the schools adhere to any policy that is in existence. One part of this adherence is the school inspection system, and whether this incorporates nutrition and diet into the inspection process. For older children, the existence of restrictions on advertising unhealthy "junk" food and its availability in schools are important factors in measuring childhood obesity.

Each sub-section begins with a tabular summary of the European countries' legal stipulations and national policy about children's nutrition at pre-school kindergartens or at school.

\section{Pre-schools}

Table 2.5 describes the current situation concerning food in pre-schools in Europe. Very few respondents provided actual figures for the indicators, suggesting that the data are not easily obtainable. Nevertheless, policies and regulations about the food provided by preschools do exist in many countries, even if quantifying the data is not possible. Slovenia, for example, has national guidelines for all educational establishments, which have been adopted by the authorities; therefore it is assumed that these guidelines are adhered to in every school and kindergarten. Similarly in Latvia in 2006, the Ministry of Health introduced guidelines about the preparation of healthy meals for children from two to 18 years of age; but no data exist to quantify whether these recommendations are adhered to and how many schools and pre-schools supply healthy meals. In Croatia, all pre-schools have a school food policy, that is supported by legislation and guidance provided by the Ministry of Health and Social Welfare (Croatian Institute of Public Health). Similarly in Belgium, guidance by 
professional body is provided in relation to pre-school nutrition. In France, pre-school food provision in schools is regulated by law. The content of school meals is subject to guidance by the Agence Française de sécurité sanitaire des aliments $\left(A f_{s s a}\right)^{1}$ and the Groupe d'étude des marchés restauration collective et nutrition (GEMRCN)'. The standards of school meals are inspected by the Direction générale de la concurrence, de la consommation et de répression des fraudes (DGCCRF) ${ }^{3}$

For the pre-school (kindergarten) ages in particular, national culture plays a great part in the results. In many European countries, children do not attend pre-school - or if they do, it is not customary for children to spend a meal-time at pre-school. But in other countries, such as in Wales and England, children attend from an early age $\left(2^{1 / 2}\right.$ or three years of age). Regulations surrounding food range from very strict, to almost entirely voluntary, guidelines.

In the Netherlands, there are almost no school meals supplied at schools, and as a result there are no national school policies that exist to control food eaten in school or pre-school. However, it is not clear if all children return home for lunch during the school day, or if there is a school policy about bringing a packed lunch. Related to this issue is whether children buy a "fast food" lunch - a factor that is known to increase the likelihood of obesity. Only around $10 \%$ of Cypriot children have their lunch at pre-school, but there is no national policy regarding the content of the lunch. Similarly, in Turkey, only around $12 \%$ of children attend a pre-school; however, if a meal is taken its content is guided by a dietician. Where snacks can be sold in schools, healthy options should be supplied, and "junk" food such as sweets and fizzy drinks is discouraged, but these regulations are not obligatory. In Malta, schools do not provide meals and all children take packed lunches.

Other countries, such as Denmark, have no information at present about school food policies, but there are indications that this may change in the future as obesity becomes more prominent on the education and political agenda. Discussions are taking place about the availability of snack foods in schools, for example. Italy also has no means of collecting data, and although policies exist to improve

\footnotetext{
${ }^{1}$ www.afssa.

${ }^{2}$ www.minefi.gouv.fr/directions_services/daj/guide/gpem/nutrition/nutrition.pdf

${ }^{3}$ www.minefi.gouv.fr/DGCCRF/
} 
nutrition and combat obesity, they are regulated regionally rather than having a national programme. In Spain, the Ministry of Education and the Departments of Education of each region have regulations about food service in pre-schools, but no data seems to be available.

In contrast, Estonia has a health-promoting kindergarten network, where $15 \%$ of kindergartens are a member. This network promotes a healthy school food policy. Luxembourg includes school meal policy as part of its national programme for healthy nutrition and physical activity. Bulgaria and the Czech Republic both have regulations about school meals, ensuring they adhere to nutritional guidelines, as does Greece. In the Czech Republic, regulations are quite detailed, specifying the amounts of each food group a child should receive on a daily basis, although at present there are no data collected about the activity. Similarly, in Lithuania, pre-school meals are subject to dietary guidelines, and menus have to be approved by public health officials on an annual basis. In Romania, the amounts and type of food provided for preschool children is regulated by law, and all pre-school and school teachers are taught about health education and hygiene.

In Sweden, the law states that all schooling and school meals are provided - and the meals follow dietary guidelines and any specific dietary needs a child might have. Nutritional guidelines in Macedonia are backed up by a regular surveillance of children's health and diet during the pre-school years, although there are no data to quantify how many schools provide healthy meals. In Germany, the German Nutrition Society Deutsche Gesellschaft für Ernährung guides pre-schools as to the nutritional content of school meals and in Austria the Austrian Nutrition Society Österreichische Gesellschaft für Ernährung, provides guidance. In France, school meals given to Kindergarten children are subject to guidance from the relevant professional body.

Latvia, Lithuania and the Czech Republic stated that their pre-school inspections contained regulations about food in schools. Macedonia, Austria and Sweden have legal requirements for the content of school meals. Other countries did not have the mechanism at present, but Denmark, for example, stated that this matter was under discussion. 


\section{Table 2.5: Pre-school food policy provision}

\begin{tabular}{|c|c|c|c|c|}
\hline & $\begin{array}{l}\text { Percentage of } \\
\text { pre-schools with } \\
\text { a school food } \\
\text { policy }\end{array}$ & $\begin{array}{l}\text { Percentage of pre- } \\
\text { schools offering } \\
\text { school meals } \\
\text { consistent to } \\
\text { dietary guidelines }\end{array}$ & $\begin{array}{l}\text { Percentage of } \\
\text { pre-schools } \\
\text { offering } \\
\text { healthy food } \\
\text { options }\end{array}$ & $\begin{array}{l}\text { Are nutrition } \\
\text { standards of school } \\
\text { meals included as } \\
\text { part of regulatory } \\
\text { kindergarten / pre- } \\
\text { school care facility } \\
\text { inspection process? }\end{array}$ \\
\hline Austria & No data & No data & No data & \\
\hline Belgium & No data & No data & No data & \\
\hline Bulgaria & No data & No data & No data & Yes \\
\hline Croatia & $100 \%$ & c. $95 \%$ & No data & Yes \\
\hline Cyprus & None & None & None & No \\
\hline $\begin{array}{l}\text { Czech } \\
\text { Republic }\end{array}$ & $100 \%$ & $100 \%$ & No data & Yes \\
\hline Denmark & No data & No data & No data & No data \\
\hline Estonia & $15 \%$ & $100 \%$ & $100 \%$ & Yes \\
\hline Finland & No data & No data & No data & No data \\
\hline France & $100 \%$ & $100 \%$ & & Yes \\
\hline Germany & & No data & No data & \\
\hline Greece & No & No & No data & Yes \\
\hline \multicolumn{5}{|l|}{ Iceland } \\
\hline \multicolumn{5}{|l|}{ Ireland } \\
\hline Italy & No data & No data & No data & No \\
\hline Latvia & No data & No data & No data & No data \\
\hline Liechtenstein & $0 \%$ & $0 \%$ & $0 \%$ & No \\
\hline Lithuania & $100 \%$ & $100 \%$ & $100 \%$ & Yes \\
\hline Luxembourg & No data & No data & No data & No data \\
\hline Macedonia & No data & $0 \%$ & $0 \%$ & Yes \\
\hline Malta & No data & No data & No data & No data \\
\hline Netherlands & $\mathrm{n} / \mathrm{a}$ & $\mathrm{n} / \mathrm{a}$ & $\mathrm{n} / \mathrm{a}$ & $\mathrm{n} / \mathrm{a}$ \\
\hline Norway & No data & No data & No data & No data \\
\hline Poland & No data & No data & No data & No data \\
\hline \multicolumn{5}{|l|}{ Portugal } \\
\hline Romania & $100 \%$ & $100 \%$ & $100 \%$ & Yes \\
\hline Slovenia & $100 \%$ & $100 \%$ & $100 \%$ & Yes \\
\hline Spain & No data & $0 \%$ & $0 \%$ & No \\
\hline Sweden & $100 \%$ & $100 \%$ & $100 \%$ & Yes \\
\hline Turkey & No data & No data & No data & Yes \\
\hline UK & No data & No data & No data & No data \\
\hline
\end{tabular}




\section{Primary schools}

Table 2.6 describes the primary school (broadly children aged 5-9 years old) provision for school meals in Europe.

Again, for primary schools, there was little actual data presented, suggesting a difficulty in retrieving data, or the lack of data, even when the regulations and policies surrounding meals and snacks in primary schools does exist. Where a law exists, but no data are given, it is assumed that $100 \%$ of schools adhere to the law; to investigate whether this is indeed the case is outside the remit of this project.

There are no data available in Latvia about the number of primary schools that provide and encourage healthy food, but some schools have taken part in the WHO pilot project Nutrition Friendly Schools in 2006, indicating that it is a priority for at least some of the nation's schools. Lichtenstein appears to have no regulations or data about healthy nutrition for school age children.

Some countries, such as the Netherlands, Greece and Norway, do not provide any school meals, and thus do not have legal or policy guidelines that are relevant. However, in Greece there are stipulations as to the standard that any food that is provided in schools must reach. In the Netherlands, there are some initiatives regarding school snacks, but no national coherence to their guidance.

In Croatia, all primary schools are subject to legislation and government policy concerning school meals; the policy also includes regular inspections of the school kitchens. Finland's school meal provision is similarly regulated by law, which is the same situation in France and the United Kingdom. In Poland, just over half of the country's primary schools (around $56 \%$ ) offer school meals, but only $9.1 \%$ of school children make use of the service. The meals provided are not subject to legal or professional guidance as to their nutritional content (which is not to assume that they are poor in nutrition). In Norway, around $90 \%$ of schools offer milk and $60 \%$ fruit and vegetables as snacks. In Ireland, school initiatives to increase the children's consumption of fruit and vegetables have begun using the "Food Dudes" programme, for which An Bord Bia (the Irish Food Board) won the Counteracting Obesity Award from WHO Europe in 2006. The programme encourages children to taste and learn about the benefits of fresh fruit 
and vegetables. The programme was extended to all schools in Ireland in 2007.

\section{Table 2.6 Primary school food policy provision}

\begin{tabular}{|c|c|c|c|c|c|c|}
\hline & $\begin{array}{l}\% \\
\text { primary } \\
\text { schools } \\
\text { with a } \\
\text { school } \\
\text { food } \\
\text { policy }\end{array}$ & $\begin{array}{l}\% \\
\text { primary } \\
\text { schools } \\
\text { offering } \\
\text { meals } \\
\text { consistent } \\
\text { to dietary } \\
\text { guidelines }\end{array}$ & $\begin{array}{l}\% \text { primary } \\
\text { schools } \\
\text { offering } \\
\text { healthy food } \\
\text { options }\end{array}$ & $\begin{array}{l}\text { Legislation } \\
\text { or code of } \\
\text { conduct, } \\
\text { against } \\
\text { promoting } \\
\text { unhealthy } \\
\text { food on TV } \\
\text { likely to be } \\
\text { viewed by } \\
\text { children? }\end{array}$ & $\begin{array}{l}\text { Legislation, } \\
\text { or national } \\
\text { policies, } \\
\text { against } \\
\text { advertising } \\
\text { (unhealthy) } \\
\text { food to } \\
\text { children? }\end{array}$ & $\begin{array}{l}\text { Legislation } \\
\text { to support } \\
\text { availability } \\
\text { and access } \\
\text { to healthy } \\
\text { food, } \\
\text { including } \\
\text { school } \\
\text { meals. }\end{array}$ \\
\hline Austria & & & & Yes & & \\
\hline Belgium & No data & No data & No data & Yes & Yes & No \\
\hline Bulgaria & No data & No data & No data & No & No & Yes \\
\hline Croatia & $100 \%$ & No data & No data & No & No & No \\
\hline Cyprus & No & No & $10 \%$ & No & $\mathrm{No}$ & Some \\
\hline $\begin{array}{l}\text { Czech } \\
\text { Republic }\end{array}$ & $100 \%$ & $100 \%$ & No data & No & No & No \\
\hline Denmark & No data & No data & No data & No & No & No data \\
\hline Estonia & $20 \%$ & $100 \%$ & $100 \%$ & No & No & Yes \\
\hline Finland & $100 \%$ & $100 \%$ & $100 \%$ & Yes & Yes & Yes \\
\hline France & $100 \%$ & $100 \%$ & & Yes & Yes & \\
\hline Germany & & No data & No data & No & No & \\
\hline Greece & No & No & No & $\begin{array}{l}\text { No specific } \\
\text { policies }\end{array}$ & $\begin{array}{l}\text { No specific } \\
\text { policies }\end{array}$ & No \\
\hline \multicolumn{7}{|l|}{ Iceland } \\
\hline Ireland & $100 \%$ & & $100 \%$ & Yes & Yes & Yes \\
\hline Italy & No data & No data & No & No & No & No \\
\hline Latvia & No data & No data & No data & No data & No data & No data \\
\hline Liechtenstein & $0 \%$ & $0 \%$ & $0 \%$ & $\mathrm{No}$ & $\mathrm{No}$ & $\mathrm{No}$ \\
\hline Lithuania & $100 \%$ & $100 \%$ & $100 \%$ & No & No & Yes \\
\hline Luxembourg & No data & No data & No data & No & No & No \\
\hline Macedonia & No data & No & No & Yes & Yes & Partly \\
\hline Malta & No data & No data & No data & No & No & No \\
\hline Netherlands & $0 \%$ & $0 \%$ & $0 \%$ & Yes & Yes & No \\
\hline Norway & $95 \%$ & $0 \%$ & $\begin{array}{l}\text { c. } 90 \% \text { milk; } \\
60 \% \text { fruit/veg }\end{array}$ & No & No & No \\
\hline Poland & No data & No data & no data & No & No & No \\
\hline \multicolumn{7}{|l|}{ Portugal } \\
\hline Romania & $100 \%$ & $100 \%$ & $100 \%$ & Yes & Yes & Yes \\
\hline Slovenia & No data & $100 \%$ & $100 \%$ & No & No & No data \\
\hline Spain & No data & $0 \%$ & $0 \%$ & Yes & & Yes \\
\hline Sweden & $100 \%$ & $100 \%$ & $100 \%$ & Yes & Yes & Yes \\
\hline Turkey & No data & No data & No data & Yes & No & No \\
\hline $\mathrm{UK}$ & $100 \%$ & $100 \%$ & $100 \%$ & Yes & Yes & Yes \\
\hline
\end{tabular}


Other countries too are beginning to give attention to the quality of school nutrition. For example, Cyprus is offering school meals consistent nutritional guidelines in $10 \%$ of schools on a trial basis. Denmark is currently debating whether to provide free fruit and vegetables for school children. The Italian Government, similarly, is encouraging programmes for preventing childhood obesity, of which school meal provision plays a part; although at present the focus is on regional rather than a national control. Spain also has regional regulations about school food, there is no data at present, but data should be available in 2008. Luxembourg is developing school meal guidelines as part of a National Programme for Healthy Nutrition and Physical Activity, established in 2006. In Turkey, it is only those children who attend boarding school (around $2 \%$ of the school population) that are subject to nutritional guidance in school meals. In day schools, snacks are regulated, but purely on a voluntary basis, and guidance is not enforced. In Belgium, a professional body provides guidance to the content of school meals.

From January 2006 all primary school children in Estonia are provided with a free school meal and currently around a fifth of schools have joined the Health Promoting Schools network, which suggests an increasing concern with school health and nutrition. Latvia, also, has become part of the World Health Organization initiative for Nutrition Friendly Schools. In Austria, the content of school meals is regulated by the Österreichische Gesellschaft für Ernährung (Austrian Nutrition Society). In the United Kingdom, initiatives such as the School Fruit and Vegetable scheme provide a piece of fruit or vegetable every day to children aged four to six years.

Bulgaria, Estonia and the Czech Republic have tightly controlled dietary guidelines for use in schools. Lithuania also has a highly regulated school meal system - where school menus are checked annually, and schools are inspected for the nutritional standards of their meals. Children do not start primary school until they are seven years old in Lithuania, but these nutrition standards apply also to pre-school children. In Macedonia, under the Food and Nutrition Action Plan all school children's nutritional status is monitored via regular checkups, although the mechanism to provide data surrounding this does not yet seem to be available. Sweden's school meals are free by law and are controlled as to 
their nutritional content. The nutritional value of school meals provided in French schools is also subject to law.

\section{Advertising of food to children}

In the Netherlands, there are rules that limit the advertising of food to children, such as forbidding celebrity endorsement of junk food, and restrictions on food advertising during children's programming on television. There is a debate in the Netherlands about making the restrictions on advertising stricter. In Sweden it is forbidden to advertise to children under the age of twelve, and no commercials are broadcast during television programming aimed at children under twelve. In addition, in Sweden, actors or celebrities who appear in television programmes must not also appear in commercials. French law also dictates how food can be advertised to children via the National Nutrition and Health Programme (PNNS). In Greece, the National Council for Radio and Television stipulates that children's physical health should be protected on Radio and TV. However, there are no specific policies to forbid the advertisement of unhealthy foods, making the code rather ambiguous. In Romania, part of the school curriculum aims to teach children about their consumer rights, and how to see beyond advertising strategies. In addition, a law prohibits the promotion of "fast food" or "junk food" to children

Other countries, for example, Austria and Germany, are discussing whether to introduce such restrictions, however, there is very little advertising on Austrian children's television, the Arbeiterkammer (AK) restricts promoting unhealthy food to children and young people, and there is little advertising compared to private television programmes. The children's television programme KI.KA is free from advertisement. In Germany, restricting advertising on television is discussed in the Aktionsplan "Gesunde Ernährung und Bewegung" (Action Plan Healthy Diet and Physical Activity). Macedonia has in place recommendations, but no requirements, about advertising food to children. In Belgium, there are guidelines against advertising, but they do not specify healthy or unhealthy food. At present, there is a voluntary code adopted by the food industry and the Union of Belgian advertisers, which is 
accompanied by an interpretative note Reclamecode voor Voedingsmiddelen Code de publicité pour les denrées alimentaires ${ }^{4}$

Countries such as Croatia, the Czech Republic and Norway have no restrictions on advertising to children; although Norway is expected to produce guidance soon about advertising of food to children. In Romania, the Ministry of Education is supportive of legislation that improves children's health. However, recent campaigning by parents about the availability of junk food in primary schools has not resulted in a ban, with the government disputing that any evidence exists as to the harmful content of junk food to children, hence child and parental choice should be the mechanism by which junk food is eaten or not.

\section{Secondary schools}

Table 2.7 describes the provision and legislation within Europe for school meals in secondary schools (children aged approximately 10-14 years).

In many respects, the organisation of secondary school meal provision is similar to that of primary schools. There is cultural variation across Europe concerning countries that do not generally provide meals at school and other countries that provide one or more meals as a matter of course. However, older children, who are more likely to choose their own diets, are perhaps more readily influenced by the presence of snack foods than their younger contemporaries. Again, there are very few data relating to school meal provision in secondary schools, suggesting that it is not collected, collated or readily available. For example, in Italy, there is no policy for collecting the type of data about school nutrition required; and in Latvia, the secondary schools take part in the WHO pilot project Nutrition Friendly Schools - as do the primary schools, although no data seem to be available about nutrition in schools.

\footnotetext{
${ }^{4}$ www.fevia.be
} 
Table 2.7 Secondary school food policy provision

\begin{tabular}{|c|c|c|c|c|}
\hline & $\begin{array}{l}\% \text { secondary } \\
\text { schools with a } \\
\text { school food } \\
\text { policy }\end{array}$ & $\begin{array}{l}\text { \% secondary } \\
\text { school meals } \\
\text { consistent to } \\
\text { dietary } \\
\text { guidelines }\end{array}$ & $\begin{array}{l}\text { \% secondary } \\
\text { schools offering } \\
\text { healthy food } \\
\text { options }\end{array}$ & $\begin{array}{l}\% \text { secondary schools } \\
\text { with nutrition policy } \\
\text { incorporated into } \\
\text { education curriculum }\end{array}$ \\
\hline Austria & No data & Initiatives & Initiatives & No data \\
\hline Belgium & No data & No data & No data & No data \\
\hline Bulgaria & No data & Yes & Yes & $\mathrm{No}$ \\
\hline Croatia & $100 \%$ & No data & No data & $100 \%$ \\
\hline Cyprus & None & None & $\mathrm{n} / \mathrm{a}$ & $100 \%$ \\
\hline Czech Republic & $100 \%$ & $100 \%$ & No data & No data \\
\hline Denmark & No data & No data & No data & No data \\
\hline Estonia & $20 \%$ & $100 \%$ & $100 \%$ & $20 \%$ \\
\hline Finland & $100 \%$ & $100 \%$ & $100 \%$ & No data \\
\hline France & $100 \%$ & $100 \%$ & & \\
\hline Germany & & No data & No data & No data \\
\hline Greece & $\mathrm{No}$ & No & No & No \\
\hline \multicolumn{5}{|l|}{ Iceland } \\
\hline \multicolumn{5}{|l|}{ Ireland } \\
\hline Italy & No data & No data & No data & No data \\
\hline Latvia & No data & No data & No data & No data \\
\hline Liechtenstein & $0 \%$ & $0 \%$ & $0 \%$ & $0 \%$ \\
\hline Lithuania & $100 \%$ & $100 \%$ & $100 \%$ & $100 \%$ \\
\hline Luxembourg & No data & No data & No data & No data \\
\hline Macedonia & No data & No & No & No \\
\hline Malta & No data & No data & No data & No data \\
\hline Netherlands & $0 \%$ & $0 \%$ & $0 \%$ & No \\
\hline Norway & $95 \%$ & $0 \%$ & $\begin{array}{l}90 \% \text { milk; } 65 \% \\
\text { fruit/veg }\end{array}$ & No data \\
\hline Poland & No data & No data & No data & No data \\
\hline \multicolumn{5}{|l|}{ Portugal } \\
\hline Romania & No data & No data & No data & No data \\
\hline Slovenia & $100 \%$ & No data & No data & No data \\
\hline Spain & $0 \%$ & $0 \%$ & $0 \%$ & $0 \%$ \\
\hline Sweden & $100 \%$ & $100 \%$ & $100 \%$ & No data \\
\hline Turkey & No data & No data & No data & No data \\
\hline $\begin{array}{l}\text { United } \\
\text { Kingdom }\end{array}$ & $100 \%$ & $100 \%$ & $100 \%$ & \\
\hline
\end{tabular}


In the Netherlands, no school provides a meal, as it is not customary to have a meal at school, although snacks are sometimes available. At present, there are no laws or regulations that specifically apply to school meals although there are initiatives such as healthy school canteens, but no data exist to quantify how many schools have adopted these principles and how successful they are. Greece and Malta also do not have a culture of schools providing food, and children bring food in from home to eat. Denmark does not have any regulations at present; however, there is a proposal to provide free fruit and vegetables for schoolchildren. There is no legislation in Norway, but as with other countries, a proposition exists to provide free fruit and vegetables to school children. In Poland, just over half of the secondary schools (53.9 $\%$ ) provide school meals, but only around $5 \%$ of children make use of the facility.

Together with the primary schools, Estonian secondary schools have joined the Health Promoting Schools network, which has developed and implemented a school food policy. Luxembourg is currently developing healthy nutrition and food policies in its secondary schools as part of a wider program to combat obesity and improve health. In Italy, the regional departments have implemented programmes to combat childhood obesity, one of which is the provision of healthy school food. Germany's school meals are subject to initiatives by the German Nutrition Society Deutsche Gesellschaft für Ernährung. In the United Kingdom, all food in schools must meet certain standards to ensure children are provided with a balanced diet. Very fatty, fried food is restricted and food such as meat or vegetables must be of a high standard.

Some states are more highly regulated than others. Macedonian regulations concerning food and nutrition for schoolchildren are backed up by a continuing programme of health surveillance of students' anthropometrical and biochemical health. Bulgaria and the Czech Republic also have school regulations which apply to food policy and diet. The Ministry of Education, Youth and Sports controls the nutritional content of each meal provided by schools. Croatian secondary schools are subject to legislation surrounding school nutrition, which also requires regular inspection of school kitchens. Lithuania also has organised regulations for school meals, the menus of which are checked by public health departments during each school 
year. In Finland, all schools are subject to legal requirements concerning school food provision. Swedish school meals are provided free of charge, and all conform to dietary requirements, in addition, all students learn home economics, including cooking and nutrition. In France, the law, via the Agence Française de Sécurité Sanitaire des Aliments (AFFSA) dictates the nutritional content of food available in secondary schools. Austrian school food is regulated by the the Österreichische Gesellschaft für Ernährung (Austrian Nutrition Society, ÖGE)

Even where there is no tradition or organised control of school meals, there are regulations in most countries about the quality of snacks that can be offered in schools. This is particularly pertinent for older children and adolescents. In Cyprus, there is no law about school meals, but legislation does exist for items sold as snacks in school canteens. This is combined with nutrition and food science education in schools that is provided weekly throughout a child's school career. The Netherlands' Nutrition Centre "Healthy School Canteen" project was designed to promote a healthy and safe range of food products in the school canteen by introducing hygiene standards, offering advice about healthy choices, addressing students' choices in the canteen and introducing policy aimed at creating a healthy school canteen. The campaign is directed at all types of schools, for all ages of children, but the 12-16 year old age group is a particular focus. The campaign involves all members of the school faculty - including students, teachers and canteen staff. Liechtenstein has a similar initiative. The government established a working group in 2000 to encourage health promotion and social education in schools. One of these targets addresses physical development, including healthy eating. In Lithuania, health promotion forms a part of the educational curriculum, of which healthy eating is a component. Germany is considering expanding its home economy curriculum to focus specifically on nutritional topics. At present, nutrition is part of the Wirtschaft, Technik, Haushalt/Soriales (Economy, Techniques, Household/Social) at secondary schools in Saxony, but within the action plan Healthy Diet and Physical Activity there is a proposal made by the Health Secretary to establish nutrition as a discrete subject; however this was met by opposition from the German Federal States. In Spain, nutrition is part of the curriculum at the discretion of individual schools or teachers. In Turkey, although there are no specific laws relating to school meal provision, there are rules for canteens that must sell healthy 
food options - such as milk, fruit and so on. However, the rules are not often adhered to.

\section{Adolescents}

Table 2.8 describes the legal and policy decisions made regarding school food and advertising of food to adolescents in Europe (typically, Adolescents aged 15 and over).

Much of the information about adolescents is similar to that provided for slightly younger children in the 10-14 age group. However, where adolescents differ from their younger contemporaries is in their autonomy about choice of food, and often, greater freedom to leave the school environment to obtain a meal during the school day. In this respect, the presence of restrictions on food advertising and placement of foods within popular culture is of great importance to the adolescent cohort.

In the Netherlands, where schools do not provide meals, there is little regulation. But there are strict guidelines concerning advertising of food to minors. In Denmark, discussions are in progress about restricting advertising to children and adolescents aged under 16. In France, advertising snack foods to adolescents is restricted by the National Nutrition and Health Program (PNNS).

Austria is considering implementing restrictions on promoting unhealthy food to children and young people, as is Norway, where there is much current debate about the subject; Germany, also, is undergoing much discussion about advertising food to children within its Action Plan Healthy Diet and Physical Activity Aktionsplan Gesunde Ernährung und Bewegung. Sweden on the other hand, has no restrictions in advertising to adolescents, but strict legislation concerning advertising unhealthy food to children aged under twelve. Italy also has no policy about advertising restrictions to young people concerning unhealthy foods. 
Table 2.8: Adolescent school food policy provision

\begin{tabular}{|c|c|c|c|c|c|}
\hline & $\begin{array}{l}\% \text { schools } \\
\text { with a } \\
\text { school food } \\
\text { policy }\end{array}$ & $\begin{array}{l}\text { \% schools } \\
\text { offering } \\
\text { meals } \\
\text { consistent to } \\
\text { dietary } \\
\text { guidelines }\end{array}$ & $\begin{array}{l}\% \text { schools } \\
\text { offering healthy } \\
\text { food options }\end{array}$ & $\begin{array}{l}\text { School } \\
\text { nutrition policy } \\
\text { incorporated in } \\
\text { education } \\
\text { curriculum }\end{array}$ & $\begin{array}{l}\text { Restrictions } \\
\text { on the } \\
\text { advertising of } \\
\text { snack foods } \\
\text { to adolescents }\end{array}$ \\
\hline Austria & & Initiatives & Initiatives & $\mathrm{No}$ & Some \\
\hline Belgium & No data & No data & No data & & \\
\hline Bulgaria & No data & No data & No data & No & No \\
\hline Croatia & $100 \%$ & No data & No data & No data & No \\
\hline Cyprus & None & None & $\begin{array}{l}\text { None only snack } \\
\text { policy }\end{array}$ & All & None \\
\hline $\begin{array}{l}\text { Czech } \\
\text { Republic }\end{array}$ & $100 \%$ & $100 \%$ & No data & Yes & No \\
\hline Denmark & No data & No data & No data & No data & No \\
\hline Estonia & $20 \%$ & $100 \%$ & $100 \%$ & No data & No \\
\hline Finland & $100 \%$ & $100 \%$ & $100 \%$ & No data & No data \\
\hline France & $100 \%$ & $100 \%$ & & & Yes \\
\hline Germany & & No data & No data & In part & No \\
\hline Greece & No & $\mathrm{No}$ & $\mathrm{No}$ & No & No \\
\hline \multicolumn{6}{|l|}{ Iceland } \\
\hline \multicolumn{6}{|l|}{ Ireland } \\
\hline Italy & No data & No data & No data & No data & No data \\
\hline Latvia & No data & No data & No data & No data & No data \\
\hline Liechtenstein & $0 \%$ & $0 \%$ & $0 \%$ & No & No \\
\hline Lithuania & $100 \%$ & $100 \%$ & $100 \%$ & Yes & Yes \\
\hline Luxembourg & No data & No data & No data & No & No \\
\hline Macedonia & No data & No & $\mathrm{No}$ & No & No \\
\hline Malta & No data & No data & No data & No data & No \\
\hline Netherlands & $0 \%$ & $0 \%$ & $0 \%$ & $\mathrm{No}$ & Yes \\
\hline Norway & $95 \%$ & $0 \%$ & $\begin{array}{l}90 \% \text { milk; } 60 \% \\
\text { fruit/veg }\end{array}$ & No & No \\
\hline Poland & None & None & None & No & No \\
\hline \multicolumn{6}{|l|}{ Portugal } \\
\hline Romania & No data & No data & No data & No data & No data \\
\hline Slovenia & $100 \%$ & No data & No data & No data & No \\
\hline Spain & $0 \%$ & $0 \%$ & $0 \%$ & No & No \\
\hline Sweden & $100 \%$ & $100 \%$ & $100 \%$ & Yes & No \\
\hline Turkey & No data & No data & No data & No & No \\
\hline $\mathrm{UK}$ & $100 \%$ & $100 \%$ & $100 \%$ & & Yes \\
\hline
\end{tabular}




\section{Lessons learned from measurements}

Perhaps the most striking of the lessons learned from this investigation is the lack of easily available data to quantify means of influencing the nutritional habits of children through policy measurements, at home or at school. Some of the initiatives described, such as Baby Friendly Hospitals, have been in place for many years, and yet it is not easy to determine how effective the interventions have been on a national level.

Other initiatives, such as school healthy eating policies and dietary guidelines being put in place in schools and nurseries, seem to be present in many countries in Europe. However, measuring the extent to which these policies are adhered to and the subsequent effect of them on the child population is, again, a challenge for the researcher.

It is also important to note the influence of particular wider determinants of behaviour. Many of the determinants of obesity are also determinants of rejecting other good health behaviours. For example, smoking, lack of parental education (particularly mother's education), low social or economic class status all mean that a mother is less likely to breastfeed. These determinants also seem to influence whether a family eats together regularly, or purchase healthy food such as fruit and vegetables. This is a strong indication that this specific sector of the population would benefit from health intervention, social and financial support to improve health overall and in the process reduce levels of obesogenic behaviour in their children. 
Part 3: Developing Indicators 


\section{Chapter 4:}

\section{Alexander D, Rigby M, Di Mattia P, Zscheppang A. (2015) Challenges in finding and measuring behavioural determinants of childhood obesity in Europe. Journal of Public Health. 23(2) 97-94.}

This paper is an update from the original work on measuring childhood obesity, carried out in 2007 by the Scientific Platform Project on Lifestyle Determinants of Obesity project. Here, the original project and its findings are described and current literature reviewed to estimate what changes in measurement, if any, had occurred in the intervening years.

Although it was impossible to repeat the original study in its entirety, the literature suggests that the situation has not changed markedly and there remains work to be done in terms of accurately measuring childhood obesity comparatively across Europe - an issue that is of increasing importance because of the pan-continental nature of food production and food manufacture - particularly that of 'junk' food. 


\section{Challenges in finding and measuring behavioural determinants of childhood obesity in Europe}

Corresponding author: Denise Alexander. Department of International Health, School for Public Health and Primary Care (CAPHRI), Maastricht University, PO Box 616, 6200 MD Maastricht, The Netherlands. (Formerly of School of Public Policy and Professional Practice, Chancellor's Building, Keele University ST5 5BG.) denise.alexander@maastrichtuniversity.nl Telephone 0044606888486.

Michael J Rigby. Nordic School of Public Health, Box 12133, SE-402 42 Gothenburg, Sweden; Emeritus Professor of Health Information Strategy, School of Public Policy and Professional Practice, Chancellor's Building, Keele University ST5 5BG.m.j.rigby@keele.ac.uk

Pasquale Di Mattia. S. Elia Hospital, Caltanissetta, Italy. (Formerly Centro per la Formazione Permanente e l'Aggiornamento del Personale del Servizio Sanitario (CeFPAS), Caltanissetta, Italy.) lino-dm@libero.it.

Anja Zscheppang. Faculty of Medicine Carl Gustav Carus: Research Association Public Health Saxony and Saxony-Anhalt, Technische Universität Dresden, Fiedlerstraße 3301307 Dresden, Germany. anja.zscheppang@tu-dresden.de 


\begin{abstract}
Aim: Childhood obesity is an important concern for child health. However, despite widespread concern about the increase in childhood obesity, its causes are not monitored systematically in Europe. In 2007, the Scientific Platform Project on Lifestyle Determinants of Obesity identified routine data sources nationally available in European countries to measure childhood obesity. This work was revisited in 2014 to monitor any progress made.
\end{abstract}

Subject and Methods: In 2007, a literature review and project discussion resulted in a list of desirable indicators that could be collected in Europe to describe child populations at risk of overweight and obesity. Participants from EU member states, the EEA, Croatia, Macedonia and Turkey set out to discover which countries collected these indicators. Eight years later, a literature search sought to establish if the surveillance of children's nutrition and physical activity behaviour had changed.

Results: In 2007 no country collected all variables for all ages, leading to major gaps in knowledge. A literature search carried out in 2014 suggests that this is unchanged. There remains inconsistency of data surveillance in Europe, and disagreement on which age-groups to collect or how to define obesity and overweight.

Conclusion: There is a lack of consistent data collection on upstream influences on obesity. The true causes of the childhood obesity epidemic remain undiscovered, and the ability of research to identify effective prevention and treatment methods is compromised.

Keywords: obesity, childhood, data, surveillance, Europe 


\section{Introduction}

Childhood obesity is one of the most serious public health problems facing the world today, and has been described by the World Obesity Federation (2012) as a health challenge that is on the verge of imposing unprecedented strain on global health, healthcare, financial capacity and on society as a whole (World Obesity Federation 2012). The rates of childhood obesity have trebled since the 1980s (World Obesity Federation 2012) and it is estimated that in 2010, one in three children aged between 6-9 years old were overweight; this is a marked increase in the numbers recorded in 2008, when one in four was overweight (Wijnhoven et al. 2014). Obesity places huge demands on European health systems. It is estimated that European nations spend between 2 and $8 \%$ of their healthcare budgets on diseases that are related to obesity (World Obesity Federation 2012) and unless the epidemic is tackled effectively, this burden will only increase.

Childhood obesity is an important concern for child health and in the context of a healthy ageing agenda. It is a predictor for many adult chronic diseases. Measuring elements of childhood lifestyles and behaviour is particularly challenging, but nevertheless important, because childhood overweight and obesity has the greatest life-long consequences (World Health Organization 2006), and childhood is a time of vulnerability to micro and macro environments. Recent research trends are to investigate the wider determinants that ultimately result in overweight, such as the influence of the built, social, political and economic environments (Brug et al. 2008; Brug, 2008; van der Horst et al. 2007; Kleiser et al. 2009; Owen et al. 2014). However, there are not the national or subnational data on children comprehensive enough to make robust international comparisons or draw conclusions. This state of affairs has resulted in confusing or conflicting evidence surrounding the environment as a factor in obesity (Brug 2008). The Health Behaviour of School-aged Children (HBSC) study, which was, and is, used as important source of knowledge about the child population in many countries, notes the importance of social context in the development of protective factors and reduction of risk factors in terms of obesity and overweight (Currie et al. 2012); but even the HBSC study report notes how difficult it is to measure physical activity or sedentary behaviour in a way that makes identifying trends in relation to 
socioeconomic status, for example, easy to understand and to act upon (Currie et al. 2012).

Coordinated international activities are a vital tool in this quest for better practical information for two principal reasons. First, international comparison is a powerful driver for change. Countries in the least favourable positions, having been made aware of this, are more motivated to find the resources and knowledge to effect improvements, but can also see which of their peer nations may be able to share guidance for success. Second, understanding and measuring the determining factors of health related behaviour in this complex field is highly challenging, and thus the pooled skills of international agencies and programmes can best assist all concerned.

In 2007, the Scientific Platform Project on Lifestyle Determinants of Obesity, a European Union (EU) funded project, set out to monitor the childhood obesity epidemic. This attempted to determine how and what data were collected nationally by 31 countries from the EU, members of the European Economic Area, Croatia, Macedonia and Turkey. This project was a partner exercise to an exploration of what data were known about adult obesity in Europe (Wolfram et al. 2008). In the seven years since the completion of the project, and subsequent publication of the accompanying book (Alexander et al. 2010), childhood obesity has become an increasingly important public health issue with implications for current and future population health.

This paper describes the findings of the original project and investigates the progress, if any, that has taken place since 2007 in collecting data on the childhood obesity epidemic. Accurately monitoring prevention efforts as well as the prevalence of the epidemic in Europe is essential to reduce childhood obesity. This is because children are arguably the section of the population most influenced by environmental and societal determinants of behaviour; they are largely dependent on adults for their health and wellbeing. Any population surveillance approach must reflect this and not only identify the prevalence of overweight, but also the prevalence of 'upstream' factors that increase the risk of overweight such as lack of availability of fresh food, or no safe places for physical activity. 


\section{Methods}

Four scientific partners collaborated in the original Lifestyle Determinants project, and twenty country-specific sub-contractors gathered data from all 31 countries in the project [. Its purpose was to identify routine data sources that were available nationally in Europe. The definition of 'routine data source' was that all people can access the information; and that data are regularly and periodically gathered, for example for legal, operational, or reimbursement purposes such as vital statistics, census data, hospital care statistics, or ambulatory care statistics.

In the 2007 project, a literature search was conducted to determine the type of data that could be sought. Peer reviewed literature relating to children's nutrition and physical activity was identified through PubMed. Search terms for this literature were specific for each age group and for the type of behaviour under investigation. For example: 'infants' AND 'nutrition behaviour'; 'adolescents' AND 'physical activity behaviour'; 'obesity' AND 'children'; 'obesity' AND '5-9 year olds'. In total, 27 separate searches were undertaken. These searches were supplemented by a follow up of references and consultation with identified experts in the fields of nutrition, physical activity and obesity. Relevant topics and indicators were refined into formal data definitions during a two-day workshop by the four main project partners from Germany, Italy, Sweden and the United Kingdom. It became obvious that solely updating the adult-oriented project's database of routine national surveys and data sources to include those relating to children would not give national policy makers adequate evidence of behavioural determinants for all child life course stages. For the child focused project, therefore, key indicator sets were created separately for nutrition and physical activity for each main stage of childhood. A child was defined according to the United Nations Convention on the Rights of the Child (United Nations Office of the High Commissioner for Human Rights 1989), namely, persons from birth up to their $18^{\text {th }}$ birthday. Indicators were sought for five year age bands; and / or pragmatic school-based age bands reflecting children's developmental stages.

Once the parameters were established, data collection began. Each country provided a one-page country profile detailing the priority given to childhood obesity by government, health services and mass media; completed the two agreed schedules of data availability; and updated the 
pre-existing adult related project database regarding projects with children within the included age groups, adding information about age groups, gender, data collected and the availability of data on behaviour measures. The national subcontractors were asked to find information readily available to them, or at least to be found with minimal effort, to replicate what an 'informed layperson' could achieve.

In 2014 the original literature review was repeated as far as possible. PubMed was interrogated to find peer-reviewed papers on childhood nutrition, physical activity and measurement. The search terms were necessarily general in order to identify as wide a range of articles as possible. They were: ('child' OR 'adolescent') AND ('nutrition behavio*' OR 'physical activity behavio*') AND 'health surveillance'. Both US and UK English spellings were used for the term 'behaviour'. In addition, a search of the EU and WHO websites was undertaken for relevant publications and references of all papers and reports were followed up. Fifteen research papers, position papers and policy documents that had been published since 2007 on the subject of national surveillance of childhood obesity and overweight in the countries in Europe were read.

\section{Results}

The results of the 2007 Lifestyle Determinants project and the 2014 update exercise will be presented here in turn.

The Lifestyle Determinants project (2007) enabled an overview of the pattern of data availability, and identified major gaps in surveillance of upstream determinants of nutrition and physical activity among children by topic or by country. The results showed whether the data were available in each country, and to some extent how easy the data were to retrieve.

Two data types were included in the final indicators identified and chosen for the project database in 2007: statistical data (of which there were 39 indicators) and policy and legal instruments (of which there were 37 indicators). The latter are potentially powerful in influencing behaviour modification, and so logically needed to be included (World Health Organization 2013; Brug et al. 2008). The most desirable data sources were those from country-level routine and repeated data collection; but the study also included robust surveys, such as the Health Behaviour in School-aged Children Study (HBSC) (Currie et al. 2012), 
one-off statistical activities and published research studies. Most of the indicators were of salutogenic or protective behaviours which have correlations with positive health, although a few were of sedentary behaviour, which may indicate a heightened risk of obesity. There was a reasonably even spread of indicators across all age groups in terms of statistical and legal and policy items.

The next and central component of the Lifestyle Determinants project was to identify the degree to which the country subcontractors could feasibly obtain these statistical measures from published data sources, and establish the existence of the Legal and Policy mechanisms. Table 1 shows how successful they were in terms of statistical items and shows where data were available from repeated and routinely analysed sources. In addition, some countries reported data availability from one-off research sources, or reported that raw data were available but not routinely analysed and published. Further details are available in the full project report (Alexander et al. 2010). The countries that were identified as collecting data for nearly all of the indicators and the required age groups used a combination of routine data sources such as national surveys or longitudinal studies; data that was collected as part of a routine source, but that is not normally analysed in a child-focused way; and research and one-off studies. Routine sources are preferable in order to monitor an epidemic; but are rarely available in a child-focused and upstream format. The potential of existing data that is not currently analysed in a child-focused manner is recognised, but these are initially costly and difficult data to obtain. Research and one-off studies are essential for science, but of limited use in monitoring a long-term epidemic. 


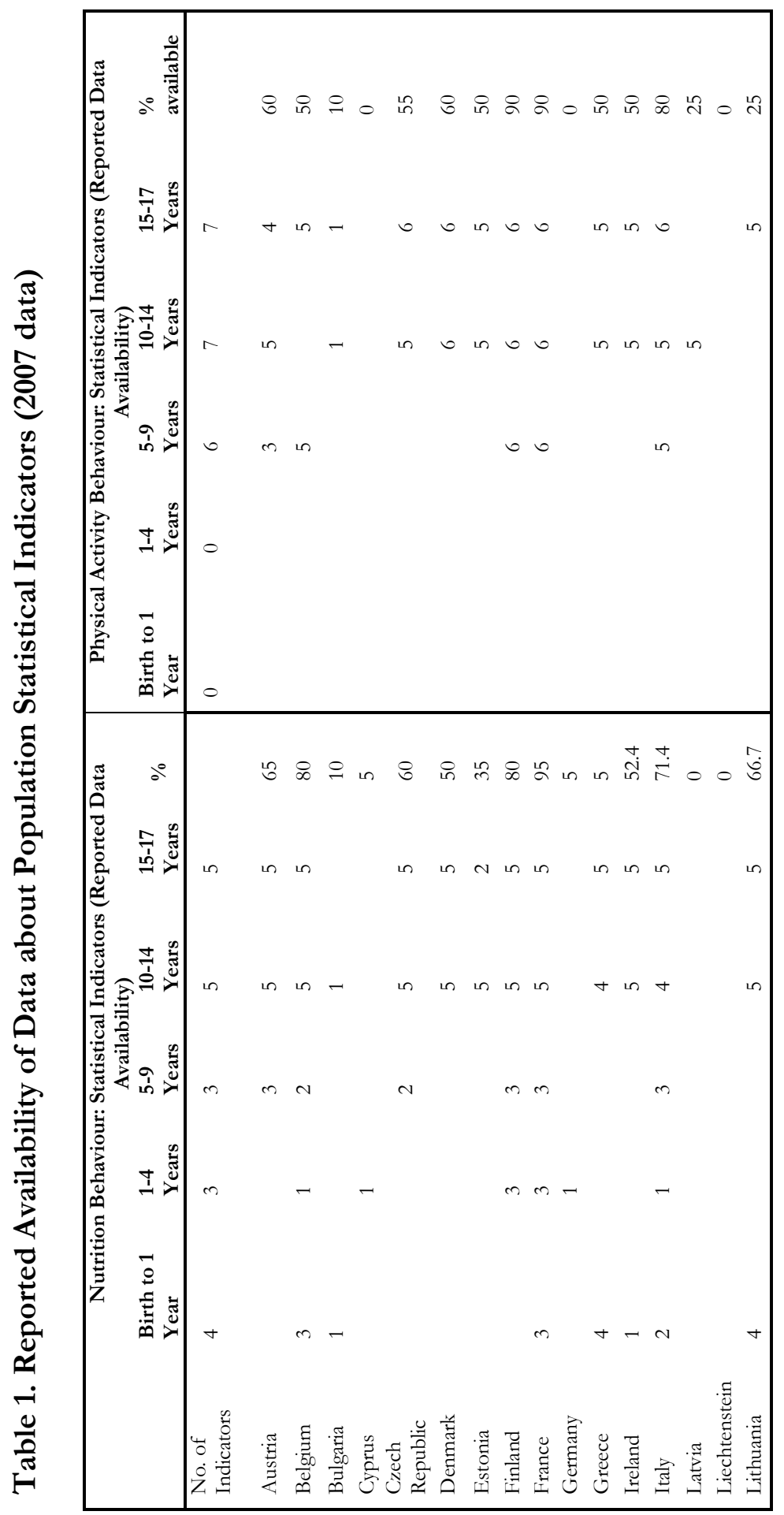




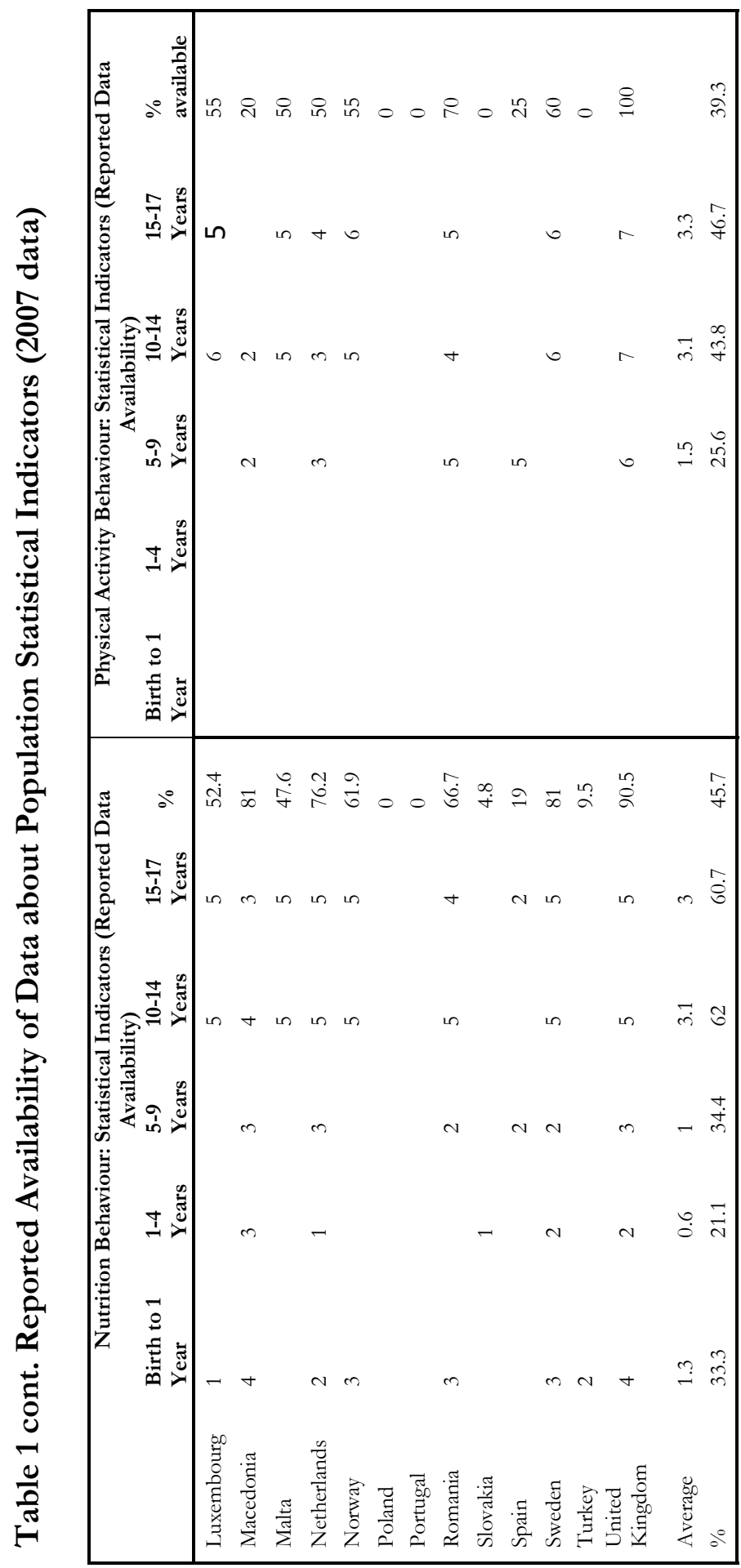


Table 1 shows that in 2007 nutritional behaviour was better monitored than physical activity, and that there was greater availability of data about older children for both nutrition and physical activity. National availability fluctuated considerably but the positive influence of specific coordinated European Studies was evident.

Table 2 shows the identifiable existence of the Legal and Policy items by country in 2007. Data about infant feeding policies were the most readily available, followed by those regarding physical activity for children under 10 years of age. There was much less knowledge of the existence of policy and legal controls for children aged over 10. National policy existence ranged widely between countries, and there were marked differences between the nutritional and physical activity items. 


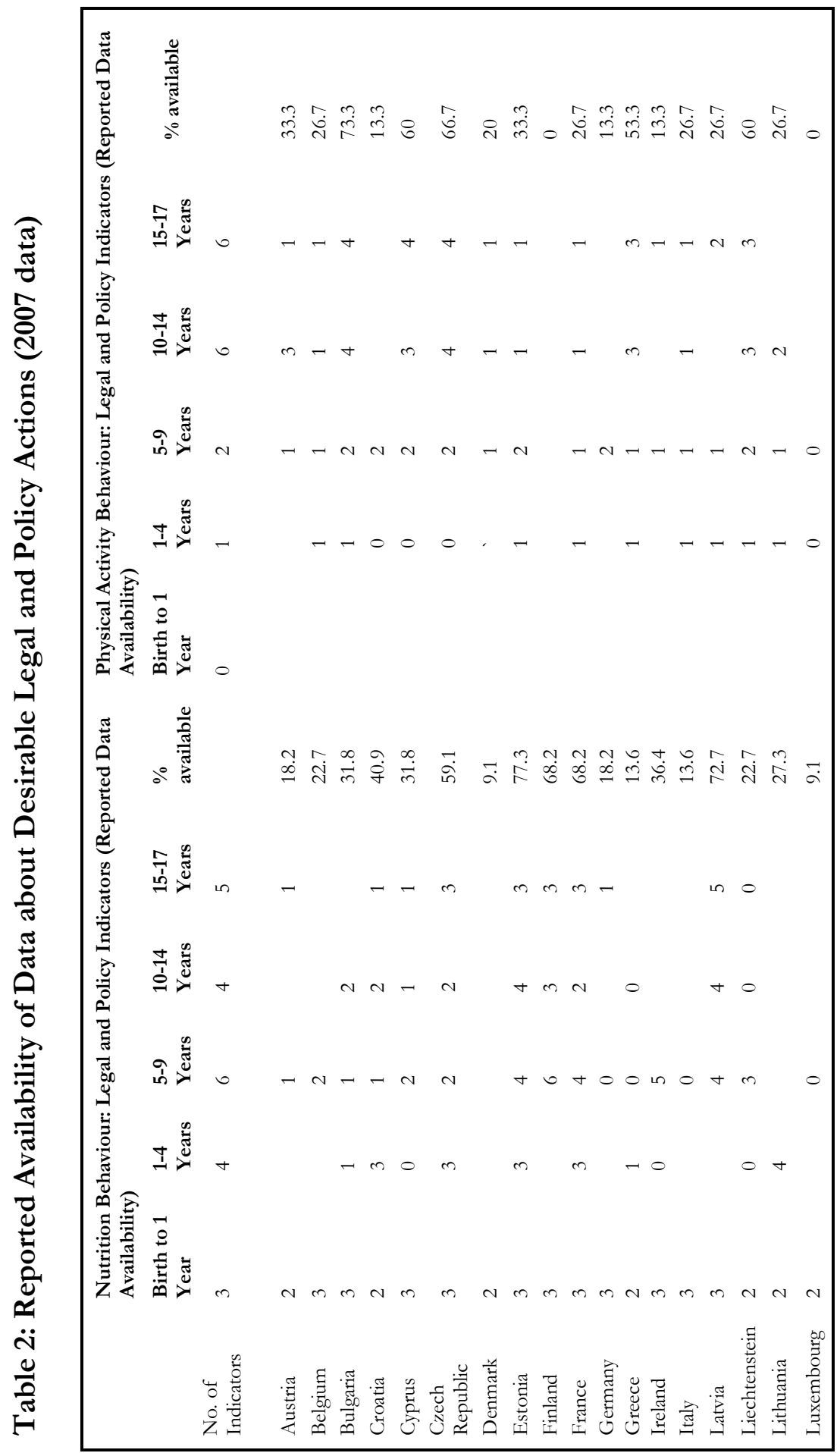




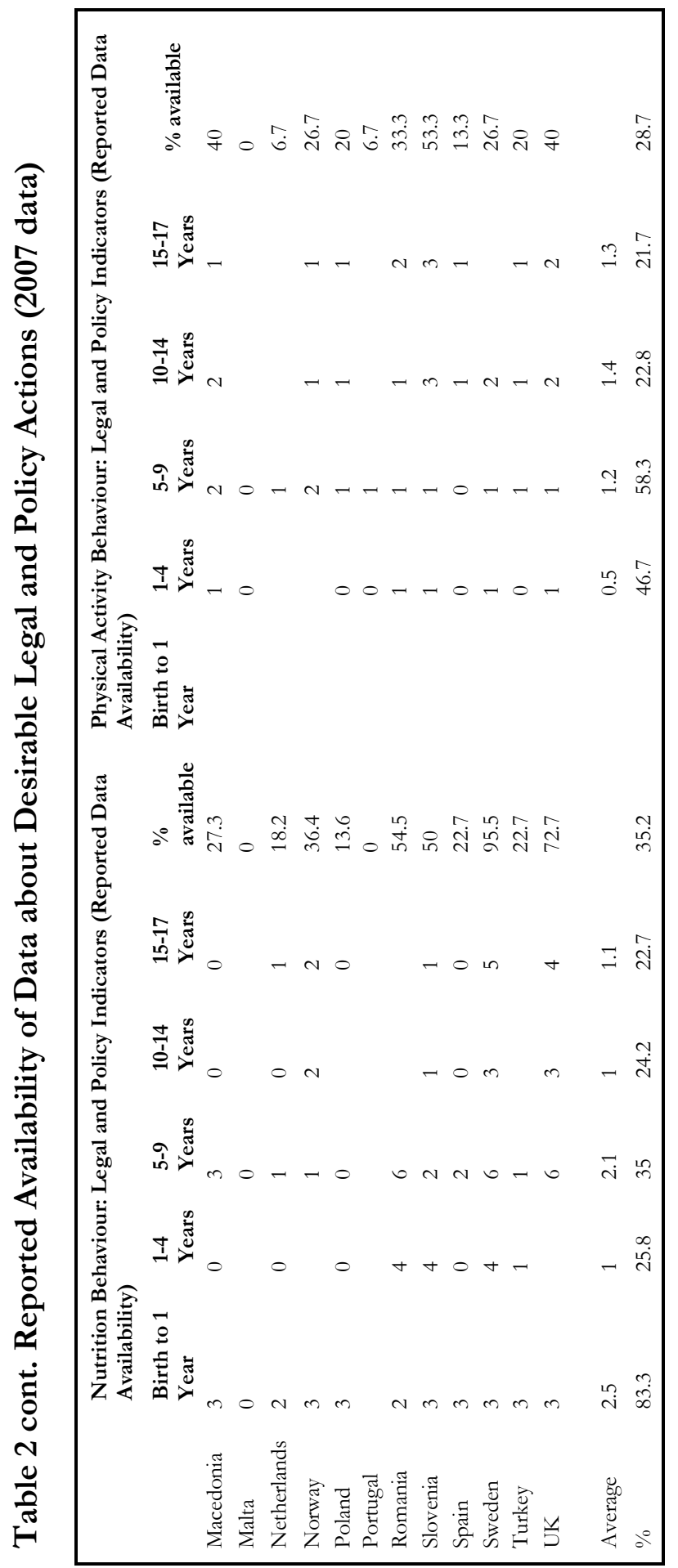


The Lifestyle Determinants project of 2007 was followed up in 2014. The update of the project was limited by budget and time constraints, meaning that a repeat of the original country-based exercise was not possible. However, current literature and lack of evidence of changes to statistical systems support the conclusion that little has changed, and work needs to be done to improve surveillance of behavioural determinants of health in Europe. From the 15 relevant papers retrieved in the literature search, a picture emerges of a still incomplete profile of the aetiology of childhood obesity. A recent exercise by the World Health Organisation (WHO) aimed to collect data on selected surveillance indicators and policy items for adults, adolescents and children in a similar vein to that carried out by the Scientific Platform project (World Health Organization 2013). To identify the number of overweight and obese adolescents, they used data from the Health Behaviour in School-aged Children (HBSC) study, as did many of the countries in the Lifestyle Determinants project. However, this only gave comparable data for 33 out of the 53 countries in the WHO exercise. The prevalence of overweight in other countries was given for ages 1519, but the data used the adult Body Mass Index (BMI) calculation criteria, which may not be fully appropriate for children, and so the results cannot be compared with the HBSC countries, and must be used with caution. When describing children aged between 5-9 years, data came from the European Childhood Obesity Surveillance Initiative (COSI) (World Health Organization 2007), and only 12 states out of 52 were able to produce data of how many children were overweight in any comparable way. Data for other countries was included when it could be found, but the results cannot be compared internationally. Data for breastfeeding - an indicator proposed as important by the Lifestyle Determinants project and the WHO exercise - produced even fewer results. No inter-country comparable data source could be identified by the WHO in 2013, so nationally identified survey data had to be used to estimate the prevalence of breastfeeding; and it is impossible to create a continent-wide picture of breastfeeding prevalence (World Health Organization 2013). A review in 2010 found very few data relating to pre-school children's dietary habits and physical activity in relation to overweight. In their search of the Global database on child growth and malnutrition, the authors found that 9 out of 27 countries had no nationally representative data on pre-school children (Cattaneo et al. 2010). Similarly, the 2013 Cochrane Review into preventing childhood 
obesity could only find 55 studies worldwide robust enough to form part of their evidence. Within the Cochrane review it was found that there was unexplained heterogeneity in the results and also a need for cautious interpretation because of the small scale of many of the studies, which may lead to bias (Waters et al. 2011).

\section{Discussion}

The Lifestyle Determinants project identified feasible ways of measuring upstream determinants of childhood obesity and overweight. Yet, despite the justified expressions of concern about the exponential increase in childhood obesity and calls for action, in 2014 it remains impossible to quantify adequately the countries where children are at most risk of becoming overweight. In 2007, a large disparity in the type and quality of data identified was found, and this remains the case seven years later, which is somewhat disappointing. The original project showed a considerable variation in policies and in the availability of important behavioural measures through routine statistical sources. No single country provided a template of perfection, but a more robust health behaviour monitoring baseline would be achieved if all countries collected the same data as those with more comprehensive health surveillance. The data collection schemes proposed by the Lifestyle Determinants project provide a feasible method of understanding the origins of the childhood obesity epidemic; it is effectively the lack of country systems and motivation that prevents greater knowledge.

The original project gathered a range of indicators, hypothesising that it is the combination of the identified indicators that will give a picture of the behavioural factors that influence the weight of Europe's school children. Any individual indicator cannot give a true picture of such a complex issue. Most children's lives feature a combination of healthy and unhealthy behaviours, which can provoke a cumulative effect on overweight and obesity (Leech et al. 2014). There is still a great deal to be discovered, as research has identified only weak associations between diet and physical activity behaviours and obesity, suggesting that effective prevention is more about encouraging an accumulation of small individual changes and a whole lifestyle approach, rather than tackling a single, underlying cause (Jago et al. 2009). As part of such a holistic approach, recent work has identified the important role of sleep, and sleep behaviour patterns in the presence of childhood overweight and obesity (Thivel et al. 2015; Adamo et al. 2013). There is also work 
that suggests important influences, at certain childhood ages, of sleep and leptin production, a hormone that affects appetite (Boeke et al 2014). In addition, sleep apnoea is more common in obese children, a condition that interrupts sleep and may establish a vicious circle that perpetuates overeating, lack of physical activity and increased obesity (Alonso-Álvarez 2014). There is a need for regular data collection that can show nutrition and physical activity actions as part of wider lifestyle behaviours in each country, extending beyond identifying children at risk but also potentially providing valuable raw, comparable data for researchers to understand more about the links between these complicated factors of obesity.

In the Lifestyle Determinants project there were not enough data to describe children in each life stage collected routinely across Europe. Some countries had no nutrition data for all age bands. In other countries, nutrition data were only available for children aged up to 1 year, or to age 4 . The lack of data about breastfeeding was of particular concern. Baby Friendly Hospitals, where breastfeeding is supported and made easier for the mothers, were an agreed priority by all health ministers (Alexander et al. 2010), yet in the original project and at present, few countries could identify how many Baby Friendly Hospitals they had. This can be seen as perhaps an indicator of a greater emphasis on rhetoric than on consistently applied simple measures such as scientifically validated data collection. For all age groups and in all countries, there was a comprehensive dearth of information about physical activity. However, the indicators about television watching and time using computers are collected by almost all European countries, at most age groups even though this is only a weak indicator. In the Lifestyle Determinants project, the majority of countries in Europe collected some of the indicators but not for all age groups. In addition, it is difficult to establish the reliability of some of the data sources, and the inclusion of one-off projects means that some countries may have collected data on a section of the child population but not repeated the exercise to assess a trend.

A limitation of the original project was that the quality and comparability of the data collected could not be ascertained confidently because the project database did not contain the actual data collected by the individual countries, just the measures or indicators used. However, definitions of measures in use showed that many were unable to be 
compared between countries, and this remains the case as evidenced by current research (Cattaneo et al 2014). Incomparability of data between countries in Europe remains a problem in 2014. Many data are incompatible with other country data because of different methods of calculation (Cattaneo et al. 2010). Some countries use, for example, the World Health Organisation (WHO) charts for ages 5-19 (de Onis et al. 2007); and others those of the Centers for Disease Control (CDC) (Kuczmarski et al. 2002) or the International Obesity Task Force (IOTF) definitions (Cole et al. 2000) as a basis for their calculations. Each system uses different reference populations and cut offs, making vital international comparisons extremely challenging, if not impossible (Catteneo et al. 2014). The National Child Measurement Programme in England weighs and measures all children at the beginning and end of state primary school (Lifestyle Statistics Team, Health and Social Care Information Centre 2013), giving a prevalence of underweight, healthy weight and overweight children; but the scheme does not give an indication as to root causes. The European Childhood Obesity Surveillance Initiative aims to collect internationally comparable data on the prevalence of childhood obesity, but does not collect from all EU countries; and does not collect upstream data to explain why certain countries have greater incidence and prevalence of childhood obesity (World Health Organization 2007). Other important measures, such as the HBSC study, are based on sample populations and not collected routinely every year, and not carried out in all countries of the EU.

The Lifestyle Determinants project had significant implications, necessitating an approach that considers aspects of childhood obesity that ultimately fell beyond its resources. Much of the current effort is placed on simply measuring the number of overweight or obese children in Europe; however, this will only identify effects after they happen. It is important to identify where children may be at more risk of becoming overweight. Lifestyle actions depend on individual choices, including cultural influences, food preferences, time for games, sleep and so on; as well as socioeconomic and environmental factors (affordability of food products and facilities for play and exercise, for example), which are themselves shaped by policies that are the responsibility of the EU Member States and the European Community (EC). Developing a health information system that is sympathetic to these individual choices as well as applicable to the child population is a complex task. At 
present, the fundamental influences on childhood obesity are not monitored systematically in the EU, even though the means of doing so is possible. The original project broke new ground in identifying scientifically-based internationally-comparable desirable measures and indicators. In conjunction with its country-specific subcontractors, it provided a snapshot of both routine data collection and one-off sources of data to achieve these measures. The results were two-fold - a demonstration of the need for further work to formally agree an indicator set, with related data definitions; and a highlighting of the current serious lack of data to illuminate a highly important child public health problem. This is still a worthy conclusion in 2014 , as it seems that there are still large gaps in our knowledge about what causes childhood obesity, and how it can be prevented and treated as evidenced by the World Health Organisation exercise among others (World Health Organization 2013).

The importance of adequate and comparable surveillance systems to inform research and successful prevention and intervention initiatives cannot be underestimated. In order to prevent this status quo from continuing, European nations need to place a greater emphasis on the health surveillance of its children and young people, who make up around of fifth of the European population. Firstly, central agreement on the key data definitions would enable greater comparable data collection and analysis. In addition, developing and agreeing a formal set of monitoring indicators, not just of overweight and obesity, but of behavioural determinants of nutrition and physical activity in children through all stages of the life course would provide some clarity about the obesity preventing or promoting behaviours that may be taking place. Compiling statistics to these indicators and publishing national data sets would allow focused prevention actions to take place, as well as identifying geographical areas where obesity is a particular risk to the population of children and young people. Alongside these actions, further analysis of the scientific knowledge on the behavioural determinants of nutrition and physical activity behaviour of children and young people is needed. Finally, a compilation of a compendium of effective good practices influencing children's nutrition and physical activity, as has already been achieved by projects related to children's environmental exposure and to enhancement of children's safety, would help to reduce the prevalence of childhood obesity in Europe. 


\section{Acknowledgements}

This initial work was supported by the Health and Consumer Protection Directorate of the European Commission, under the Public Health Information Programme [Grant number 2005111].

The Project Director for the overall two-year project was Prof. Dr. Wilhelm Kirch of Technische Universität Dresden, Germany; Scientific Director of the children's nutrition phase was Prof. Michael Rigby of Keele University.

Other members of the original Lifestyle Determinants project were:

Rosa G Frazzica. Centro per la formazione permanente e l'Aggiornamento del Personale del servizio sanitorio (CeFPAS), Calanisetta, Siciliy, Italy. frazzica@cefpas.it.

Grit Kühne. Faculty of Medicine Carl Gustav Carus: Research Association Public Health Saxony and Saxony-Anhalt, Technische Universität Dresden, Fiedlerstraße 3301307 Dresden, Germany. grit.kuhne@tu-dresden.de

Wilhelm Kirch Faculty of Medicine Carl Gustav Carus: Research Association Public Health Saxony and Saxony-Anhalt, Technische Universität Dresden, Fiedlerstraße 3301307 Dresden, Germany. Email: Public.Health@mailbox.tu-dresden.de

\section{Conflict of Interest}

None Declared

\section{References}

Adamo KB, Wilson S, Belanger K, Chaput JP (2013) Later Bedtime is Associated with Greater Daily Energy Intake and Screen Time in Obese Adolescents Independent of Sleep Duration. J Sleep Disorders Ther 2:126. doi: 10.4172/2167-0277.1000126

Alexander D, Rigby M, Sjostrom M, Frazzica RG, Hillger C, Neumann G, Kirch W (2010) Challenges and Findings in Measuring the Behavioural Determinants of Obesity in Children in Europe. Huber, Bern 
Alonso-Álvarez ML, Cordero-Guevara JA, Terán-Santos J, GonzalezMartinez M, Jurado-Luque MJ, Corral-Peñafiel J, Duran-Cantolla J, Kheirandish-Gozal L, Gozal D (2014) . Obstructive sleep apnea in obese community-dwelling children: the NANOS study. Sleep 37(5):943-9. doi: 10.5665/sleep.3666

Boeke CE, Storfer-Isser A, Redline S, Taveras EM (2014) Childhood sleep duration and quality in relation to leptin concentration in two cohort studies. Sleep 37(3):613-20. doi: 10.5665/sleep.3510

Brug J (2008) Determinants of healthy eating: motivation, abilities and environmental opportunities. Family Practice 25: i50-i55. doi: 10.1093/fampra/cmn063

Brug J, Kremers SP, van Lenthe F, Ball K, Crawford D (2008) Environmental determinants of healthy eating: in need of theory and evidence. P Nutr Soc 67:307-316. doi: 10.1017/S0029665108008616

Cattaneo A, Monasta L, Stamatakis E, Lioret S, Castetbon K, Frenken F, et al. (2010) Overweight and obesity in infants and pre-school infants in the European Union; a review of existing data. Obes Rev 11: 389-398. doi: 10.1111/j.1467-789X.2009.00639.x

Cole T, Bellizzi M, Flegal K, Dietz W (2000) Establishing a standard definition for child overweight and obesity worldwide: international survey. BMJ 320:1240-3. doi: http://dx.doi.org/10.1136/bmj.320.7244.1240

Currie C, Zanotti C, Morgan A, Currie D, de Looze M, Roberts C, Samdal O, Smith ORF, Barnekow V (2012) Social determinants of health and wellbeing among young people. Health Behaviour in SchoolAged Children (HBSC) Study: international report from the 2009/2012 survey. World Health Organization Regional Office for Europe, Copenhagen

de Onis M, Onyango AW, Borghi E, Siyam A, Nishida C, Siekmann J (2007) Development of a WHO growth chart reference for school-aged children and adolescents. Bulletin of the World Health Organization 85:660-667 
Jago R, Ness A, Emmett P, Mattocks C, Jones L, Riddoch C (2009) Obesogenic diet and physical activity: independent or associated behaviours in adolescents? Public Health Nutrition 13: 673-681. doi: 10.1017/S1368980009992151

Kleiser C, Rosario AS, Mensink GB, Prinz-Langenohl R, Kurth BM (2009) Potential determinants of obesity among children and adolescents in Germany: results from the cross-sectional KiGGS study. BMC Public Health 9:46. doi:10.1186/1471-2458-9-46

Kuczmarski RJ1, Ogden CL, Guo SS, Grummer-Strawn LM, Flegal KM, Mei Z, Wei R, Curtin LR, Roche AF, Johnson CL (2002) 2000 CDC Growth Charts for the United States: methods and development. Vital and Health Statistics 246:1-190

Leech RM, McNaughton SA, Timperio A (2014) The clustering of diet, physical activity and sedentary behavior in children and adolescents: a review. IJBNPA 11:4. doi:10.1186/1479-5868-11-4

Lifestyle Statistics Team, Health and Social Care Information Centre (2013) National Child Measurement Programme: England 2012/13 school year. HSCIC / Public Health England

Owen N, Salmon J, Koohsari MJ, Turrell G, Giles-Corti B (2014) Sedentary Behaviour and health: mapping environmental and social contexts to underpin chronic disease prevention. Br J Sports Med 48: 174-177. doi:10.1136/bjsports-2013-093107

Thivel D, Isacco L, Aucouturier J, Pereira B, Lazaar N, Ratel S, Doré E, Duché P (2015) Bedtime and sleep timing but not sleep duration are associated with eating habits in primary school children. J Dev Behav Pediatr 0:1-8 (e-publication ahead of print)

United Nations Office of the High Commissioner for Human Rights (1989) Convention on the Rights of the Child. United Nations, Geneva

van der Horst K, Oenema A, Ferreira I, Wendel-Vos W, Giskes K, van Lenthe F, Brug J (2007) A systematic review of environmental correlates of obesity-related dietary behaviors in youth. Health Educ Res 22: 203226 
Waters E, de Silva-Sanigorski A, Burford BJ, Brown T, Campbell KJ, Gao Y, et al. (2011) Interventions for preventing obesity in children: Cochrane Database of Systematic Reviews. Report No.: CD001871. Cochrane Collection. doi: 10.1002/14651858.CD001871.pub3

Wijnhoven TMA, van Raaij JMA, Spinelli A, Starc G, Hassapidou M, Spiroski I, Rutter H, Martos E, Rito AI, Hovengen R, Pérez-Farinós, Petrauskiene A, Eldin N, Braeckevelt L, Pudule I, Kunešová M, Breda J (2014) WHO European Childhood Obesity Surveillance Initiative: body mass index and level of overweight among 6-9-year-old children from school year 2007/2008 to school year 2009/2010. BMC Public Health 14:806 http://www.biomedcentral.com/1471-2458/14/806

Wolfram N, Rigby M, Frazzica RG, Kirch W (2008) Nutrition and Physical Activity - Health information sources in EU member states, and activities in the Commission, WHO, and European Networks. Springer, New York

World Health Organisation (2006) Global Strategy on Diet, Physical Activity and Health: a framework to monitor and evaluate intervention. World Health Organization, Geneva

World Health Organisation (2007) WHO European Ministerial Conference on Counteracting Obesity Conference Report. World Health Organization Regional Office for Europe, Copenhagen

World Health Organisation (2013) Country profiles on nutrition, physical activity and obesity in the 53 WHO European Region Member States. World Health Organization Regional Office for Europe, Copenhagen

World Obesity Federation (2012) About obesity. http:/ /www.worldobesity.org/aboutobesity/. Accessed 20 January 2015 


\title{
Chapter 5:
}

\begin{abstract}
Alexander D, Rigby M, Minicuci N (in draft) Measuring behavioural determinants of child maltreatment - an alternative approach, focusing on preventive and risk factors. (Under review at Central European Journal of Public Health, 2015)
\end{abstract}

This paper extends the notion of developing upstream indicators to a more challenging remit. It argues that there is the potential to measure subjects that are extremely difficult to quantify at present. Child maltreatment is particularly difficult because, in its very nature, it is covert; and it is an extremely serious outcome for children - with repercussions that can last a lifetime. It is very difficult to identify.

Work from a European Commission funded project PHASE identified indicators that could be used to measure the incidence and prevalence of physical child maltreatment in Europe. This was expanded upon in this paper as indicators were identified from established projects and recognised organisations to measure the risks, preventive actions and incidence or prevalence of child maltreatment in Europe.

Of course, there will always be some cases that occur, but it is hypothesised that many cases that originate from external stress or circumstances may be lessened or prevented entirely by identifying and dealing with certain upstream risk factors. 


\section{Measuring behavioural determinants and incidence of child maltreatment in Europe - an alternative approach, focusing on preventive and risk factors}

Denise Alexander. Department of International Health, School for Public Health and Primary Care (CAPHRI), Maastricht University (Formerly of School of Public Policy and Professional Practice, Keele University.)

Michael J Rigby. Nordic School of Public Health, Gothenburg, Sweden. (Formerly of: School of Public Policy and Professional Practice, Keele University.)

Nadia Minicuci PhD. CNR, Neuroscience Institute, Padova, Via Giustiniani, 2, 35128 Padova (Italy).

Address for Correspondence: Denise Alexander. Department of International Health, School for Public Health and Primary Care (CAPHRI), Maastricht University, PO Box 616, 6200 MD Maastricht, The Netherlands. denise.alexander@maastrichtuniversity.nl. Telephone: 00441606888486. 


\section{Summary}

Aim: The World Health Organisation recently called for preventive action against child maltreatment, including effective measurement of the phenomenon. This paper aims to establish the utility and availability of upstream measures of child maltreatment factors on an international scale to be used in conjunction with traditional child maltreatment statistics.

Methods: Indicators originally identified and tested by the 2008 PHASE project were supplemented by three other large-scale European projects that focused on children and included maltreatment as part of their investigations. Experiences from these projects and evidence from further literature searches enabled a list of indicators to be created that hope to provide a framework for European countries to measure how protected their child populations are from the risk factors of maltreatment. The indicators were grouped in a number of topic headings that relate to the known risk factors and consequences of maltreatment.

Results: 32 indicators were identified that describe a broad spectrum of risk factors and incidence and prevalence of maltreatment to children. However, data were not plentiful to populate many of the indicators.

Conclusion: Using an upstream public health approach in this way, alongside traditional statistics, will provide more comprehensive and informative information than is available at present. This will provide much greater emphasis on prevention, thus building on the aims of the World Health Organisation action plan with specific, measurable objectives.

\section{Keywords:}

child, maltreatment, measurement, indicators, child public health, upstream measurement 


\section{Introduction}

Child maltreatment is a significant problem in Europe; and the need to prevent it is a vital public health action (1). Accurately measuring maltreatment in the population is essential. Indeed, the first objective of the recently published Child Maltreatment Prevention Action Plan (1) is to: "Make bealth risks such as child maltreatment more visible by setting up information systems in Member States". However, as this paper argues, the indicators recently suggested by the World Health Organisation (WHO) make only tentative steps towards generating comparable information across member states and run the risk of providing an incomplete picture. They are still largely restricted to measuring the problem after the damage and hurt has occurred, although research now suggests that seeking to measure causative factors, and monitor preventive actions, is of considerable utility in preventing child maltreatment $(2,3)$. At present, we remain at risk of considerable gaps in our knowledge and our ability to evaluate preventive actions.

Agencies, such as the International Society for the Prevention of Child Abuse and Neglect (ISPCAN) and WHO, admit that accurate information is difficult to find (4). Measuring incidence and prevalence is important but difficult, not least because perpetrators go to extreme lengths to hide maltreatment and abuse of children. The difficulty of measuring a covert act is compounded by the problems of definition and resulting challenges in identifying comparable data across regions and nations. There is a huge body of work attempting to define maltreatment and to develop reliable and ethical measures to describe its prevalence (5-11), but this work is as yet largely uncoordinated.

An important dimension to this issue is the value of measuring upstream risk factors and causes of maltreatment. This may provide a more feasible means of measuring what is in effect an enabling culture, and facilitate effective prevention. A small European Union co-funded project entitled Public Health Action for a Safer Europe (PHASE) (12) has previously attempted this, and is, together with more recent indicator work, discussed in this paper. We identify existing potential indicators that use relevant data to measure child maltreatment in terms of its prevention - focusing on upstream factors that can make lives easier for families, parents and children, and maltreatment less likely (9). Hopefully, this provides a starting point for a discussion about upstream measurement as an integral part of monitoring and preventing child 
maltreatment in European society, and at the same time is in line with the WHO call for operational definitions of child maltreatment to be standardised, and information gathered and shared from child helplines, the justice sector and child protection services as a measure of response to child maltreatment (1).

\section{Significance of child maltreatment}

Maltreatment has serious and long-lasting consequences for the children concerned. Its outcomes last longer than physical bruises and can have serious effects upon emotional and mental health that can perpetuate throughout a lifetime and into the next generation (1,13-14); although the precise causal relationships of sequellae are still the subject of research (15). Some studies suggest that the stress of experiencing maltreatment in childhood can impair or change brain development (1, 14); other studies demonstrate that poor health and health-harming behaviour may result from childhood experience of maltreatment, and consequently impact upon educational, social, economic and health outcomes throughout life (16-18). Maltreated children tend to be at greater risk of being future victims or perpetrators of violence $(1,9)$. Maltreatment does not exist in isolation; but can be closely connected to other adverse childhood experiences, such as household dysfunction, parental violence, having a family member with mental illness, drug or alcohol dependency, or who is in prison. All of these are identified risk factors for maltreatment $(1,15,19-21)$.

\section{Prevention is better than treatment}

It is widely recognised that the causes of maltreatment are complex and many faceted; as are its preventive factors. Addressing child maltreatment requires sustained and coordinated work not only in the health sector but involving education, employment, welfare, justice, housing, trade and industry, media and communications, and nongovernmental organisations. The action plan by the World Health Organisation Regional Office for Europe (1) outlines how many outcomes of child maltreatment can be addressed to some extent by social policy changes.

A large amount of work has been carried out to establish risk and protective factors for child maltreatment by the European Network of National Observatories on Childhood (22). On an immediate level it is the abusing perpetrators whose behaviour is the major factor; but the 
determinants of this behaviour would benefit from attention. Children with disabilities or behaviour problems can be at increased risk of maltreatment due to the strain of caring for them (23). Young, single and poor parents with low educational levels seem to be more likely to maltreat their children (24) although direct associations are often small, the research suggests that it is the effect of stress that may contribute to maltreatment (25-26). The individual stress of mental illness, alcohol and drug abuse and lack of parenting skills are also known to be risk factors for maltreatment, although there are conflicting results in this field, due to the complexity of the issue (27-30). Deprived communities, poverty and the presence of social and economic inequalities tend to be where maltreatment is more widespread than in more affluent and socially cohesive areas (22), although this is not a given - some deprived communities do not have high rates of maltreatment. Cultural norms also play a role, for example, if physical punishment is readily accepted in a society, maltreatment rates may well be higher $(25,31)$. Supporting protective factors, such as family support, good parenting programmes and providing adequate help for families with challenging children, are important preventive factors (22), as is building resilience in children, families and communities (1).

\section{Challenge of case measurement and revealing the true magnitude}

The WHO states that even those few countries that have official statistics on child maltreatment need to supplement these data with regular community surveys to ascertain the true extent of the problem (25). Retrospective surveys can give an indication of how prevalent violence against children was in the past, but victims or perpetrators may take many years to be able to acknowledge the presence of abuse and it is difficult to measure current prevalence $(7,32)$. National policies regarding maltreatment vary across Europe; making it difficult to compare across nations because there are differences in perceptions of what constitutes maltreatment. WHO Europe estimates that the actual prevalence of child maltreatment is around 10 times that described by official statistics (1). For example, in the United Kingdom it is estimated that for every death due to maltreatment, there are about 620 children under a child protection plan, 5520 children in need, and 6930 children in the community who have previously been abused $(25,33)$. In France it is estimated that there are 300 substantiated cases of child maltreatment for every death; in Australia it is thought that there are 150 
cases of substantiated physical abuse and 600 of child maltreatment for every death in children aged under 15; and in Canada it is thought that for every death due to maltreatment, there are around 1000 maltreated children (25). The WHO estimates that around 30\% of children are emotionally abused at some point in their childhood; $13.4 \%$ of females and $5.4 \%$ of males are sexually abused; and $22.9 \%$ of children are physically abused (25). These figures come from a combination of proxy measures, measures of mortality and hospital, and data from surveys or other research.

Creating an alternative measurement system is a challenging and yet vitally important task. It should be able to identify and measure the presence of upstream preventive factors in a society, and work alongside traditional prevalence data (3). This would not only give a better calculation of the presence of abuse, but enable more rigorous evaluation of European prevention programmes. These measures, in combination with routine statistics, may give us a better picture of the safety of Europe's children in terms of their risk of maltreatment, and also focus our attention on creating safer, protective households and communities.

\section{Material and Methods}

This work has arisen primarily from a large European wide project, the Public Health Action for a Safer Europe (PHASE) (12) which was an EU part-funded investigation into national measurement and surveillance of physical maltreatment of children, youth, interpersonal violence and older people. This initial work took place in 2007, and it devised and tested indicators of child physical maltreatment in 27 countries of the European Union. The indicators in this project were devised from a literature review, which included the interrogation of a number of databases including PubMed (www.ncbi.nlm.nih.gov/pubmed), SafetyLit.org, End all Corporal Punishment of Children (www.endcorporalpunishment.org), Applied Social Sciences Index and Abstracts (ASSIA) (www.proquest.com/products-services/ASSIA-Applied-Social-SciencesIndex-and-Abstracts.html) and bmj.com. In addition to this, policy documents were identified from a variety of sources including the World Health Organisation (www.who.org), the European Commission (http://ec.europa.eu/index_en.htm), UNICEF (www.unicef.org) and links from voluntary organisations in some of the countries, such as the 
National Society for Prevention of Cruelty to Children (NSPCC) (www.nspcc.org.uk) in the United Kingdom.

The indicators in the original PHASE project were compiled so that they would describe an environment where maltreatment was discouraged or prevented by that country; although not all indicators were salutogenic. It should be noted that this project had an important limitation in that it only dealt with physical abuse, and not specifically sexual, emotional abuse or neglect - all of which are important forms of child maltreatment.

Thus, to update the PHASE work and to identify wider measures of child maltreatment we looked to three other large-scale Europeanfocused projects that also used indicators of child maltreatment as one of their outcomes. These were the ChildOnEurope group (22), who published a review of existing national statistics and monitoring systems for child abuse in European Member States; the World Health Organisation Investing in children: the European child maltreatment prevention action plan 2015-2020 (1), which identified a number of preventive indicators in the light of the WHO report on Preventing Child Maltreatment (25); and the Research Inventory of Child Health in Europe (RICHE) project (34), which contains a repository of Europewide and validated indicators on a wide range of child health topics including maltreatment. In addition to this, a literature review was carried out of the PubMed and PsychInfo databases, using the search terms Maltreatment AND Child AND Measurement to find further indicators. The indicators chosen focus on preventive measures, in combination with measures of prevalence and response to maltreatment to provide a holistic approach to measurement of child maltreatment. The indicators were organised under headings to describe the individual, family, economic and social aspects, which reflect the multi-faceted aetiology of maltreatment, and echo the risk factors for maltreatment categories proposed by the ChildOnEurope group (22).

\section{Results}

The indicator search resulted in a list of indicators to potentially map the prevalence of risks of child maltreatment and the prevalence of maltreatment across Europe. Table 1 shows the indicators that were identified. These are from the WHO (1), ChildOnEurope (22) and RICHE (34) projects that described other forms of child maltreatment 
were added to the core PHASE list of indicators, together with the International Society for Prevention of Child Abuse and Neglect (ISPCAN) (35-36), Euro-Peristat (37)and the Child Health Indicators for Life and Development (CHILD) project (38). Many of the preventive indicators do not imply a linear causal link between maltreatment and the particular condition of living (such as living in poverty, or being a teenage mother). Such a causal relationship can only be addressed through a longitudinal study. The majority of literature has been based on cross-sectional design, which can identify odds ratios of risks of maltreatment $(36,39-41)$. As such, the preventive indicators have been identified in this way as risk factors for maltreatment, particularly if many risk factors are also present.

The following issues are noteworthy in relation to the above categories of indicators.

\section{Measurement of harm to individuals}

Some of these indicators are already used by a number of countries to measure incidence and prevalence of child maltreatment. Others in this group are used to give an important context to these data. Experience from the PHASE project showed that all countries could provide population data, but very few could provide comprehensive hospital episode data that specifically describe injury or intentional violence, or crime data that related directly to children, despite the existence in most cases of the raw data. In many countries there is not the commitment to initiate regular analyses of these data; while in others the raw data may not yet exist. At present, these indicators alone are unable to give a true picture of child maltreatment in European countries, and this seems an indictment of low commitment to modest investment in data systems to capture and analyse current activity.

\section{Empowerment factors for individuals}

These indicators relate to avenues where victims of maltreatment have a means of asking for help, or escaping their predicament, but only provide part of the overall picture. The efficacy of an available e-based source of reporting or a telephone service may vary from country to country. It is important that these services are properly funded; and that they provide access to practical help to children and young people who have the courage to contact them. 


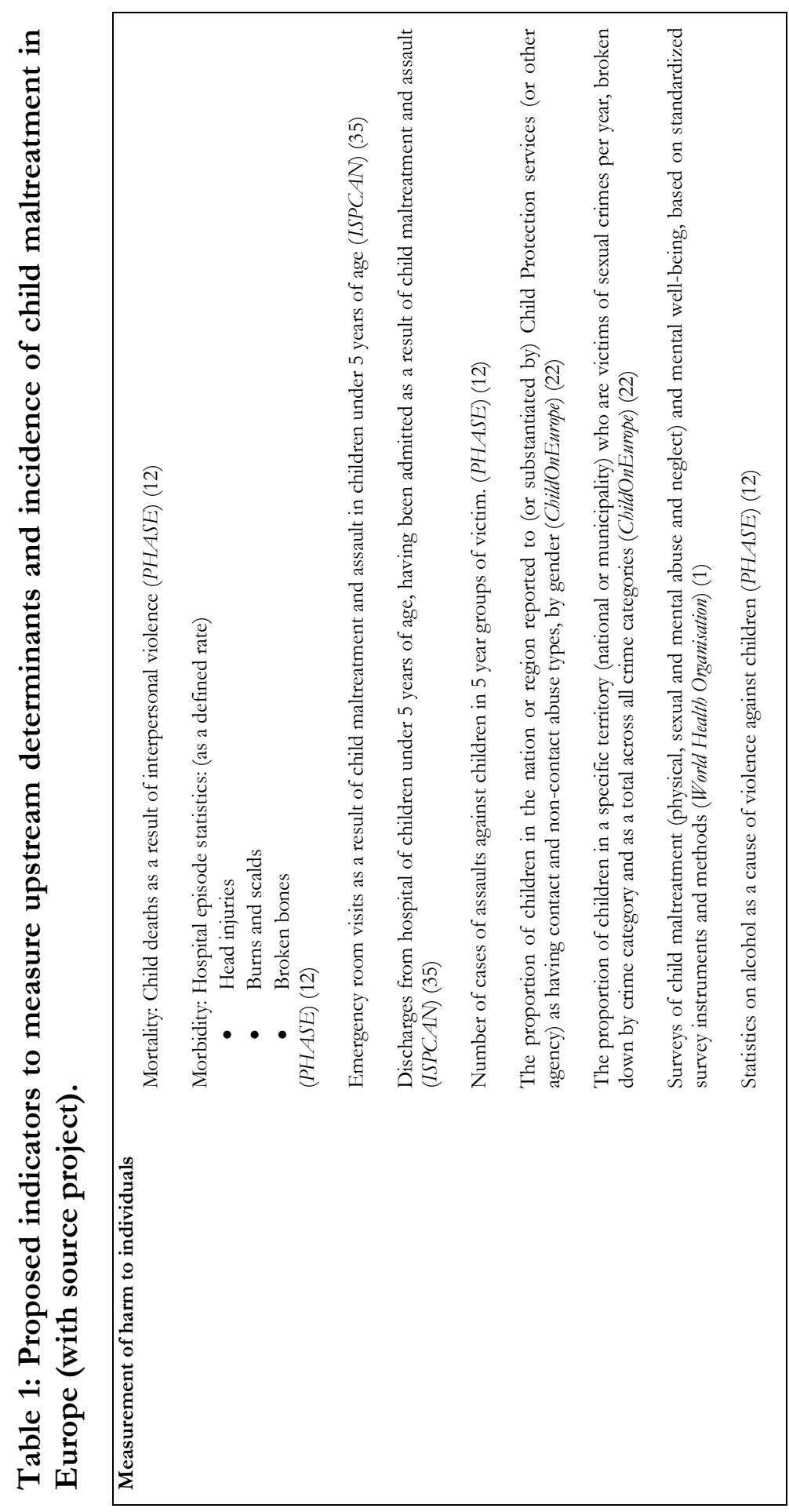




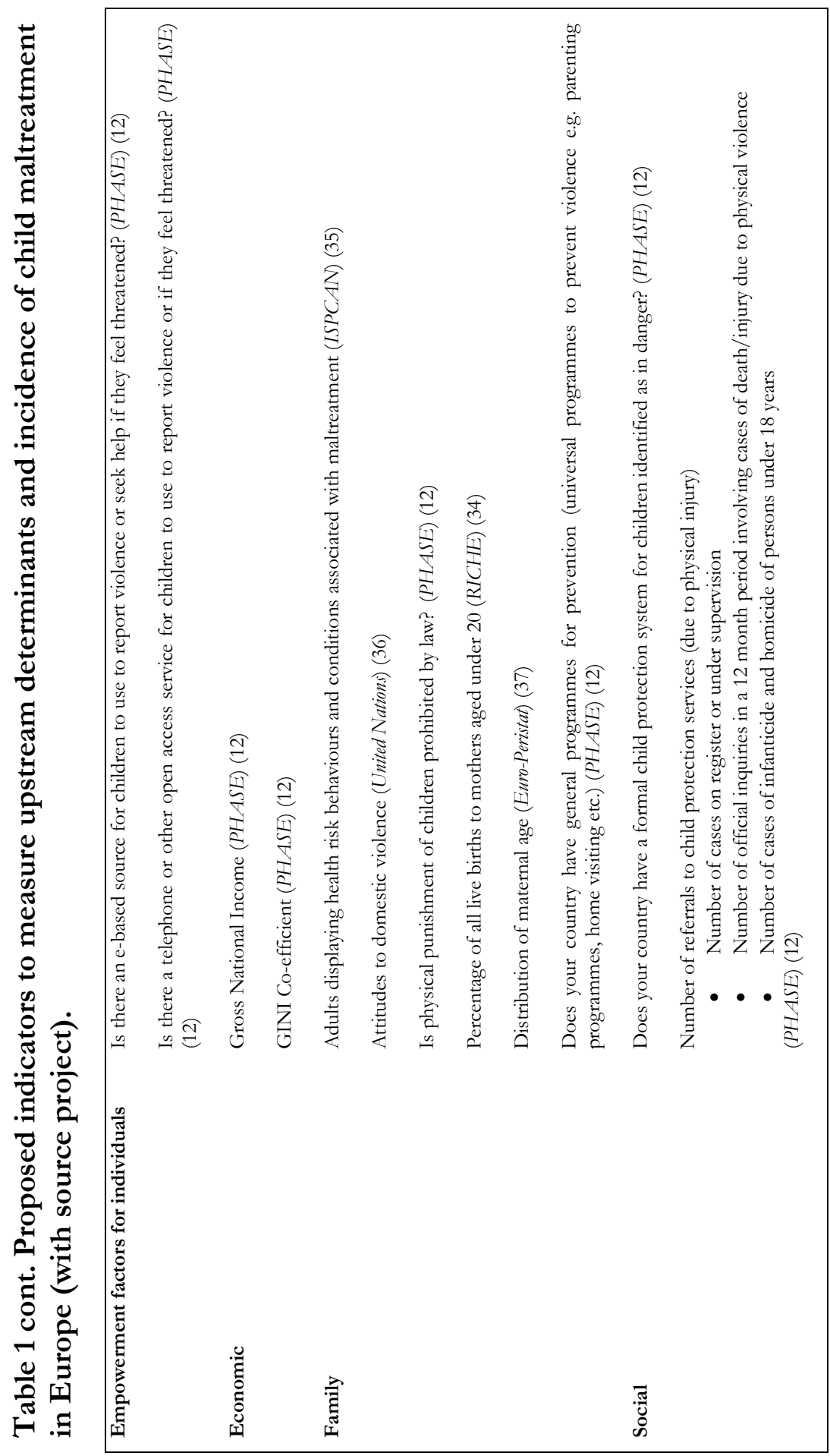




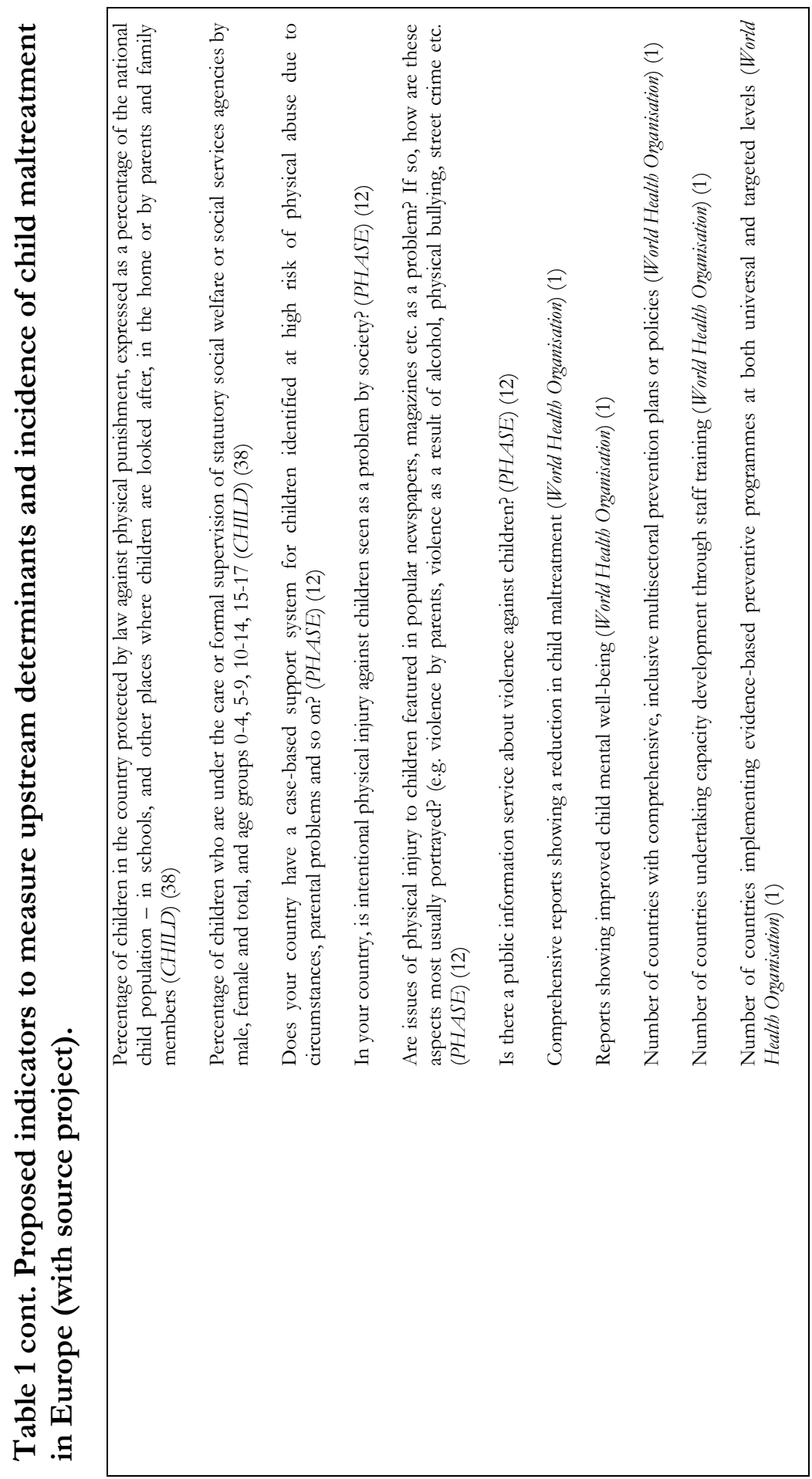




\section{Economic}

These indicators give an important background; particularly as poverty is a known risk factor for maltreatment. The GINI coefficient in particular, relating to the amount of inequality in the country, gives an important indication as to the potential risks of maltreatment to those families and individuals living under the stress of poverty. What would augment these economic indicators are local area poverty or deprivation indicators, which would potentially help in focusing on areas that are at particular risk of economic deprivation and the accompanying stress that can lead to maltreatment.

\section{Family}

Again, these indicators are important in identifying those at particular risk of maltreatment. However, populating these indicators and making these data available to preventive services could be problematic because of reasons of confidentiality and reliability of the data. The indicator of 'Adults displaying health risk behaviours and conditions associated with maltreatment' refers to those with alcohol or drug problems, families where there is known to be interpersonal violence, or families in extreme poverty and other stresses.

\section{Social}

These indicators relate to the social environment of a country; and the policy attitude towards maltreatment. In addition to this, figures about the number of children placed into care, or onto child protection lists can give an indication as to whether maltreatment is increasing or decreasing. Another aspect of the social indicators is the cultural attitude towards maltreatment, punishment of children and of other risk factors, such as alcohol or drug taking.

\section{Data and testing of the indicators}

In the projects where the indicators originated, data were sought to populate the chosen indicators. There were considerable difficulties in populating all of the indicators in a consistent and clear way from existing sources, such as in the PHASE experience (42). However, in some cases, such as those indicators obtained from the RICHE inventory (34), the indicators had been tested and validated within a European or global project, though not all data are universally available and comparable. 
In the original PHASE project an attempt was made to map what data were held by the countries of Europe concerning child maltreatment, its causes or enabling environments; and to show where there were gaps in knowledge about how many children experienced abuse (42). To do this WHO National Focal Persons were requested to identify what data were available in their country, and these data were supplemented by a search of official statistics from the European Hospital Morbidity Database (http://data.euro.who.int/hmdb); the European Health for All Database (HFA-DB) (www.euro.who.int/en/data-andevidence/databases/european-health-for-all-database-hfa-db); Eurostat (http://ec.europa.eu/eurostat); WHOSIS (www.who.int/whosis/en); and the WHO Global Burden of Disease (www.who.int/topics/global_burden_of_disease/en). It can be assumed from these experiences that there is a considerable lack of data availability in the countries of Europe - even if the data exist, they may not be made available to researchers, policy-makers and practitioners keen to implement interventions. Research has also identified that there are 'major gaps' in the knowledge of child maltreatment in almost all countries studied. Particularly worrying is the lack of ability to evaluate outcomes of programmes designed to prevent maltreatment; or national surveys of prevalence of child maltreatment (43).

\section{Discussion}

At present child maltreatment continues to be a subject addressed more by emotion than evidence, despite its prevalence, abhorrent nature, and long term personal and societal effects. Causes and predisposing factors are even less well addressed, yet the possibility of moving towards systematic comparable measurement has been identified by many responsible agencies and expert projects. Further, although the indicator spread identified uses existing indicators or existing proposals for indicators, it is not always possible for them to be populated using routine data from European countries. Thus, a system that ought to be straightforward, and take important steps in preventing maltreatment to children is not useable or useful in its present state. Indicators of different forms of child maltreatment abound, but there remains a lack of coordinated and comparable data to describe how many children are maltreated in Europe; and little systematic measuring of causal factors. The WHO hopes that countries can use existing and incipient surveys that focus not only on maltreatment, but also on risk factors such as age, 
gender and socioeconomic determinants of risk to identify maltreatment in countries of Europe. In addition to this, the production of comprehensive reports that include indicators and information sources of child homicide rates, emergency department cases involving maltreatment and assault rates including other indicators will also help to improve the data that describe maltreatment (1). However, these actions will do little to improve comparability and the ability to identify trends across Europe. There is a lack of comparable data in Europe (and globally). Even where data exist, they are often not collected in a systematic way across the continent - despite the fact that the world is becoming increasingly international, and national borders are not so culturally impregnable in the modern world. Using a combination of indicators, as suggested in this paper, however, may well provide a starting point for a meaningful discussion as to how to measure, in a comparable and practical way, the incidence and prevalence of child maltreatment, and importantly, whether rates are rising or falling something that is not easy to achieve at present (43). This approach has the potential to break the cycle of violence by highlighting the issue and providing guidance as to best practice.

What is urgently needed is a European consensus about how pragmatically to measure prevention of maltreatment, alongside prevalence and incidence rates. It may never be possible to measure incidence and prevalence accurately, but it would be effective to draw attention to risk factors, and consequently to take effective preventive action which would provide brighter futures for many families and children across the continent. Only when we can compile comparable data across Europe, on prevention as well as incidence and prevalence, will effective action be stimulated.

\section{Acknowledgements}

The Public Health Action for a Safer Europe (PHASE) project was funded by the European Commission EC Grant Agreement No. 2006123.

\section{Conflicts of interest}

None declared. 
These results have not been published previously, are not under submission elsewhere and all co-authors are cognizant of the submitted text and agree to its publication in CEJPH.

\section{References}

1. World Health Organisation Regional Office for Europe. Investing in children: the European child maltreatment prevention action plan 20152020. Copenhagen (Denmark): World Health Organisation Regional Committee for Europe 64 ${ }^{\text {th }}$ Session; 2014.

2. Putnam-Hornstein E, Wood JN, Fluke J, Yoshioka-Maxwell A, Berger RP. Preventing severe and fatal child maltreatment: making the case for the expanded use and integration of data. Child Welfare. 2013; 92(2): 52-75.

3. Chahine Z, Sanders D. The road ahead: comprehensive and innovative approaches for improving safety and preventing child maltreatment fatalities. Child Welfare. 2013; 92(2): 237-53.

4. Dubowitz H, (ed.). World perspectives on child abuse $11^{\text {th }}$ edition. Aurora, (US): International Society for the Prevention of Child Abuse and Neglect; 2014.

5. Jackson Y, Gabrielli J, Fleming K, Tunno AM, Makanui PK. Untangling the relative contribution of maltreatment severity and frequency to type of behavioral outcome in foster youth. Child Abuse Negl. 2014; 38(7): 1147-1159. doi: 10.1016/j.chiabu.2014.01.008.

6. Tonmyr L, Hovdestad WE. Commentary on Canadian child maltreatment data. J Interpers Violence. 2014; 29(1): 186-197. doi: 10.1177/0886260513504643.

7. Fergusson DM, Horwood, L, Boden JM. Structural equation modelling of repeated retrospective reports of child maltreatment. Int Jf Methods Psychiatr Res. 2011; 20(2): 93-104. doi: 10.1002/mpr.337.

8. Dunne MP, Zolotor AJ, Runyan DK, Andreva-Miller I, Choo WY, Dunne SK, et al. ISPCAN Child Abuse Screening Tools Retrospective version (ICAST-R) Delphi study and field testing in seven countries. Child Abuse Negl. 2009; 33(11): 815-825. doi: 10.1016/j.chiabu.2009.09.005. 
9. Smith CA, Ireland TO, Thornberry TP, Elwyn L. Childhood maltreatment and antisocial behaviour: Comparison of self-reported and substantiated maltreatment. Am J Orthopsych. 2008; 78(2): 173-186. doi: 10.1037/0002-9432.78.2.173.

10. Runyan DK, English DJ. Measuring child abuse and neglect using child protective services records. In: Feerick MM, Knutson JF, Trickett PK, Flanzer SM (eds.) Child Abuse and Neglect: Definitions, classifications and a framework for research. Baltimore (US): (Paul H. Brookes Publishing; 2006.

11. Manly JT. Advances in research of child maltreatment. Child Abuse Negl. 2005; 29(5): 425-439.

12. European Commission. PHASE - Public Health Action for a Safer Europe Final report including an Inventory of interventions in violence prevention and tools for capacity building in view of making violence prevention part of formal public health education and training. Verona (Italy): Regione Veneto ULSS 20 Verona. EC Grant Agreement No.: 2006123; 2008.

13. Godinet MT, Li F, Berg T. Early childhood maltreatment and trajectories of behavioural problems: Exploring gender and racial differences. Child Abuse Negl. 2014; 38(3): 544-556. doi: 10.1016/j.chiabu.2013.07.018.

14. Beach S R, Kaslow N J, Foran H M, Heyman R E, Garcia-Moreno C. Future directions for science and public health. In: Foran HM, Beach, SR, Slep AMS, Heyman RE, Wamboldt MZ (editors.). Family problems and family violence: reliable assessment and the ICD-11. New York (US): Springer; 2013.

15. Esaki N. The effect of maternal childhood abuse on parenting attitude and behaviour. New York (US): State University of New York at Albany; 2008.

16. Gilbert R, Kemp A, Thoburn J, Sidebotham P, Radford L, Glayser D, MacMillan HL. Recognising and responding to child maltreatment. Lancet. 2009; 373(9658): 167-80. doi: 10.1016/S0140-6736(08)61707-9. 
17. World Health Organisation. The cycles of violence: the relationship between childhood maltreatment and the risk of later becoming a victim or perpetrator of violence - Key facts. Rome (Italy) and Birmingham (UK): Violence and injury prevention programme, WHO European Centre for Environment and Health and WHO Collaborating Centre for Child Care and Protection, University of Birmingham; 2007.

18. Bethell CD, Newacheck P, Hawes E, Halfon N. Adverse childhood experiences: assessing the impact on health and school engagement and the mitigating role of resilience. Health Aff (Millwood). 2014: ; 33(12): 2106-15. doi: 10.1377/hlthaff.2014.0914.

19. Ridenour TA, Reynolds M, Ahlqvist O, Zhai ZW, Kirisci L, Vanyukov MM. Tarter RE. High and low neurobehavior disinhibition clusters within locales: implications for community efforts to prevent substance use disorder. Am J Drug Alcohol Abuse. 2013; 39(3): 194203. doi: 10.3109/00952990.2013.764884.

20. Elwyn L, Smith C. Child maltreatment and adult substance abuse: the role of memory. J Soc Work Pract Addict. 2013; 13(3). doi: 10.1080/1533256X.2013.814483.

21. Taussig HN, Culhane SE, Garrido E, Knudtson M D, Petrenko CL. Does severity of physical neglect moderate the impact of an efficacious preventive intervention for maltreated children in foster care? Child Maltreat. 2013; 18(1): 56-64. doi: 10.1177/1077559512461397.

22. ChildONEurope. Guidelines on Data Collection and Monitoring Systems on Child Abuse. Florence (Italy): Istituto degli Innocenti; 2009.

23. Jones L, Bellis MA, Wood S, Hughes K, McCoy E, Eckley L et al. Prevalence and risk of violence against children with disabilities: a systematic review and meta-analysis of observational studies. Lancet. 2012; 380(9845): 899-907. doi: 10.1016/S0140-6736(12)60692-8.

24. Wulczyn F. Epidemiological perspectives on maltreatment prevention. Future Child. 2009; 19(2): 375-91.

25. Sethi D, Bellis M, Hughes K, Gilbert R, Mitis F, Gauden G (eds.). European report on preventing child maltreatment. Copenhagen (Denmark): World Health Organisation; 2013. 
26. Stith SM, Liu T, Davies LC, Boykin EL, Alder MC, Harris JM et al. , Som A, McPherson M. Dees JEMEG. Risk factors in child maltreatment: a metaanalytic review of the literature. Aggress Violent Beh. 2009; 14(1): 13-29.

27. Dube SR, Anda RF, Felitti, VJ, Croft JB, Edwards VJ, Giles WH. Growing up with parental alcohol abuse: exposure to childhood abuse, neglect and household dysfunction. Child Abuse Negl. 2001; 25(12): $1627-1640$.

28. Bellis MA, Hughes S, Hughes K. Child maltreatment and alcohol. Geneva: World Health Organization; 2006.

29. Atkinson A, Anderson Z, Hughes K, Bellis MA, Sumnall H, Syed Q. Interpersonal violence and illicit drugs. Liverpool (UK): World Health Organization and Centre for Public Health, Liverpool John Moores University, Liverpool; 2009.

30. Walsh C, MacMillan HL, Jamieson E. The relationship between parental substance abuse and child maltreatment: findings from the Ontario Health Supplement. Child Abuse Negl. 2003; 27(2): 1409-1425.

31. United Nations Children's Fund (UNICEF). Child Disciplinary Practices at Home: Evidence from a Range of Low- and Middle-Income Countries. New York (US) United Nations Children's Fund (UNICEF), Division of Policy and Practice.; 2010.

32. MacMillan HL. Commentary: Child maltreatment and physical health: A call to action. J Pediatr Psychol. 2010; 35(5): 533-535. doi:10.1093/jpepsy/jsq017.

33. Radford L, Corral S, Bradley C, Fisher H, Bassett C, Howart N, Collishaw S. Child abuse and neglect in the UK today. Birmingham (UK): National Society for the Prevention of Cruelty to Children; 2011.

34. Research Inventory of Child Health in Europe RICHE [Internet]. Dublin: Indicators and Measurements. [Cited 2015 April 4]. Available from www.childhealthresearch.eu. 
35. Dara D (ed.). World Perspectives on Child Abuse: 7th Edition. Aurora (US): International Society for Prevention of Child Abuse and Neglect ISPCAN; 2006.

36. Pinheiro PS. World report on violence against children. The United Nations Secretary General's Study on Violence Against Children. Geneva (Switzerland): United Nations; 2006.

37. Euro-Peristat [Internet] Brussels: Indicator Development. [cited 2015 April 4]. Available from www.europeristat.com/ourindicators $/$ indicators-of-perinatal-health.html?id $=2$.

38. Rigby M, Köhler L, (eds.) Child Health Indicators for Life and Development (CHILD). Brussels (Belgium): European Commission 2002.

39. Berger LM. Income, family characteristics, and physical violence toward children. Child Abuse Negl. 2005; 29(2): 107-133. doi: 10.1016/j.chiabu.2004.02.006.

40. Samms-Vaughan ME, Jackson MA, Ashley DE. Urban Jamaican children's exposure to community violence. W Indian Med J. 2005; 54(1): 14-21. doi: 10.1590/S0043-31442005000100004.

41. Machado C, Goncalves M, Matos M, Dias AR. Child and partner abuse: Self-reported prevalence and attitudes in the north of Portugal. Child Abuse Negl. 2007; 31(6): 657-670.

42. European Commission. PHASE - Public Health Action for a Safer Europe Report on methodological issues, deficiencies and recommendations. Verona (Italy): Regione Veneto ULSS 20 Verona. EC Grant Agreement No.:2006123; 2008.

43. Mikton C, Power M, Raleva M, Makoae M, Al Eissa M, Cheah I, et al. The assessment of the readiness of five countries to implement child maltreatment prevention programs on a large scale. Child Abuse Negl. 2013; 37(12): 1237-1251. doi: 10.1016/j.chiabu.2013.07.009.

44. Gilbert R, Fluke J, O’Donnell M, Gonzalez-Izquierdo A, Brownell M, Gulliver P et al. Child Maltreatment: variation in trends and policies in six developed countries. Lancet. 2012; 379(9817): 758-72. doi: 10.1016/S0140-6736(11)61087-8. 
Part 4: Using indicators 


\section{Chapter 6:}
Alexander D, Rigby M, Gissler M, Kohler L, MacKay M. (2015) The challenges of compiling data profiles to stimulate local preventive health action - a European case study from child safety. International Journal of Public Health 60(4) 449-56. doi: 10.1007/s00038-015-0665- $\mathbf{Z}$

This paper investigates further challenges that arise from measuring children's health in Europe. Injury is the biggest killer of children and young people, and yet the data do not exist to measure the risks of injury to children in a manner that is likely to make a real difference, empowering young people and the communities that they live in to make real changes for the better.

In this paper, indicators were taken from well-established national indicator sets, and a feasibility study was carried out to determine if these indicators would successfully inform an index of local injury risk. The hope was that the index would allow a region or community to identify injury risks in their area, and also compare risks with other communities across Europe. The reason for a continent-wide comparative group is that this widens the potential for knowledge and examples of good practice - leading to an improvement in health throughout and at the same time promoting greater equality in injury risk across Europe, something that is sorely needed. 


\section{The challenge of compiling data profiles to stimulate local preventive health action - a European case study from child safety.}

Denise Alexander ${ }^{1}$, Michael Rigby ${ }^{2}$, Mika Gissler ${ }^{2,3}$, Lennart Köhler ${ }^{2}$, Morag MacKay ${ }^{4}$

1. Department of International Health, School for Public Health and Primary Care (CAPHRI), Maastricht University, Maastricht, The Netherlands. Email: denise.alexander@maastrichtuniversity.nl. Telephone +31-43-3882446. Fax +31-43-3884225

2. Nordic School of Public Health, Gothenburg, Sweden.

3. National Institute for Health and Welfare, Helsinki, Finland

4. European Child Safety Alliance, Birmingham, United Kingdom 


\begin{abstract}
Objectives. Positive recent experience of presenting comparative child safety data at national level has instigated policy action in Europe. It was hoped a Child Safety Index could quantify how safe a community, region or locality is for its children in comparison with similar areas within Europe, as a focus for local targeted action.
\end{abstract}

Methods. Validated indicators proposed by previous European projects identified from areas of child injury prevention, such as road safety, burns or poisoning, were selected to give a balanced profile, and populated from available published data. An index using a sub-score for each specific injury topic was proposed. The indicators' presentation, sensitivity and appropriateness were considered, as well as data availability.

Results. Satisfactory indicators were not identified for all areas and very few local area data were available. This forced the researchers to conclude that at present, constructing a reliable Child Safety Index for use at the local level is not feasible.

Conclusion. There is a worrying lack of data available at the subnational level to support injury prevention, evaluate interventions, and enable informed local decision making. 


\section{Introduction}

Unintentional injury is one of the most important public health issues for children and young people. It is the largest cause of death for children over 5 years of age, and a major cause of disability, pain, and stress to children and their families (Sethi et al. 2008). Despite the recognised importance of this issue, we know comparatively little about what it is in regions and communities that makes children more vulnerable to unintentional injury, or how policies can be prioritised based on evidence of need.

There are still major challenges in measuring and identifying the true extent of injury prevalence to children in Europe. At national level, the European Child Safety Alliance has achieved successes in producing and promoting comparative national data analyses (MacKay and Vincenten 2012; MacKay and Vincenten 2009), but, at more local level there are few data available. To address this, the creation of a sub-national Child Safety Index was proposed as part of a European Commission (EC) project entitled Tools to Address Childhood Trauma, Injury and Children's Safety (TACTICS) (European Child Safety Alliance 2014). The aim of the Child Safety Index was to help regions and communities evaluate injury risk and the safety of children and young people, to then provide an input to facilitate decision making on positive actions.

\section{Under-valued importance of local data}

Effective preventive public health relies upon good national and international data (The Prevention Institute 2008). However, while national data give essential information about the wider picture of a country's health status, they have limitations. National data alone cannot identify specific populations or geographical locations in real need of action by identifying areas of deprivation or high prevalence of injury occurrence. National actions to reduce injury are important, but policy prioritisation and other action at more local level have a significant part to play. Once means of determining this is to identify and accurately measure the injury prevalence to children in Europe on a sub-national scale (Tamburlini et al. 2002). Work by Safe Kids Worldwide (2014) has identified how important local community and individual effort is in making communities safer for young people. This is echoed by the European Healthy Cities Network (de Leeuw et al. 2014), a central goal of which is to strengthen caring a supportive environments through local community responsibility; and by the current World Health 
Organisation Health 2020 strategy (2013), which emphases community resilience and empowerment. An important means of doing this is to make available information on a community level, allowing relevant decisions to improve health, and reduce inequalities in local settings. Alongside this is the central aim of the TACTICS project, which is to find a means of democratising data, making information available and understandable to public and professionals equally and accessibly. This fits with a long-standing recognition of the importance of community empowerment in promoting health (Laverack and Labonte 2000). Thus the intended universality of the Child Safety Index was important, its indicators and data should be equally available across and between countries, using validated components and existing available data.

\section{Child Safety Index concept}

The Child Safety Index was to be compiled of relevant existing validated indicators of child safety and injury, but using these indicators at a subnational level. This would allow a degree of comparability between the international, national and local situations that could be useful in identifying highest need, promoting solutions and evaluating interventions. The Index would also be built using existing routine data, available uniformly across a country and the continent. There has been much recent work into harnessing and measuring data on a local level. The European Urban Health Indicators System Part 2 (EURO-URHIS2) project made an important contribution to the field of local health indicators; and is similar to TACTICS in that it seeks to validate the indicators by means of using existing population based registries and databases. However, this project differs from TACTICS in its use of a combination of routine and survey-based work (EURO-URHIS-2 2009) and its primarily urban focus. The Child Safety Index aimed to measure small units of a whole country, not just the urban elements of a country, and to be affordable and accessible by using only existing data. Other locally-focussed initiatives rely upon survey data (Pettman et al. 2104; Stöcklin et al. 2013) but these data often cannot be reliably generalised or there is no commitment to regular data collection so trends over time cannot be visualised. Systematic review and meta data analysis play a vital role in our knowledge of sub-national regions, particularly in subjects that are difficult to measure, such as child maltreatment (Barth et al. 2013). These means of data gathering can be costly and impractical, particularly if a repeatable and regular data analysis is required to 
demonstrate a trend. Data retrieved in this way are not often readily accessible to a lay audience. Using hospital episode data can also be problematic, despite its use in a number of other public health analyses (Palacio-Viera et al. 2013) but the techniques are not easily transferrable to the specific subject of injury, due to the high number of injuries not presented at hospital (Peden et al. 2008) and because of the small numbers involved on a local level. Thus there is a potential need for an injury-focused index of child safety.

It is known that much of the action required to tackle injury must be undertaken locally, even where policy is made at the national level (Tamburlini et al. 2002; Sethi et al. 2010). Using only national data only would therefore be insufficient to describe specific local risks and inform meaningful targeted action. The hope for the Child Safety Index was that it would provide an immediate comparative quantification of an area's child safety merits and disadvantages, and thus indicate priorities for action. However, the attempt to create this Child Safety Index illuminated fundamental gaps in the data about children and young people as well as about injuries, problems of meaningful small area analysis, and difficulties in finding a practical and 'real life' solution to a well-researched problem.

\section{Methods}

\section{Definition of the child population}

For the purposes of this exercise, the definition of a child as a person up to the age of 18 years, as stated by the United Nations Convention on the Rights of the Child (Office of the High Commissioner for Human Rights, 1989), was used. Alongside this definition, the TACTICS team recognised that the Child Safety Index must be flexible enough to take into account the vast differences in needs, abilities and exposures encompassed by this age group. In addition, when defining and choosing indicators to include in the Child Safety Index, account was taken of the influences of the family and other wider environmental influences in children, such as the physical and school environments (Glasgow Centre for Population Health, 2013).

\section{Identifying potential indicators}

The first stage was to identify potential indicators that could be used to form the Child Safety Index. To do this, we conducted a literature 
search of PubMed using the initial search strategy of 'safety' AND 'community' AND 'local' AND 'health', which retrieved 147 abstracts. In addition to this, we conducted specific searches to find evidence relating specific injury types, as detailed by the Child Safety Report Card work carried out by the European Child Safety Alliance (MacKay and Vincenten 2012). These were: 'poisoning' AND 'child' AND 'local' (61 abstracts); 'falls' AND 'child' AND 'local' (44 abstracts); 'water safety' AND 'child' AND 'local' (4 abstracts); ('moped' OR 'scooter') AND 'child' AND 'local' (4 abstracts); 'transport' AND 'child' AND 'local' (14 abstracts). Papers were searched worldwide from the past ten years. We also conducted searches of relevant literature to identify indicators from the Child Friendly Cities initiative (UNICEF 2014), the Child Health Indicators for Life and Development (CHILD) project (Rigby and Köhler 2002) and other European Union (EU) initiatives, including the EU-funded Child Safety Action Plan (MacKay and Vincenten 2007; MacKay and Vincenten 2010) and its Child Safety Report Card indicators (MacKay and Vincenten 2012), the Environmental Health Information System (ENHIS) (World Health Organisation Regional Office for Europe 2014), the Child Environmental and Health Action Plan for Europe (CEHAPE) (World Health Organisation Regional Office for Europe 2004), the Adolescence and Risk Taking (AdRISK) project (EuroSafe 2014), Children's health and environment: a review of the evidence (Tamburlini et al. 2002), the European Report on Preventing Violence and Knife Crime Among Young People (Sethi et al. 2010), the Health Evidence Network (HEN) (Health Evidence Network 2004), and Public Health Action for a Safer Europe (PHASE) (2008). These, together with other indicators listed on the Research Inventory of Child Health in Europe (RICHE) project (2014), were examined and all those relating to injury or safety were identified. All of the above projects contained indicators pertinent to children and to safety against injury, and all were based on scientific rationale and had defined data constructs and potential sources.

\section{Policy and outcome indicators}

Two types of indicators were identified, policy and statistical indicators. These are not mutually exclusive; they provide different, but valuable, types of information. Policy indicators are powerful at national level, showing for instance the existence of specific safety legislation or regulation. However, they can be more problematic at local level, as 
either the national law applies uniformly or, for devolved legislation, they require collation of municipal and local laws. There are also important issues surrounding the enforcement of laws and local laws, particularly as research suggests that enforcement of such laws can differ between localities (Erikson et al. 2014). Statistical indicators, showing the outcome, or mechanism of injury in a particular area can provide extremely rewarding data. However, these data are not routinely collected on a sub-national scale. In terms of statistical indicators, mortality data were excluded from the Child Safety Index project because of the very small numbers, which would lead to issues concerning statistical reliability and confidentiality risks including circumstantial identification.

\section{Sub-national indicator compilation}

In selecting the national indicators to be used on a sub-national scale we drew upon experience from the Nordic School of Public Health in Gothenburg, Sweden, in re-analysing national level indicators to a municipal population level (Köhler 2006; Köhler 2012c) and by the National Institute of Child Health in Hungary at a regional level (Pall 2004). Köhler (2006, 2012c) used national indicators developed by the CHILD project (Rigby and Köhler 2002) in a new way, to map children's health and wellbeing in small geographical areas, such as municipalities and even sub-municipalities. This model has been successfully used in practice (Köhler 2012b; Köhler 2013; Köhler and Henriksson 2013). Pall (2004) used the CHILD indicators at a regional level with some success, identifying areas of elevated risk that were not known when using national data alone (Pall 2004). The resulting long list of potential indicators was then categorised in terms of type of injury they describe. The categories included several from the Child Safety Report Cards (European Child Safety Alliance 2014) such as drowning and water safety; road safety; burns and scalds; falls; poisoning; choking, suffocation and strangulation - as well as others viewed as important (such as products and safety in the home; and alcohol, self-harm and violence).

\section{Testing of candidate indicators}

A scheme was devised in order to 'test' each indicator to assess its suitability to be included, so that indicators could be chosen consistently and with a degree of scientific rigour. The selection criteria consisted of four dimensions: representation, data and baseline availability, statistical 
meaning, and utility. In terms of representation, it was felt essential that indicators should be capable of representing their category in a systematic way within an integrated index. Data need to be available for a reasonable number of localities at the level selected, and statistically valid within the size/time interval/frequency of available data, even if techniques such as moving averages had to be applied. The reliability of the indicator definition and accuracy of compilation are also statistical factors that were taken into account. Finally, in terms of utility, each indicator in the index should be valuable in describing and measuring what is child injury risk or protection, and to conform to a number of criteria, outlined in Table 1.

Table 1: Criteria agreed upon by the TACTICS project to establish utility levels of each proposed indicator for inclusion in the Child Safety Index. Milan, Italy 2012.

\begin{tabular}{|l|l|}
\hline & Utility Criteria \\
\hline 1. & In Use and with a rationale \\
\hline 2. & Significant Trauma, or Outcome Burden to individual child \\
\hline 3. & Significant Burden to Family and Society \\
\hline 4. & Risk occurs in Normal Life, not specialist activities \\
\hline 5. & Regularity and Repeatability, to enable trend analysis \\
\hline 6. & Topic amenable to Effective Action \\
\hline 7. & Understandable to Individuals and community \\
\hline 8. & Understandable to Policy Makers and politicians \\
\hline
\end{tabular}

These selection criteria made up a scoring system that was applied to each identified indicator in a methodology similar to that which had successfully been used in the CHILD project (Rigby and Köhler 2002). The indicators on the long list were discussed by the TACTICS partners and scored with a point if they met the terms of the representation, data and baseline availability, and statistical meaning requirements, and additionally with a point for each of the elements that make up the utility requirement. 


\section{Creation of the index}

The intention of the TACTICS project was to draw into one analytic tool the safety related proposals scattered through a number of recent proposals, into a single composite index, which would incorporate all dimensions of injury risk. The team identified and reviewed alreadyexisting composite health indexes, to establish whether their methodology was suitable for adoption to produce a child injury risk index to aid prevention measures. An evaluation of existing composite indexes was carried out, and the construct of a number of respected indexes in European child health were examined, including An Index of Child Wellbeing in Europe (Bradshaw and Richardson 2009) and Comparing Child Wellbeing in OECD Countries (Bradshaw et al. 2006). Discussions were held to consider issues such as weighting of items, and the use of a framework model.

Once a well-conceptualised and operationalised indicator was identified it was evaluated in terms of its standardisation and interrelationships between other measures and representativeness of the issue. After careful consideration, there was no hierarchy placed on the indicators chosen, and therefore no weighting. This lack of weighting was because very few indicators have the evidence to assign justifiable higher value to them; and because the potential elements of the Index change in their respective relevance to injury risk or prevention in terms of age, geography and a young person's immediate social and cultural environment (Köhler 2012a). Constructing the index in this way meant that for each domain the indicators would be combined into a single summary figure, effectively a sub-index; and the sub-indexes would then be combined into a single summary index that is understandable and simple to interpret.

\section{Results}

\section{Number of initial indicators}

After interrogating the projects listed above, 106 potentially relevant indicators were identified. They were selected if they corresponded to children and to injury risk factors, using the agreed-upon Child Safety Index categories. A degree of pragmatism was used to ensure as wide a spread of indicators as possible at this stage. 
The majority of indicators found were policy indicators as opposed to indicators of exposure or safety measures. In some categories there were few or even no statistical, population based indicators, as illustrated in Table 2.

Table 2. Potentially relevant indicators from European project sources (2002 - 2008), by Child Safety Index category and indicator type. (Discussed in TACTICS meeting Milan, Italy, 2012).

\begin{tabular}{|l|l|l|l|}
\hline Child Safety Index category & $\begin{array}{l}\text { Total } \\
\text { indicators in } \\
\text { feeder } \\
\text { projects }\end{array}$ & $\begin{array}{l}\text { Of which } \\
\text { indicators }\end{array}$ & $\begin{array}{l}\text { Statistical } \\
\text { indicators }\end{array}$ \\
\hline Alcohol, self-harm and violence & 5 & - & 5 \\
\hline Bullying and violence & 10 & 1 & 9 \\
\hline Burns and scalds & 8 & 6 & 2 \\
\hline $\begin{array}{l}\text { Choking, suffocation and } \\
\text { strangulation }\end{array}$ & 6 & 6 & - \\
\hline Drowning & & & \\
\hline Falls & 9 & 9 & - \\
\hline Poisoning & 6 & 6 & - \\
\hline Products and safety in the home & 10 & 5 & 5 \\
\hline Road Safety & 12 & 12 & - \\
\hline Workplace Injury & 36 & 26 & 10 \\
\hline Total & 4 & - & 4 \\
\hline
\end{tabular}

Table 2 illustrates the challenging findings that appeared from the outset. Some areas were very strongly represented, but other topics were very poorly covered. Moreover the statistical indictors were patchy and poorly distributed. For example, road safety is over-represented, while key areas such as drowning and falls had no proposed measures. Moreover, there were no indicators describing crime, perceptions of safety, playground injuries or sport-related injuries despite their importance to communities and to children's safety. Whilst over- 
representation can be handled by selection of items, gaps cannot be remedied that way. Added to this, many of the policy indicators related to presence or absence of national policies such as legislation, or tax incentives, so there is little scope for local versions of these.

\section{Number after suitability tests}

The chosen indicators were then analysed in terms of the devised scoring system, concerning representation, local area data availability, statistical validity and utility. Of these indicators, not one scored highly enough on all of the criteria in order to be suitable for the creation of a Child Safety Index.

In terms of representation, most of the indicators conformed to this criteria, because they were already in use and tested as indicators as part of other European or Global projects. However, because the Child Safety Index is concerned with sub-national data, it was felt that a number of indicators, which purely describe national policy or laws would not be applicable to inclusion in the index. Once these indicators were deleted from the list, 54 indicators remained.

In terms of local area availability there were considerable obstacles encountered. It was important to define the statistical units to determine the scale of sub-national data that could be used by the Index. In Europe, the statistical units commonly used are the Nomenclature of Territorial Units for Statistics (NUTS) (Eurostat 2012). The project team attempted to use NUTS units on as small a level as possible to test the remaining 54 indicators, but this proved problematic. Even the higher level NUTS units were challenging to use in countries with smaller populations, for example Ireland or Finland. In these countries NUTS units were primarily geographical clusterings of smaller, lower-level units and bore little relationship to local administrative boundaries, or to other data sources such as health data, which made it difficult to generate real meaning from the information gained. Using smaller, lower-level NUTS units was problematic because data are too sparse for statistics to be reliable, and issues of confidentiality become pertinent, as well as fewer of the data sources being published at this level. Thus it proved highly problematic to identify a NUTS level small enough to be meaningful in terms of local relevance, and large enough to be commonly defined and statistically robust. 
The chosen indicators were already tested on a national scale and were robust in terms of their statistical meaning. They were also concise in terms of the utility scoring system devised by the project. However, the statistical meaning for many indicators became compromised when used sub-nationally, due to lack of data or extremely small numbers. In most countries, many issues relating to child safety such as playgrounds, parks, fencing, traffic calming, and school crossing patrols, are influenced by decisions and investment at a very local level such as municipality or county. Clearly the kind of statistical indicators being considered would not be meaningful at this level, while larger areas of several million overall population would be statistically more robust but would be remote from local decision-making.

\section{Discussion}

The results suggested that the creation of meaningful sub-national public health analyses to support effective local action, in this case a Child Safety Index, is generally problematic in Europe, except in the largest federal countries where, at best, regional data in units as large as many EU Member States seem valid. This study showed that the objective of using existing indicators and populating the Index with existing data was not feasible on a meaningful sub-national level in Europe. This was disappointing and in some respects, surprising. The obstacles encountered in the work on the Child Safety Index, however, become interesting areas of discussion, not least by highlighting the urgent need for sub-national data on injury to children to be collected and analysed.

\section{Indicators that describe injury}

Injury has a multitude of risk factors, determinants and behavioural influences; and its complexity requires a range of indicators to adequately describe it. The indicators identified by the project were fragmented across many initiatives in Europe, which impacts upon their influence on injury levels and may account for the imbalance of coverage in the Child Safety Index. There was a strong emphasis on road safety, but very few indicators to describe poisoning, burns or injuries due to leisure activities. In addition to this, the choice of indicators can itself be complex. Adding in specific indicators describing the presence or absence of a safety strategy, such as "the presence or absence of walk-to-school initiatives", may prevent the inclusion of other local preventive initiatives. However, using a broad indicator such 
as "Policies to ensure safe transportation to school" may not yield useful data to allow communities to take effective action. Specific indicators often do not have universal definitions or have different contexts, meaning that a 'walk-to-school' scheme in one locality is very different to one in another locality thus rendering comparison difficult. Some important environmental determinants of injury and safety were missing entirely such as perception of crime and perceived neighbourhood safety (World Health Organisation 2014). What is needed are indicators of exposure to injury on a sub-national scale, the creation of which is a task that was well outside the original EU project or any other attempt to utilise already available and published data from official sources.

\section{Analysis of injury data}

Exposure data and incidence data for injury are not straightforward to interpret. For example a higher than average number of cycling injuries may mean dangerous roads; or that there is an extremely active and inclusive cycling culture in the area, with a large number of children enjoying the physical, social and mental benefits of regular exercise using their bicycles. Finally, in terms of an index, combining these extremely disparate elements would run a real risk of compromising its value. Given the complexity of causality, the combination of such heterogeneous elements such as drowning incidence and a lack of infant car restraint law would arguably be too artificial a construct to have any meaningful or major influence on policy or action, other than possibly highlighting the need for investigative action where overall rates of injury are high.

The shortcomings of available indicators to comprise an index mean that any resulting data would not be interpretable in a meaningful manner. The limited data available on a sub-national level only exacerbates the difficulty. A large geographical area is likely to be diverse in its character, containing rural and urban areas, and areas of differing economic prosperity. With available data it is not possible to identify communities at real need of specific intervention.

Injury prevention needs to take place at a community level alongside national-level policy changes to improve safety (Tamburlini et al. 2002; Sethi et al. 2010). But the data available were not helpful for local decision-making purposes. Additionally, injury risk has been shown to be highly influenced by socio-economic status and by the environment 
in which a child lives, plays or goes to school (Sethi et al. 2010). The data available at present are not able to measure or describe social inequalities in risk or inequalities in exposure to injury that research has demonstrated exist (Laflamme 2012). Data that are only available at a higher level cannot effectively describe the extent of community cohesion. Communities themselves are not homogenous. A geographical index would mask these effects; but stratifying any index would cause problems with small numbers and data reliability.

\section{Conclusions}

This study shows that production of meaningful local public health data, particularly child safety and injury data, provides a conundrum. Only local data are strongly relevant to influencing appropriate local actions, but availability of such data in meaningful form is shown to be limited, and what is present is not comparable with that of other local areas. There have been a number of published research results on studies to measure child health topics; but these are predominantly survey based, are limited to certain locations only, or use and provide data that is challenging for a variety of interested parties to interpret. The results of these studies align with our findings that although there have been successes in measuring specific child health topics, the nature and limitations of these studies though intrinsically successful, provide no added insights into how to make common measures related to safety available to stakeholders in an accessible way from routine and publicly available data. Additionally, facts such as degree of exposure to specific hazards or preventive measures, or local demographic variants, can easily be masked. This continues to be a subject needing further research.

\section{Acknowledgments}

This analysis was part of the Tools to Address Childhood Trauma, Injury and Children's Safety (TACTICS) project. The TACTICS project was part-funded by the European Union in the framework of the Health Programme. Project number 20101212.

\section{References}

Barth J, Bermetz L, Heim E, Trelle S, Tonia T (2-13) The current prevalence of child sexual abuse worldwide: a systematic review and meta-analysis. Int J Public Health 58:469-483. doi: 10.1007/s00038-0120426-1 
Bradshaw J, Hoelscher P, Richardson D (2006) Comparing Child Wellbeing in OECD Countries: Concepts and Methods. UNICEF Innocenti Working Paper no 2006-03; Innocenti Research Council, Florence

Bradshaw J, Richardson D (2009) An index of child well-being in Europe. Child Ind Res 2:319-351. doi:10.1007/s12187-009-9037-7

De Leeuw E, Tsouros AD, Dyakova M, Green G eds (2014) Healthy Cities: promoting health and equity - evidence for local policy and practice. Summary evaluation of Phase V of the WHO Healthy Cities Network. World Health Organisation Regional Office for Europe, Copenhagen

Erickson DB, Lenk KM, Sanem JR, Nelson TF, Jones-Webb R, Toomey TL (2014) Current use of underage alcohol compliance checks by enforcement agencies in the United States. Alcohol Clin Exp Res 6:1712-1719. doi: 10.1111/acer.12397 doi: 10.1111/acer.12397

European Child Safety Alliance (2014) What is TACTICS? www.childsafetyeurope.org/tactics/index.html. Accessed 14 July 2014

European Child Safety Alliance (2014) Child Safety Report Cards. www.childsafetyeurope.org/reportcards/index.html. Accessed 14 July 2014

European Urban Health Indicator System Part 2 (EURO-URHIS-2) (2009)

Newsletter. http://www.urhis.eu/media/mhs/internationalconferenceonurbanhealt h/Newsletter-01.pdf. Accessed 15 January 2015

EuroSafe (2014) Adolescents \& Risk Taking - AdRisk Project. www.eurosafe.eu.com/csi/eurosafe2006.nsf/wwwVwContent/12adolesc entsrisktaking-adriskproject-adrisk1.htm. Accessed 14 July 2014

Eurostat (2012) NUTS - Nomenclature of territorial units for statistics. Introduction.

http://epp.eurostat.ec.europa.eu/portal/page/portal/nuts_nomenclatur e/introduction. Accessed 14 July 2014 
Glasgow Centre for Population Health (2013) The built environment and health: an evidence review. Briefing paper 11 Concepts series. Glasgow Centre for Population Health, Glasgow

Health Evidence Network (2004) How can injuries in children and older people be prevented? World Health Organisation Regional Office for Europe, Copenhagen

Köhler L (2006) Health indicators for Swedish children: a contribution to a municipality index. Save the Children, Stockholm

Köhler L (2012a) Apples and oranges or fruit salad? On the use of indicators and index. Report from the RICHE project. Nordic School of Public Health, Gothenburg

Köhler L (2012b) Indicators of children's health: selected European Studies. In McKee M (ed) For the sake of the children: social paediatrics in action. Karlstad University, Karlstad

Köhler L (2012c) Separate indicators or composite index - an area of concern also for TACTICS. Nordic School of Public Health, Gothenburg

Köhler L (2013) Barnhälsoindex för Göteborg. Ett system för att följa barns hälsa i Göteborg och dess stadsdelar. (A Child Health Index for the city of Gothenburg and its town districts A system of indicators for monitoring children's health.). Nordic School of Public Health, Gothenburg

Köhler L, Henriksson G (2013) Barnhälsoindex för Västra Götalandsregionen. Ett system för att följa barns hälsa i Västra Götalandsregionen och dess kommuner. (A Child Health Index for the 49 municipalities in the Region of Västra Götaland in South-West of Sweden). Nordic School of Public Health, Gothenburg

Laverack G, Labonte R (2000) A planning framework for community empowerment goals within health promotion. Health Policy Plan 15; 255-262. doi: 10.1093/heapol/15.3.255

Laflamme L (2012) Socioeconomic inequalities and injuries in children: two preventable burdens. In McKee M (ed) For the sake of the children: social paediatrics in action. Karlstad University, Karlstad 
MacKay M, Vincenten J (2010) Action planning for child safety: 2010 update on the strategic and coordinated approach to reducing the number one cause of death for children in Europe - injury. European Child Safety Alliance EuroSafe, Amsterdam

MacKay M, Vincenten J (2007) Action planning for child safety: a strategic and coordinated approach to reducing the number one cause of death for children in Europe. European Child Safety Alliance EuroSafe, Amsterdam

MacKay M, Vincenten J (2009) Child safety report card 2009: Europe summary for 24 countries. European Child Safety Alliance EuroSafe, Amsterdam

MacKay M, Vincenten J (2012) Child safety report card 2012: Europe summary for 31 countries. European Child Safety Alliance EuroSafe, Birmingham

Palacio-Viera JA, Villalonga-Olives E, Valderas JM, Herdman M, Alonso J, Rajmil L (2013) Predictors of the use of healthcare services in children and adolescents in Spain. Int J Public Health 58:207-215. doi: $10.1007 / \mathrm{s} 00038-012-0360-2$

Pall G (2004) Presentation to the $7^{\text {th }}$ World Conference on Injury Prevention and Safety Promotion, World Health Organisaion, Vienna

Peden M, Oyegbite K, Ozanne-Smith J, Hyder AA, Branche C, Rahman AKMF, Rivara Frederick, Bartolomeos K (eds) (2008) World report on child injury prevention. World Health Organization / UNICEF, Geneva

Pettman L, Magarey A, Mastersson N, Wilson A, Dollman J (2014) Improving weight status in childhood: results from the eat well be active community programs. Int $J$ Public Health 59:43-50. doi: 10.1007/s00038-013-0455-4

Public Health Action for a Safer Europe (PHASE) (2008) Final report including an inventory of interventions in violence prevention and tools for capacity building in view of making violence prevention part of formal public health and training, EuroSafe, Amsterdam

Research Inventory of Children's Health in Europe (RICHE) www.childhealthresearch.eu. Accessed 14 July 2014 
Rigby M, Kohler L (2002) Child health indicators of life and development (CHILD), European Commission, Brussels

Safe Kids Worldwide (2014) Our Network. www.safekids.org/ournetwork. Accessed 6 October 2014

Sethi D, Hughes K, Bellis M, Mitis, F, Racioppi F (2010) European report on preventing violence and knife crime among young people. World Health Organisation Regional Office for Europe, Copenhagen

Sethi D, Mitis, Racioppi F (2010) Preventing injuries in Europe: from international collaboration to local implementation. World Health Organisation Regional Office for Europe, Copenahgen

Sethi D, Towner E, Vincenten J (2008) European report on injury prevention. World Health Organisation Regional Office for Europe, Copenhagen

Stöcklin L Loss G, von Mutius E, Weber J, Genuneit J, Horak E, Sozanska B, Danielewicz H, Cullinan P, Heederick D, Braun-Fahrländer C and the GABRIEL study group (2013) Health-related quality of life in rural children living in four European countries: the GABRIEL study. Int J Public Health 58:355-366. doi: 10.1007/s00038-012-0410-9

Tamburlini G, von Ehrenstein O, Bertollini R (2002) Children's health and environment: a review of the evidence. A joint report between the European Environment Agency and the WHO Regional Office for Europe. World Health Organisation Regional Office for Europe, Copenhagen

The Prevention Institute (2008) UNITY RoadMap: A Framework for Effectiveness and Sustainability. http:/ /www.preventioninstitute.org/component/jlibrary/article/id30/127.html. Accessed 6 October 2014

UNICEF (2014) Child Friendly Cities. http://childfriendlycities.org. Accessed 15 January 2015

United Nations Office of the High Commissioner for Human Rights (1989) Convention on the Rights of the Child. United Nations, Geneva 
World Health Organisation Regional Office for Europe (2004) Children's environment and health action plan for Europe. In Fourth Ministerial Conference on Environment and Health. World Health Organisation; Budapest

World Health Organisation Regional Office for Europe (2014) Environmental health information system ENHIS. www.euro.who.int/en/data-and-evidence/environment-and-healthinformation-system-enhis. Accessed 14 July 2014

World Health Organisation Regional Office for Europe (2013) Health 2020 A European policy framework and strategy for the $21^{\text {st }}$ Century. World Health Organisation, Copenhagen

World Health Organisation (2014) Children's environmental health injuries. http://www.who.int/ceh/risks/cehinjuries2/en/. Accessed 3 September 2014 


\section{Chapter 7}
Alexander D, Bourek A, Kilroe J, Rigby M, Staines A. (2013) The RICHE taxonomy - an innovative means of classification of child health research. Child: Care, Health and Development 40(5) 632-9 doi: 10.1111.ccj.12119

This paper moves on from the micro-level indicator work, which sought to find ways of measuring upstream elements of certain childhood health outcomes in order to promote preventive action. Here, the notion of measurement focuses on navigating and identifying indicators and other elements of children's health research in an environment that is, at present, uncoordinated and very disparate. This suggests that much work is unknowingly being replicated across Europe, and there remain many areas of children's health research that are under-investigated despite there being a need for research to help vulnerable children.

The Research Inventory of Child Health In Europe (RICHE) project aimed to find a means of identifying research carried out into children's health, and provide a means of coordinating the work. This was carried out by means of an online database of research done, and enabling continued updating of the database so that it becomes a central hub of who is researching what and where. This facility is vital for modern coordination of research work, and also essential for navigating the huge numbers of indicators and research projects that already exist into children's health and wellbeing.

The database was created by first examining the literature into the creation of taxonomies in health, and adapting these to the specific needs of the RICHE project. The database was subsequently tested and revised continuously throughout the duration of the project. 


\section{The RICHE taxonomy - an innovative means of classification of child health research}

\section{Short title: The RICHE taxonomy development}

\section{Authors}

Ms Denise Alexander BA (Hons) MRes. Nordic School of Public Health, Göteborg, Sweden. C/O 8 Moorlands Avenue, Cuddington, Cheshire CW8 2LU. Telephone $0044 \quad 1606 \quad 888486$ denise.alexander@nhv.se

Dr Ales Bourek MD PhD. CEO of Center for Healthcare Quality, Faculty of Medicine, Masaryk University, Brno, Czech Republic. Svitavska 33, 61400 Brno, Czech Republic. Telephone: 00420603 477645 ales@bourek.eu

Ms Jean Kilroe BA MSocSc MBA. RICHE Project, Child Health Research Fellow, School of Nursing and Human Sciences, Dublin City University, Dublin 9, Ireland. Telephone 0035317007861 jean.kilroe@dcu.ie

Professor Michael J Rigby PhD, FRSM, FBCS. Nordic School of Public Health, Göteborg, Sweden. Lavendar Hill, 6 Carrighill Lower, Calverstown, Kilcullen, Co. Kildare. Telephone: 0035345485858 michael.rigby@nhv.se

Professor Anthony Staines PhD. School of Nursing and Human Sciences, Dublin City University, Dublin 9, Ireland. Telephone: 003531 7007861 anthony.staines@dcu.ie

For correspondence: Ms Denise Alexander BA (Hons) MRes. Nordic School of Public Health, Göteborg, Sweden. C/O 8 Moorlands Avenue, Cuddington, Cheshire CW8 2LU. Telephone 00441606888486 denise.alexander@nhv.se

Keywords: child, public health, health information, taxonomy 


\begin{abstract}
Background. Research outputs increase inexorably. Health is now a required element in all policies of the European Union. There is a need for a system that helps to navigate the vast body of children's health research, identify pertinent research institutions, discover on-going and recently funded research projects and identify gaps where there is little knowledge.
\end{abstract}

Methods. The European Commission funded the Research Inventory of Child Health in Europe (RICHE) project through the Framework 7 Programme, to identify gaps in child health research in Europe. A necessary first step was to identify and index current research, for which a website repository was created. As a basis for this task, an innovative taxonomy was necessary to encompass the many arenas of children's health and development, including subjects outside the traditional areas of children's health. Drawing inspiration from existing taxonomies, library systems and other forms of classification, a multi-axial approach was selected as the best way to encompass the many influences on children's health. Six axes were identified and their contents defined. All of the axes can be viewed and searched independently, as well as in relation to each other. The axes encompass factors and service areas that impact on children, including health, education, justice, the environment and others. This has created a system that is consistent and impartial, but adaptable to an enormous variety of uses.

Results. The taxonomy has been tested and validated by a number of well-respected academics, researchers and practitioners across Europe. It forms the basis of an intuitive and accessible database. This allows research knowledge to be easily identified and for networking to take place.

Conclusions. The RICHE taxonomy facilitates retrieval of knowledge on-going research as well as findings - in order to inform researchers and policy makers who wish to include children's health as an element of new policy. 


\section{Introduction}

Research and the quest for new knowledge is a stimulating and invigorating process that potentially has real benefit to the lives and experience of children. However, as the quantity of published and ongoing research into children increases, it becomes harder to find and retrieve items on a topic. This produces an effect opposite to that desired, in that despite the importance of evidence-based policy and evidence-based services, it is arguably becoming more difficult to identify or access pertinent research and translate this into policy action. Furthermore, as child health becomes ever more addressed by specialist literature, it becomes increasingly difficult to make that knowledge accessible to professionals of other domains even though they affect children's health. This runs counter to the core concept of Health in All Policies (Ståhl et al. 2006) in the European Union. A closely related problem is the duplication of effort, and failures of coordination, which can happen when there is considerable funding and effort on a particular 'hot topic' without knowledge of other similar ongoing projects looking at the same topic. This uncoordinated approach fosters a research imbalance, and also potentially slows the use of knowledge in policy and practice.

In addition, although the importance of a holistic and integrated approach to children's health is increasingly recognised, and now commonly articulated, the essential underpinning evidence is very much locked into disciplinary and service silos, and into uncatalogued grey literature. There is also a regressive tendency for recent research to highlight related areas for further work, which results in the potential reinforcing of such silos as there is no countervailing mechanism to identify research gaps, while at the same time policy analyses and programme evaluations are unnoticed. To address these points, the Research Inventory of Child Health in Europe (RICHE) project, which consists of 34 members within 24 institutions across Europe, aims to provide a holistic analysis of child health research and current gaps, initiated by compiling a web-based database of research knowledge and funding knowledge specifically focused on European child health and wellbeing.

The web repository will contain a range of literature and knowledge located in a searchable database of published literature, grey literature and projects that have recently been funded or are in progress. It also 
seeks to develop communication within the research community by providing a members' forum and advice and signposts about agencies that fund research. Underpinning and enabling this functionality is an innovative taxonomy that has been developed with rigorous testing and consultation at every stage.

\section{Methods}

In order to facilitate the many functions of the RICHE website, the taxonomy needs to be comprehensive, accessible, scientifically robust and able to extend beyond traditional child health arenas. It also needs to be flexible enough to cater for different types of data to be stored within - peer-reviewed research, grey literature, funding agencies, researchers' interests, and other types of data repositories. The functions of the taxonomy were identified as illustrated in Figure 1.

Figure 1: The required functions of the RICHE child health taxonomy

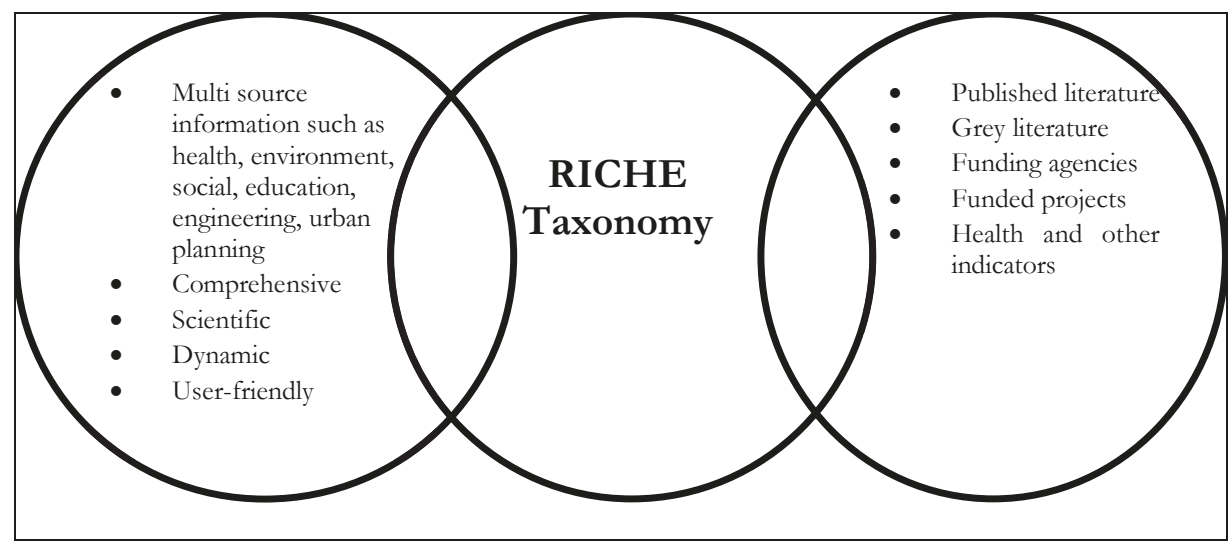

The aims and boundaries for the function and use of the taxonomy, how it should be developed, and for what audiences, were key discussions at the RICHE inaugural meeting in February 2010. The parameters of the type of information and research were defined in public health terms. Child public health aims to protect and promote children's health by preventing problems with health, serving the entire child population, and including upstream health determinants. It is closely related to clinical health disciplines but encompasses wider influences including demography, education, the justice system, social 
care, environmental issues and the influence of design and engineering among others.

Identifying the potential users of the RICHE platform helped to inform structuring of the semantics of the taxonomy terms and the development of the web platform. Three types of users were initially thought likely to benefit from the taxonomy and resulting database: policy makers who wished to find out current research on a particular topic; researchers who want to find others with common interests to share methods, collaborate or undertake comparative or meta-analysis; and researchers and research funding bodies who wish to identify what is currently not being researched in Europe. Users are not confined to these groups, however, and the repository is developed in such a way that a wide variety of professionals, students, parents and young people who are interested in child health research will be able to benefit from the use of the database.

In order to construct the taxonomy informedly, and within the time and budget constraints of the RICHE project, elements of a number of taxonomies and reference systems were considered and adapted to form an initial framework. The sources are listed in Table 1.

The taxonomy team identified that a structure that best reflected the complex and diverse lives of children across Europe would consist of six distinct dimensions, and that these mapped on to discrete but complementary axes, namely: Demographics; Population group; Language and geographical perspective; Health issues, determinants and measures; Agents, influences and settings; and Type of study, scale, state of progress and setting; all with the child as a central focus. Each axis contains a discrete taxonomy of categories and subcategories that are related to the overall heading; and is also related to the other axes. Within the website search function, a faceted search approach enables the categories to be related to any other category in any other axis, enabling a broad or specific search of research, knowledge and funding priorities. Figure 2 describes this important initial structure. 


\title{
Table 1: Taxonomies and Reference systems that inspired the RICHE taxonomy
}

\author{
Source \\ - World Health Organization - Health for All Database (2012) \\ - $\quad$ ICD-10 (World Health Organization, 2010) \\ - International Classification of Functioning, Disability and Health (WHO- \\ FIC) World Health Organization (2012) \\ - International Classification of Function Children and Youth version (ICF- \\ CY) (2012) \\ - World Health Organization Europe Health Topics (2012) \\ - UK Clinical Research Collaboration Health Research Classification System \\ (HRCS) (2012) \\ - European Commission Public Health Website (2012) \\ - PubMed Medical Subject Headings (MeSH) (US National Library of \\ Medicine, 2011) \\ - Health on the Net Foundation (World Health Organization / United \\ Nations, 2012) \\ - Evidence in Health and Social Care (NHS Evidence, 2011) \\ - Children's Environmental Health Action Plan for Europe (CEHAPE) (World \\ Health Organization Europe, 2004) \\ - The Cochrane Library (2012) \\ - The European Multilingual Thesaurus on Health Promotion in 12 languages \\ (2001)
}


Figure 2: the Axis-based structure of the RICHE taxonomy

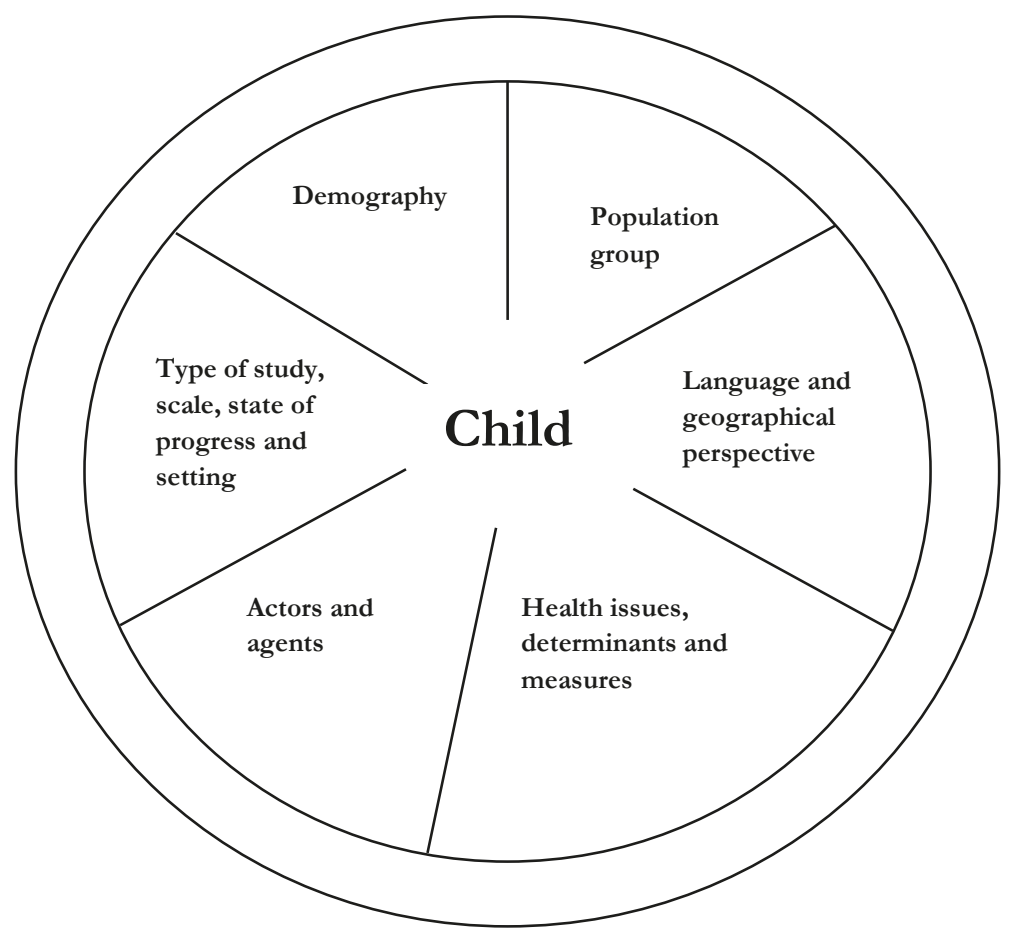

\section{Axis: Demographics}

Initially this axis was designed to reflect a life course of a child from birth until adulthood which is generally accepted as age 18 as stated by the Convention on the Rights of the Child (Office of the United Nations High Commissioner for Human Rights.1989). However, this is a very heterogeneous population, and within this time period a number of divisions or progressions must be made. The World Health Organization Europe (2005) states that:

the general term children's health fully includes infants, pre-school children, older children and adolescents. These groups comprise subgroups that differ in stages of development, risks to and determinants of health, and needs for services and public health measures. (p.46) 
As a child ages, autonomy grows, and health and social needs change dramatically. In addition the cumulative effect of experiences and actions over time has been shown to have an effect on children's health and future adult health (Kuh et al. 2003), all of which should be reflected in the taxonomy. Using traditional five-year age bands was the first solution, linked to traditional statistical groupings, although this takes the final age up to 19 years. However, as the project developed it became obvious that this was too narrow a focus. There was a need for an alternative method of determining and defining crucial ages in childhood. Traditional five year age bands used by epidemiologists were complemented by terms to describe more loosely defined functional and service provision age groups and stages of childhood or education level, as well as unborn and newborn babies. In addition the ability to note the sex of a child was necessary to classify research that focuses on gender issues.

\section{Axis: Population Groups}

This axis addresses the concern held by many, including the Council of the European Union (2008) that society is not homogenous, and certain children do not receive equal attention from research and similar opportunities for good health and future prospects as others. Marginalised children, ethnic minority groups, traveller children, those with mental health problems, children in poverty and so on have specific problems and have specific research needs. In order to identify terms for all these groups a number of sources were consulted - such as UNESCO (2011), the European Anti Poverty network (2012), The Children's Society (2012), the Royal College of Psychiatrists (2012) and The European Federation for Street Children (2006). In addition projects that describe or list a number of population groups such as the CHILD health indicators project (Rigby and Köhler. 2002) and the European Multilingual Thesaurus on Health Promotion (2001) were consulted. Elements from these organisations and reports were combined into a system of general headings and more specific subheadings and then discussed among the RICHE members to produce the taxonomy where research into children with particular personal, familial, education or environmental situations could be easily catalogued and retrieved. 


\section{Axis: Agents, influences and settings}

A high proportion of research into children's health actually investigates the actions of adults who work with them or who make decisions on their behalf, such as parents, teachers, and health staff. Although a great deal of work has been carried out to enable young children to participate actively in research and give their views, for example in the Kidscreen project (2011), many children - especially babies and young children cannot contribute effectively to research. To reflect this aspect and to highlight its presence, this axis takes into account those people whose opinions and actions sometimes act as proxy for children's views and life experiences. It was developed from a group discussion and encompasses a broad range of research topics, from the types of circumstances in which children live (such as in a supportive household, or one where there is violence); and how the culture of that household affects the children, to research aiming to unpick what motivates a teacher to provide health-promoting education to the effect of class sizes on children's wellbeing.

\section{Axis: Health issues, determinants and measures}

Influences from a wide variety of classification systems and taxonomies were drawn upon to create a thorough and all-encompassing range of topics from the structures of the human body, to determinants of health, to political aspects of child health and health systems. Databases and systems interrogated to form this taxonomy included the World Health Organization (2010), the European Commission Public Health website (2012), and the Cochrane library (2012).

Ultimately seven general headings were created: Demographic (measurement); Determinants; Outcomes; Interventions; Services / Health care; Body functions; and Body Structures. Each of these was subdivided into numerous more specific headings and sub headings, creating a very wide-ranging component of the taxonomy.

\section{Axis: Languages and geographical perspective}

Europe is rich in its diverse linguistic and cultural landscape. Most international research is published in English, but there are over 40 indigenous languages spoken in Europe (British Broadcasting Corporation. 2012), not to mention the number of languages spoken by immigrant and refugee population groups. Knowledge that can make a positive difference to children's lives and health may well be published 
or used in a language other than English. This includes important grey literature such as government reports, locally commissioned studies, and academic work. To ignore this potentially rich source is a mistake, Thus it was important for the RICHE web platform to cope with documents in languages other than English, or those in two or more languages. Ultimately, the entire RICHE website and taxonomy will be useable in a number of European languages to find local-language studies to be identified. An equally important aspect is the ability to catalogue and identify material that is based in a specific country or locality. This is because of the potentially profound influences on health that cultural differences and characteristics can pose. This rich diversity also influences the generalizability of research results and is important to consider within a European perspective.

\section{Axis: Type of Study, Scale, State of Progress and Setting}

Scientific inquiry differs from casual observation of everyday life in that it is systematic and its methods clearly described. Measurement and observation are carried out in different ways according to the type of research and the aims of its results - whether it is quantitative or qualitative for example. Interpretation of results also differs fundamentally according to the methodology employed by the researchers. The scale of study has more than one dimension: potentially it can include the cohort size or the financial size of the study as well as the scale of its geographical area. Thus, the taxonomy has the capacity to describe a study carried out in a small city, region or country; a small unidisciplinary sample or an integrated and larger cohort; or a large, multinational study such as the Health Behaviour in School-Aged Children (HBSC) (2012). Recording the research setting has important consequences for searching the database, as well as for the generalizability and interpretation of results: findings of a rural study may not be applicable to urban children's experiences for example. A study that is finite and completed may have different messages to one that is on-going and awaiting a follow up - such as in a longitudinal study. All of these aspects add a further dimension to knowledge and to the searching process - allowing the vast landscape of research into children to be navigated more precisely by users of the RICHE site.

Table 2 provides an overview of the general headings within each axis, and examples of some of the more specific subheadings within each general heading. 


\section{Table 2: Axes of the RICHE taxonomy with general taxonomy headings}

\begin{tabular}{|c|c|}
\hline Axis & General headings (examples) \\
\hline Demography & $\begin{array}{l}\text { Sex } \\
\text { Age group } \\
\text { Stage of childhood e.g. infant - first year of life, baby not walking; young (preschool) child (including } \\
\text { those attending Kindergarten/ playgroup/ childcare) }\end{array}$ \\
\hline $\begin{array}{l}\text { Population } \\
\text { Group }\end{array}$ & $\begin{array}{l}\text { Economic-type terms e.g. street children, children in poverty } \\
\text { Living status terms } \\
\text { e.g. children living with alcoholic parents, children who are carers } \\
\text { Family / parenthood terms e.g. teenage parents, adopted children, children in care but supervised at } \\
\text { home } \\
\text { Migration type terms } \\
\text { e.g. asylum seekers, refugees } \\
\text { Criminality type terms e.g. children in penal institutions, children whose parents are in penal } \\
\text { institutions } \\
\text { Sexual orientation / reproductive health type terms e.g. children from surrogate parents, } \\
\text { homosexual children }\end{array}$ \\
\hline $\begin{array}{l}\text { Language } \\
\text { and } \\
\text { geographical } \\
\text { perspective }\end{array}$ & $\begin{array}{l}\text { Languages } \\
\text { Countries }\end{array}$ \\
\hline $\begin{array}{l}\text { Health, } \\
\text { disability, } \\
\text { health issues } \\
\text { and } \\
\text { determinants }\end{array}$ & $\begin{array}{l}\text { Demographic (measurements) e.g. population, mortality, morbidity, economic data } \\
\text { Determinants e.g. lifestyle indicators (obesity, mental health, sexual health and so on), social } \\
\text { determinants (community, social and civic life, family health and relations, school, support and relationships } \\
\text { etc.), special situations (child TV stars etc.), economics, finance and industry (inequalities, target groups, } \\
\text { training etc.) environment (air pollution etc.), psychological determinants (mental bealth etc.), education and } \\
\text { training (school etc.) } \\
\text { Outcomes e.g. mortality data, life expectancy, morbidity. } \\
\text { Interventions e.g. risk assessment, prevention, medicines. } \\
\text { Services / health care e.g. health care resources, health policy, health security. } \\
\text { Body functions e.g. mental functions, sensory functions, functions of the nervous system } \\
\text { Body structures e.g. the eye, ear and related structures, structures of the cardiovascular, immunological } \\
\text { and respiratory systems }\end{array}$ \\
\hline $\begin{array}{l}\text { Agents, } \\
\text { influences } \\
\text { and settings }\end{array}$ & $\begin{array}{l}\text { Children as agents and influences e.g. research involving direct participation of children, violent } \\
\text { children } \\
\text { Family e.g. single parent families, parental/guardian reporting about children, grandparents } \\
\text { Health care e.g. children's rights in hospital, health care involving children } \\
\text { Health professionals e.g. medical doctors, nursing care, multi-disciplinary researchers } \\
\text { Household e.g. household structure, foster care, households with tobacco smoke. } \\
\text { Housing e.g. homelessness, temporary accommodation, unfit housing. } \\
\text { Institutions e.g. children's homes } \\
\text { Physical environmental influence e.g. rural, urban, climate change, } \\
\text { Education e.g. class sizes, teachers, school health services, truancy } \\
\text { Law and jurisprudence e.g. police, courts systems, family courts } \\
\text { Care of children e.g. child-minders, nursery assistants, foster parents } \\
\text { Interpersonal threats and perpetrators e.g. violence against children, paedophiles, animals who } \\
\text { attack. injure children } \\
\text { Accidents and safety e.g. road safety, water safety, fall prevention } \\
\text { Research e.g. ethical issues }\end{array}$ \\
\hline $\begin{array}{l}\text { Type of } \\
\text { study, scale, } \\
\text { state of } \\
\text { progress and } \\
\text { setting }\end{array}$ & $\begin{array}{l}\text { Quantitative e.g. systematic reviews, cohort incidence study, survey research. } \\
\text { Qualitative e.g. observation and participant observation, life course study, focus group methodology. } \\
\text { Setting e.g. rural, urban, household. } \\
\text { Scale of study e.g. municipality or community, national, EU Europe (including EEA) } \\
\text { State of progress e.g. recently started, on-going, completed and published. }\end{array}$ \\
\hline
\end{tabular}




\section{Results}

In May 2010, The RICHE taxonomy group decided that the child must be placed at the centre of any structural development. It was also felt that the taxonomy must function from the user's perspective. Thus, every decision was considered in terms of clarity and intuitiveness. After discussion, the taxonomy was provided to the software development team for the creation of the website. Each entry is coded along multiple dimensions, which permits the items to be searched, accessed and ordered in many ways rather than in a single, pre-determined, taxonomic order. The tool visually reflects the multi-axial taxonomy and readily permits the refinement or extension of searches.

Once this process was completed, a thorough testing of the taxonomy via the website took place. Joint discussions between the teams working on the taxonomy and on the creation of the RICHE web platform agreed that the testing would take place in three broad strands, each of which could lead to modification of the platform database.

The initial testing process was carried out by a RICHE member who was familiar with the taxonomy but not with the website. In this process, a number of documents on varied subjects were added to the database, and detailed comments about the process were reported back. This process resulted in greater intuitivism on the part of the web platform, and a testing of the breadth of subject matter of the taxonomy.

Subsequently all members of the RICHE project were asked to submit research inquiries that could be used to interrogate the database. The 'answers' were not available as the database was not yet populated, but the taxonomy structure was tested to see if, in theory, the categories existed to answer the question at a future date. This was to ensure that the design was truly needs led, and not biased by the the nature of initial entries or researchers. Questions came from a wide variety of subjects so that the focus was not specifically medical. The questions were used in two ways: as an academic check of the taxonomy using the RICHE core documents, and as a check of the website.

Finally, all RICHE members were asked to upload a selected spread of documents and to report their experiences of doing so. This provided much needed information about the ease of use of the website, and also 
additional information about items that may be missing from the taxonomy, or the need for different organisation of the taxonomy in order for users to have a more effective and productive experience.

At each stage of the testing process the taxonomy was refined until there was a satisfactory level of completeness for the website to be made publicly available. It was of great importance that the taxonomy be able to evolve as users discovered its limitations or any duplication within. However, in order to create stability, it was agreed that the taxonomy only be amended every six months, with the changes collated by the taxonomy development team and inputted to the master taxonomy list and communicated to the software development team.

The taxonomy was released for general use in early 2011, and by May 2013 1,445 entries had been uploaded, involving 19,683 tag applications. Of these entries, 424 were grey literature, 637 were details of current ongoing research projects, and 21 were details of projects formally approved but not yet started - all items not readily found elsewhere. Entry of literature readily identifiable on bibliographic sites such as PubMed was not a priority.

Taxonomy tags are identified by two methods - in the entry process the title, key words, and abstract are parsed by the software against the taxonomy and possible terms suggested for confirmation by the person uploading, while this person can also select any of the nearly 800 terms and tag them to the entry. Entries can be made by bibliographers, authors of individual items, or researchers who find particular items valuable and worth wider sharing.

The six monthly taxonomy review process in the first year led to over 70 additional terms being added in the light of user feedback - many were refinements of items, or additions to lists such as languages or countries. By contrast, in the last 12 months only six new items were added, and eight reworded, suggesting that the taxonomy is reaching maturity. The taxonomy, repository, and user-driven search facility are available for use on www.childhealthresearch.eu, using the Find research function.

\section{Discussion}

The RICHE taxonomy does not just facilitate the cataloguing of ongoing research but is also an agent of change in that it highlights issues 
and hopefully stimulates work that is of true benefit to Europe's children, and it is important for the wider child health community to be aware of it and to use it. For example, the presence of an axis such as 'Population Groups' that enables retrieval of knowledge on those known to be vulnerable to poor health may in itself prompt more work that benefits these children and reduces their marginalisation.

There is now a real chance that greater coordination and identification of research activity can be achieved. In addition, and most uniquely, research in progress can be discussed; and formative relationships between researchers and research institutions can be forged, based on specific interests.

The RICHE taxonomy and website also aim to make translation from research findings into policy easier and timelier. The aim of the Commission of the European Communities is to include health as a concern in all policies (Commission of the European Communities. 2007), recognising that it is the wider world that most influences an individual's health, but this is often challenging to achieve. As stated by Ståhl et al (2006): 'integrating health considerations in other policies requires a solid information base' (p.3) as well as the skills to interpret the knowledge and navigate the policy system.

\section{Acknowledgements}

The project was funded by the European Commission DG Research under Framework 7 contract 242181 within the Public Health programme. We acknowledge the contributions of members of the RICHE project throughout the formative and testing stages of the work.

\section{Conflicts of interest}

None declared

\section{Key messages}

Child health research and research into children's wellbeing is abundant and valuable in Europe, but communication and coordination between researchers and institutions - particularly across disciplines and domains - needs to be improved and gaps identified rather than existing strands proliferating. A structured taxonomy should enable finding of knowledge from different research and publication domains. 
Children's health and wellbeing is influenced by many factors, not just traditional health disciplines - but those of justice, education and environmental science among others. The taxonomy must facilitate knowledge sharing between these disciplines if it is to be successful.

A comprehensive child health research taxonomy needs to harmonise with, and draw from, numerous specialist lexicons, and this has been achieved.

The taxonomy, as the foundation of the RICHE website, needs to meet a double challenge of organising knowledge for effective dissemination and identifying gaps in information and expertise.

Thorough testing and continual refinement ensures the RICHE taxonomy and website best serves their purpose.

\section{References}

British Broadcasting Corporation (2012) Languages across Europe [online]. Available from: http://www.bbc.co.uk/languages/european languages/languages/inde x.shtml [accessed 22 June 2012].

Commission of the European Communities (2007) Together for Health: A Strategic Approach for the EU 2008-2013 (White Paper) [online]. Available from: http://ec.europa.eu/health-eu/doc/whitepaper en.pdf [accessed 22 June 2012].

Council of the European Union (2008) Draft Resolution of the Council and the Representatives of the Governments of the Member States, meeting within the Council, on the health and well-being of young people. Brussels: Permanent Representatives Committee (Part 1): 2008 Oct. Report No.: 14877/08JEUN 103 SAN 240 SOC 646 [online]. Available from: http://register.consilium.europa.eu/pdf/en/08/st14/st14877.en08.pdf [accessed 22 June 2012].

European Commission (2012) Public Health. [online]. Available from: http://ec.europa.eu/health/index en.htm [accessed 22 June 2012].

European Federation for Street Children: Help us save the children from the streets (2006) [online]. Available from: http://www.efsc-eu.org [accessed 22 June 2012]. 
Health Behaviour in School-Aged Children (2012) [online]. Available from: http://www.hbsc.org/ [accessed 22 June 2012].

Kidscreen (2011) [online]. Available from: http://www.kidscreen.org [accessed 22 June 2012].

Kuh, Diana et al. (2003) Life course epidemiology. Journal of Epidemiology and Community Health. 57(10), pp. 778-783.

NHS Evidence (2011) Evidence in Health and Social Care [online]. Available from: https://www.evidence.nhs.uk [accessed 22 June 2012].

Office of the United Nations High Commissioner for Human Rights (1989) Convention on the Rights of the Child. Adopted and opened for signature, ratification and accession by General Assembly resolution 44/25 of 20 November 1989 entry into force 2 September 1990, in accordance with article 49 [online]. Available from: http://www2.ohchr.org/english/law/crc.htm [accessed 22 June 2012].

Rigby, Michael and Köhler, Lennart (eds) (2002) Child Health Indicators of Life and Development CHILD. Report to the European Commission. Brussels: European Commission.

Royal College of Psychiatrists (2012) Young People [online]. Available from:

http://www.rcpsych.ac.uk/mentalhealthinfoforall/youngpeople.aspx [accessed 22 June 2012].

Ståhl, Timo et al. (eds) (2006) Health in all policies: prospects and potentials. Finland: Ministry of Social Affairs and Health.

The Children's Society (2012) Include Programme [online]. Available from: http://www.youngcarer.com/showPage.php?file=index.htm [accessed 22 June 2012].

The Cochrane Library (2012) [online]. Available from: http://www.thecochranelibrary.com/view/0/index.html [accessed 22 June 2012].

The European Anti Poverty network: Fighting for a social Europe free of poverty! (2012) [online]. Available from: http://www.eapn.eu [accessed 22 June 2012]. 
The European Multilingual Thesaurus on Health Promotion (2001) [online].

http://www.vocabularyserver.com/hpmulti/en/index.php [accessed 22 June 2012].

United Kingdom Health Research Classification System (HCRS) (2012) [online]. Available from: http://www.hrcsonline.net [accessed 22 June 2012].

United Nations Educational, Scientific and Cultural Organization UNESCO (2011) Education: Inclusive education [online]. Available from: http://www.unesco.org/new/en/education/themes/strengtheningeducation-systems/inclusive-education [accessed 22 June 2012].

United States National Library of Medicine National Institutes of Health (2011) Medical Subject Headings (MeSH) [online]. Available from: http://www.nlm.nih.gov/mesh/meshhome.html [accessed 22 June 2012].

World Health Organization (2007) International Classification of Functioning, Disability and Health - Children and Youth Version ICF-CY [online]. Available from:

http://apps.who.int/bookorders/anglais/detart1.jsp?codlan=1\&codcol $=15 \& \operatorname{codcch}=716$ [accessed 22 June 2012].

World Health Organization (2012) International Classification of Functioning, Disability and Health (WHO-FIC) [online]. Available from: http://www.who.int/classifications/icf/en [accessed 22 June 2012].

World Health Organization / United Nations (2012) Health On the Net Foundation [online]. Available from: http://www.hon.ch [accessed 22 June 2012].

World Health Organization Europe (2004) Fourth Ministerial Conference on Environment and Health: Children's Environment and Health Action Plan for Europe [online]. Available from: http://www.euro.who.int/ data/assets/pdf file/0006/78639/E83338 .pdf [accessed 22 June 2012]. 
World Health Organization Europe (2005) European Health Report 2005: Public Health Action for Healthier Children and Populations. Copenhagen: WHO Regional Office for Europe.

World Health Organization Europe (2012) European Health For All Database (HFA-DB) [online]. Available from: http://www.euro.who.int/en/what-we-do/data-andevidence/databases/european-health-for-all-database-hfa-db2 [accessed 22 June 2012].

World Health Organization Europe (2012) Health Topics [online]. Available from: http://www.euro.who.int/en/what-we-do/healthtopics [accessed 22 June 2012].

World Health Organization ICD-10 (2012) International classification of diseases and related health problems $10^{\text {th }}$ Revision [online]. Available from: http://apps.who.int/classifications/apps/icd/icd10online [accessed 22 June 2012]. 
Part 5: General Discussion 


\section{Chapter 8}

\section{Characteristics of the problems identified}

As Chapters 2 to 7 seek to show, measuring children's health determinants is not a simple process. Chapter 2 illustrates that it is not feasible to use adult indicators and measures and apply them to child populations. In terms of children's lives, and in attempting to measure behavioural determinants of their health, measuring health outcomes is only one element of a far more complex whole picture. Taking into account the behavioural determinants of those actions is arguably more interesting, more easily measured, and more beneficial to the child population and to the whole population of which they are a part because they address potential causes, and act as a stimulus to prevention.

The main elements in measuring children's health as identified in this work are the importance of the social and physical environment as part of children's preventive health; the difficulty in identifying data; and the general lack of comparable data at international, national and subnational level. This is somewhat paradoxically combined with the fact that there are so many research projects and indicators that exist into aspects of child health that how to measure can easily become overwhelming. These main issues point to the fact that an agreed-upon system of upstream indicators which address behavioural determinants of child health, on a wide-ranging and holistic scale makes sense to improve health and measurement of children's health.

\section{The environment as a determinant of health}

The chapters in this thesis have illustrated how important it is to include environmental influences when attempting to create indicators to measure children's health and wellbeing. In this sense, the term environment is a broad one - it encompasses not just the physical environment, but also the structural environment, perceived environment and the policy environment among others. This can be seen in the range of indicators that were chosen in the Lifestyles project to describe the determinants of childhood obesity and in the environmental viewpoints taken in the attempts to create a Child Safety Index (Chapter 6) and in terms of measuring childhood Maltreatment (Chapter 5). Research by Olsen and Dahl (2007) found that age, education, economic satisfaction, social network, unemployment and occupation are potent influences on an individual's health, particularly 
so for children. A child's dependence upon others for his or her wellbeing means they are deeply influenced by their surroundings. Thus, indicators of children's health behaviour need to take into account the age, developmental status and environments of the children they purport to measure. The Lifestyle Determinants project described in Chapters 2, 3 and 4 attempted to do this when identifying upstream indicators to measure the underlying causes of obesity in children; even to the point of having slightly different indicators according to the broad ages of the children.

One important element of a child's environment is the influence of inequalities in socio-economic status and in opportunities for health and wealth. The ECHIM project has stated that inequalities in Europe would be reduced and health vastly improved if we measured children's health systematically and similarly across the continent and as a result brought the least healthy to the standards of the healthiest (Kipeläinan et al., 2008); a statement underlined by the World Health Organisation (Marmot, 2010) and most recently in the World Health Organisation Health 2020 strategy; which states that although Europe has some of the lowest child mortality rates in the world, there is also a wide variation across the region, as countries with the highest mortality rates are 20 to 30 times more than countries with the lowest rates (World Health Organisation, 2013). A change in focus brought about by comparable measurements would enable preventive action to be targeted appropriately and highlight where public health could be improved.

Socio-economic indicators are interesting in terms of their influence on children's and community health and make an important contribution to upstream indicators of behavioural determinants of health, children are particularly vulnerable to the socio-economic influences that surround them (Marmot, 2010) and this goes beyond terms of economic deprivation or family hardship. Janevic et al. (2010) found that Roma children who lived in urban populations, where traditional and cultural support was reduced, were less healthy than Roma children remaining in more traditional rural surroundings; despite experiencing similar economic circumstances (Janevic et al., 2010). A study in South Africa found that living in social and economic disadvantage negatively affected a child's bone health (Norris et al., 2008), and research carried out in the Arab region found that in districts where there are large inequalities between the rich and poor there also exist deeply entrenched health 
inequalities (Boutayeb and Serghini, 2006). Examples of this were the far higher rates of maternal and infant mortality in the poorest areas compared to the wealthiest; but the socio-economic differences extend beyond a lack of wealth. Poor literacy, cultural status of women, or a lack of suitably qualified health care staff in poorer areas affected health outcomes (Boutayeb and Serghini, 2006). From this, we see that indicators need to focus also on social elements such as lack of social capital, violence in the community and social support, as is seen in Chapter 6 in terms of childhood injury. These aspects have a profound effect on health (Berntsson et al., 2006).

\section{Lack of accessible data or indicators describing determinants of health}

Despite the existence of some indicators, there is a lack of existing data that comprehensively measure children's health outcomes and the behavioural determinants of children's health. In the words of ECHIM, Europe has uneven and poorly comparable data on health in different Member States (Kipeläinan et al., 2008). Many data exist in varying formats in many countries, but rarely in an accessible way; routinely collected over a number of years; or in a format which is comparable across nations. This means that it is very difficult, and in some cases impossible, to calculate trends in children's health across nations or even within a nation. The lack of comparable data compromises our ability to benefit from the rich knowledge and diverse experiences across Europe. In addition, the statistical benefit from having a large population base is not achieved at present because the data differ across nations.

Modern communication means that country borders are less restricting when it comes to lifestyle and health issues. Health and health behaviour is becoming far more international. Measuring from a global point of view, and learning from international examples is valuable.

\section{Subnational data}

There is also a lack of sub-national data about children. This was investigated in depth in Chapter 6, and to some extent in terms of Maltreatment (Chapter 5) and childhood obesity (Chapters 2, 3 and 4). But this experience is replicated in other subjects that concern children's health. It is often on a subnational scale that decisions can be made and actions taken that directly affect the determinants of health, such as improving the safety and economic security of a town, leading to less 
stress for families, easier healthy choices and so on. Measuring children's health on a subnational scale can be challenging for ethical reasons and the difficulty of maintaining confidentiality. It is important that steps are taken to protect this vulnerable population. However, leaving children's health unsystematically measured, and important determinants of good health ignored or unrecognised is also, arguably, unethical and damaging.

Chapter 6 demonstrated that at present it is not possible to perform a meaningful sub-national public health analysis of threats to safety to children because of the lack of sub-national data. Injury has multiple risk factors, in line with many other threats to children's health, such as obesity; and as such, has multiple causes and avenues of prevention. Using upstream measurements may well highlight these as well as forming a means of awareness.

\section{Lack of standardisation and definitions across Europe}

Related to the issue of comparability is the lack of standardisation of many outcome terms in children's health, which causes difficulties in creating and using indicators of behavioural determinants of health. For example, Chapter 4 showed that childhood obesity is defined and measured in different ways across Europe and globally. Maltreatment is also a term that has differing meanings across the continent as seen in Chapter 5. This creates difficulties in obtaining comparable statistics.

One reason for the lack of standardisation is that many data sets are not designed with children in mind; meaning that the indicators do not provide information that is most relevant to children's lives and the elements that most influence their health behaviour. One example of a lack of standardisation is the two international child growth standards. The World Health Organisation released new child growth standards in 2006, which contrasts to the National Center of Health Statistics (NCHS) which were previously used by the World Health Organisation and are still used in the United States. The NCHS uses a different reference population, and so indicators of whether a child is over- or under-weight or not growing normally are different between the two systems (de Onis et al., 2006; Vessel, 2010). A study by Yang and de Onis (2008) found that reanalysis of the old data in light of the new World Health Organisations standards is in some cases impossible because the raw data are unavailable. This means that in order for a 
trend to be calculated, an algorithm must be used to data from one system into estimates that conform to the other system. Although this problem is becoming less of an issue because of the length of time since the WHO growth standards have been released, it still affects comparable child statistics and will do for years to come. The ECHIM project, established by the European Union to establish continent-wide comparable health information, has made great strides to improve indicators and data across the European Union; but data on children's determinants of health are still few and far between (Kipeläinan et al., 2008).

\section{Finding the most appropriate measurements}

Many data that exist are not able to describe adequately children's life in the $21^{\text {st }}$ Century. This can be seen in Chapter 6 where mortality statistics are relied upon to describe children's injury rates - even though mortality is a very small, albeit extremely serious, proportion of the injuries that in many cases profoundly affect children's lives in Europe today. Chapter 5 also shows how current statistics measuring child death from maltreatment only give a very small proportion of the number of children who are blighted by abuse in many forms in Europe. Chapter 4 describes how statistics to describe the obesity epidemic are not consistent across Europe. Although we know that many children are overweight and storing up health issues for the future, the true prevalence across nations is not known, thus making it difficult to see how interventions and public health actions are helping or hindering these children to become a healthy weight. By combining the existing outcome statistics with routinely measured upstream behavioural determinants of children, households and the wider environment we may achieve a more robust and informative data picture of children's health in Europe.

Exposure data for injury to children, as described in Chapter 6 is also extremely complex to interpret in isolation. The varied causes of injury mean that context is extremely important when analysing data. High participation in sports may mean more injuries, but an overall healthier population, for example, and without knowledge of this context, an erroneous conclusion may be drawn and potentially a policy that does not address the needs of a local population. 


\section{Appropriate age groups - life course influences}

There is often little consensus among nations about the age group divisions at which data is collected; making comparability across nations difficult. The age groups used by researchers and in data analysis may be chosen using pragmatism, and based on general stages of social, physical and mental development rather than what is needed. They encompass babyhood, preschool age, primary school age and adolescence. Often, it seems that the researcher has to use the group that is most easily contactable or children old enough to provide information; rather than the group that most needs investigating. Thus, there are data about babyhood where parents can answer as a proxy; and data about adolescence when young people can answer for themselves but there is often a lack of information about the 5-9 age group (Alexander et al., 2010). The CHILD project identified how difficult it was to find even basic population data in some cases, particularly about specific age groups (Rigby and Köhler 2002). An example is adolescents, aged around 15-18 years. This is an important time a young person's life and development, but the specific age group can be hidden within the traditional quinquennial age which data is traditionally collected (Rigby and Kohler, 2002). At the other end of the childhood age-range, Sudden Infant Death Syndrome (SIDS) is an outcome that falls within the 0-4 age category; despite the fact that SIDS itself, by definition, almost always occurs during the first year of life (Hjern, 2012). This disparity makes analysis more challenging. A further example is that of suicide statistics, which are generally published as ages $0-14$, although almost all suicides are to adolescents, thus the age definitions used in collection compromise the efficacy of the data.

\section{Unmanageable number of indicators}

Paradoxically in the light of such a lack of data is the sheer number of indicators and research projects that exist into children's health. This was identified in Chapter 7, as part of the Research Inventory of Child Health in Europe (RICHE) research exercise. The lack of coordination of this huge body of work has led to it becoming potentially unmanageable. The RICHE project attempted to make sense of the number of indicators, with the taxonomy of knowledge and the indicator list within it. By focusing on the child as a central element, the broad axes that describe aspects of children's lives, environment and levels of autonomy or dependence allowed the many facets of children's health and 
determinants of health to be clearly mapped and retrieved for perhaps the first time. The structure of axes radiating from the child as a central premise means that terms can be searched for and retrieved in a number of dimensions, not just in a prescribed order. This reflects the differing influences on children's lives.

\section{Common themes that emerge}

The main theme that emerges in this thesis is the lack of focus on behavioural indicators of health, despite increasing work that suggests their utility in health measurement. Behavioural indicators exist, but are not used effectively and comprehensively in Europe. Data are also patchy, and unable to describe children's health and their lives adequately so that risks to health are identified in a timely manner and prevention of disease can be undertaken. We are in effect, data rich but information poor.

\section{Utilising indicators into behavioural determinants of health}

There is a lack of adequate knowledge about the determinants of children's health behaviour in Europe, accompanied by a less than perfect knowledge of their health status on an international scale. This is despite a lot of work being carried out and a number of indicators that exist or are in use in some form. This suggests that a change in perspective or coordination needs to take place.

There are many influences on children's health and health behaviour. Behavioural determinants not only apply to individual children, but really to the family, community and wider environment whether it is rural or urban. In this sense, behavioural determinants of health are the essence of a truly public health approach to health surveillance. The number of taxonomy categories in the RICHE project bears witness to this (Chapter 7). In addition certain outcomes can themselves become determinants of behaviour and future health outcomes. For example teenage pregnancy may affect education and economic status, as well as potentially impacting on family structure. A young person's alcohol abuse may cause health, social and economic difficulties in adult life and so on. We can measure children's health better by using what is already out there, as the RICHE taxonomy and RICHE project demonstrated. Although ultimately, it did not fulfil its potential, RICHE was groundbreaking in its attempts to draw together children health research. 
The work into measuring obesity described in Chapter 4showed that there remain major gaps in surveillance of one of the most serious threats to current child health and future adult health facing the European population. The research exercises in 2007 and 2014 demonstrate that indicators (and potentially data) are present in Europe, but that they are not collected or analysed systematically. Although no country had comprehensive indicator coverage, if all adopted the coverage achieved by those with the most, a baseline of behaviour monitoring would be easily achieved in Europe.

\section{Reliance on survey data}

In any research, there must be a dialogue between what is ideal to collect, and what is actually possible. Most of the time a researcher, an indicator or a data collection system must settle for what is pragmatic and 'good enough' for the result to give accurate information about what is happening in the population (Hjern 2012). There will always be weaknesses in surveillance systems or other sources of data; but it is possible and necessary to attempt to minimise these weaknesses, particularly before international comparisons can be made.

The majority of indicators on behavioural determinants are from surveys, such as the important Health Behaviour in School-aged Children (HBSC) survey. These data are useful in terms of gaining information directly from respondents and enabling an understanding of the social environment, health related behaviour and attitudes, essential in understanding the influences upon health experienced by children. However, survey data has limitations. These include representativeness, because the researcher can only claim with confidence that the results relate to the particular population surveyed and those populations very similar in age, gender and socio-economic status; and the design and execution of surveys across the member states can be very different, making comparability of results extremely hard.

Obtaining direct evidence from children can be problematic for ethical and practical reasons. This is particularly challenging when addressing the measurement of threats to health and wellbeing such as childhood maltreatment (Chapter 5). In this case, upstream indicators have great potential, as by taking a step further back, the 'unmeasurable' becomes more quantifiable. Upstream indicators in this sense can be empowering 
for individual families and communities to reduce violence and maltreatment.

Despite the difficulties, there is a place for including children's views and experiences as much as possible in research, otherwise conclusions drawn risk being irrelevant to the child populations they seek to help. This is where survey data can be potentially useful. For example, a group of teenagers' opinions as to why food is eaten to excess or why physical activity is shunned may provide a valuable insight into the unwitting perpetuation of the obesogenic environment. However, survey data can be far from ideal as a proxy for routine data and regular collection to specific indicators. Children do not all complete questionnaires and surveys - particularly if they are about sensitive subjects such as sexual health or even potentially traumatic subjects such as maltreatment. Children of a similar age may exhibit very different levels of literacy, understanding and competence, and some may not feel a responsibility to complete a questionnaire accurately. Younger children are not robust respondents and are reliant on adults as proxy responders. For example, in collecting breastfeeding data, the information is not directly derived from the baby and its nutritional status. As a child grows older, nutrition data cannot easily and ethically be obtained by means of blood or saliva samples. Nevertheless, this must be balanced against the benefits of obtaining information directly about children's experiences of their food habits and physical activity - and the challenges and support systems that surround them.

\section{Lack of routine behavioural indicators about children}

The International Society for Child Indicators (ISCI) and the United National Committee on the Rights of the Child recommend that all states:

"Should establish a national system enabling disaggregated data to be collected in all ... domains ... with regard to all persons under 18 years of age, including those who belong to the most vulnerable groups (for example migrant children, children with handicaps, children in economically disadvantaged families, children who are in conflict with the law etc) and to ensure that the information thus collected shall be used to assess ... progress made ... and to define appropriate policies" ChildONEurope Secretariat, 2009). 
A more systematic approach in routine statistical measurements would provide a clearer picture of children's health and its primary influences. A means of achieving this should be through routine data collection. This is an obvious and relatively low-cost way of gaining information about the child population. But in practice, these data are often incomplete, as evidenced to some extent in the difficulties in identifying indicators in the Obesity and Injury projects (Chapters 4 and 6). Routine data are unlikely to tell us the whole story about the issues and risks to health that face a population of generally well and happy children, as we have seen in Chapter 6. The World Health Organization states that existing child health data are often incomplete, inaccurate or inconsistent; and the methods, definitions, calculations and analyses vary considerably from country to country. This adds to the difficulty of meaningful comparative analysis (WHO Europe 2005; WHO Regional Committee for Europe $64^{\text {th }}$ Session, 2014).

In the arena of routine data collection there are vast differences between health, welfare and registration systems across the countries of Europe, making the creation and use of relevant and comprehensively understood and meaningful indicators difficult, as was found by the CHILD project as far back as 2002 (Rigby and Kohler, 2002). There are different agencies responsible for services, and functions and patterns of primary and secondary care, and these combined with the need for cultural and demographic local knowledge in order to interpret the data correctly mean that statistical surveys are often the best methods of gaining information about the health of the child population (Hjern, 2012). Even international comparisons based on data from hospital discharges can be problematic. Large variations exist in available beds for paediatric care between countries and the way international systems for diagnoses are interpreted differ between countries, and sometimes even between hospitals (Hjern, 2012).

At the same time, there is huge potential in routine data that already exists. The CHILD project identified the value in representing existing data from a child focused point of view. For instance, census data describing: percentage of households in which one or more adults smoke could be analysed further as: percentage of children, by five year age bands, living in a bousebold where they are exposed to tobacco smoke. This is a fairly simple reanalysis that could provide a vast new body of information (Rigby and Köhler 2002; Hjern 2012). 
In order to overcome many of the difficulties in comparability in international statistics, the European Commission and the World Health Organisation amongst others use certain classification systems, including their concepts and definitions, to establish indicator and statistical sets. Shortlists of indicators (such as those used in ECHIM) are derived from classification systems such as the International Classification of Diseases and Related Health Problems (ICD); and Eurostat and the International Shortlist for Hospital Morbidity Tabulation, 2005 use ICD-10. Other classification systems are used, such as the International Classification of Functioning (ICF) and the International Standard Classification of Occupations (ICSO); the Diagnostic and Statistical Manual of Mental Disorders (DSM-IV) and Diagnostic Related Groups (DRG) to derive a range of statistical indicators (European Commission, 2014). But these are almost exclusively outcome measures based on illness or describe contact with health services.

\section{Strengths and limitations}

This scientific project aims at pragmatic solutions, actions and recommendations. The use of scientific principles to come to conclusions on a variety of subjects combines with lessons from humanities and social science, which gives a holistic approach to public health that is accessible and robust. Using previously tested indicators, or indicators that have been devised by well-thought out European projects, helps to avoid a sense of 'reinventing the wheel'; and makes adopting this approach more practical in policy-making terms. Projects such as the EU Youth strategy have started this process of designing indicators specifically for young people (European Commission, 2011), and the results of this thesis fit neatly into their aims and objectives. However, in this thesis the perspective extends to encompass all children, and looks at utilising existing work in new ways.

What is new is the use of these indicators in these combinations, and the idea that a number of health issues that particularly affect children can be measured, and indeed improved, using this method. It is an essentially simple process, but one that has the potential to forge great steps in improving the overall health of children in Europe, particularly in terms of reducing the inequalities in health across the region. Measurement in this sense is powerful because it focuses effort and attention. The topics discussed in this thesis are all extremely pertinent to present and future child health, and the scientific work was carried 
out within strong European Union-funded projects that involved the key experts in each field. These experts were consulted in terms of group discussions, expert rounds and reviews of the methods employed in finding and using the indicators of relevant behavioural determinants of child health. As a result, the assessment and synthesis of knowledge embedded in this thesis has a strong scientific basis.

There are limitations to this work: most notably the fact that it has not been able to test this hypothesis and combination of indicators on a European population. However, this was not the principle aim of this research. In effect, within the cycle of Assessment / Policy Development / Assurance this work has focused on the assessment rather than implementation. In terms of future child health, however it would be extremely interesting and beneficial to compare the data from upstream indicators with existing outcome data for children to be able to see if obesity / maltreatment / injury is predicted or prevented because of this type of measuring. In many cases, as we have seen, these data do not yet exist in Europe, even for the comparative outcome data in many cases. This is a significant barrier at present, meaning thatto conduct such an exercise would entail a longitudinal and wide-ranging study, one that is outside the remit of this exercise. It would require decisions made at a high level to implement the data collection of these indicators, or the specialist analysis of already-collected data in certain cases.

This work has highlighted the potential that exists in Europe to collect a raft of data items that will directly benefit child populations in the present and in the future. It has also highlighted the lack of consistent and usefully available data about children that exists at present.

\section{Recommendations for the future}

This project has illustrated a number of important factors when it comes to the measurement of the behavioural determinants of children's health, factors that impact beyond its original aims. These include the value of using upstream indicators to describe children's lives and also to measure difficult subjects that affect children's health; the lack of available data; the lack of coordination in existing indicator research; and the lack of consistency across countries in Europe in their collection of data about children, which leads to a disparity in children's situations and health outlooks across the region. 
There are a number of reasons why using indirect measurement is appropriate and useful when researching children. Firstly, it is difficult to measure children using data provided by themselves, it is impossible for very young children to provide their own data, and it is challenging for a number of reasons to gather data from children until they are approaching young adulthood. Secondly, the child population is generally well, and as such are best measured in terms of their wellness. Measuring only poor health, in terms of hospital data for example, will by definition miss out the majority of children. It makes far more sense to focus attention on keeping healthy and garnering good habits for adulthood and as the next generation of parents. Thirdly, children's lives are so heavily influenced by their environments and their experience of life as they grow up that it is valuable to focus on these elements. The obesity project, for example, showed how the interaction of a child and the family or home situation in which he or she lives is an important determinant of health in itself.

The project has identified how difficult it is to find indicators and corresponding data that describe children's lives and health outcomes in Europe. This is despite the recognition that health surveillance needs to move beyond measures of survival to those of wellbeing and health promotion. These data simply do not exist, or if they do, they do not exist in any form that is accessible to those with the desire to make changes - such as policy makers, health professionals or youth advocates. Evidence must be understandable, relevant and accessible for it to be of any use. If it is not, or if evidence is patchy, disparate and incomparable it runs the risk of creating scepticism about all evidence in the minds of policy-makers, and demotivating the desire to search for and learn from the evidence base that exists (Shepherd, 2014).

Children make up around a fifth of Europe's population, yet, the data collection and investment in measurement from European countries falls far short of that proportion. There is work identifying and creating indicators of the upstream factors in children's lives, but the coordination of these actions is not yet present. Navigating through the vast number of research projects and indicators is a difficult task, but one which needs to be taken and made easier.

A focus needs to be placed on consistency in definition of terms and on comparable collection of data so that children's lives can be monitored 
effectively in Europe. There is great disparity in the health experience of children across the European region, and this could be made less by focusing on consistent measures, and following these, consistent actions and interventions.

A consensus on consistent monitoring indicators of children's lives at specific points in the life course, such as at birth, at school entry, on entry to high school, and on leaving education and so on are important. This project has used specific health topics as examples, but the indicators of obesity, maltreatment, injury and many other factors have similarities. Focusing on creating positive environments, such as those promoted by Child Friendly Cities, and Healthy Cities programmes, can create positive environments that become determinants of positive health behaviour. This conclusion fits into a number of already existing narratives of healthy communities and healthy environments. In addition, the upstream measures also promote the idea of the power of an individual to promote and improve his or her health through healthpromoting behaviour, which in turn is known to lead to further good mental and physical health. 


\section{References}

Alexander D (2011) International Indicators. RICHE Work Package 2. www.childhealthresearch.eu (Accessed 9.3.15)

Alexander D, Rigby M, Sjöström M, Frazzica RG, Hillger C, Neumann G, Kirch W. (2010) Challenges and Findings in Measuring the Behavioural Determinants of Obesity in Children in Europe. Huber, Bern.

Beach SR, Kaslow NJ, Foran HM, Heyman RE, Garcia-Moreno C. (2013) Future directions for science and public health. In Family problems and family violence: reliable assessment and the ICD-11. In Foran HM (ed) Beach SR (ed) Slep AMS (ed) Heyman RE (ed) Wamboldt MZ (ed) New York NW. Springer Publishing Co. 269-275.

Berntsson L, Köhler L, Vuille JC (2006) Health, economy and social capital in Nordic children and their families: a comparison between 1984 and 1996. Child: Care, Health and Development. 32(4) pp441-51.

Bolte G, Tamburlini G, Kohlhuber M (2009) Environmental inequalities among children in Europe - evaluation of scientific evidence and policy implications. European Journal of Public Health. 20(1) 14-20. doi: 10.1093/eurpub/ckp213

Boutayeb A and Serghini M (2006) Health indicators and human development in the Arab region. International Journal of Health Geographics. 28(5) 61.

Boylan SM, Gill TP, Hare-Bruun H, Andersen LB, Heitmann BL (2014) Associations between adolescent and adult socioeconomic status and risk of obesity and overweight in Danish adults. Obes Res Clin Pract. 2014 Mar-Apr;8(2):e163-71. doi: 10.1016/j.orcp.2013.03.006.

Briggs FB, Acuña BS, Shen L, Bellesis KH, Ramsay PP, Quach H,Bernstein A, Schaefer C, Barcellos LF. (2014) Adverse socioeconomic position during the life course is associated with multiple sclerosis. J Epidemiol Community Health. 68(7):622-9. doi:10.1136/jech-2013203184. Epub 2014 Feb 27. 
Cattaneo A, Cogoy L, Macaluso A, Tamburlini G (2012) Children's Health in the European Union. Executive Agency for Health and Consumers, European Union, Trieste, Italy.

ChildONEurope Secretariat (2009) The ongoing debate on the assessment of children's conditions of life: the proceedings of the ChildONEurope Seminar on Child Well-being Indicators. Istituto degli Innocenti. Firenze. www.childoneurope.org (Accessed 9.3.15)

Children's Environment and Health Action Plan for Europe (CEHAPE) (2004) Fourth Ministerial Conference on Environment and Health. World Health Organization Regional Office for Europe. Budapest, Hungary, 23-25 June 2004 http://www.euro.who.int/_data/assets/pdf_file/0006/78639/E83338 .pdf?ua $=1$ (Accessed 9.3.15)

Cooper R, Hardy R, Bann D, Aihie Sayer A, Ward KA, Adams JE, Kuh D; MRC National Survey of Health and Development Scientific and Data Collection Team. (2014) Body mass index from age 15 years onwards and muscle mass, strength, and quality in early old age: findings from the MRC National Survey of Health and Development. J Gerontol A Biol Sci Med Sci. 69(10):1253-9. doi: 10.1093/gerona/glu039. Epub 2014 Mar 28.

Currie C, Nic Gabhainn S, Godeau E, Roberts C, Smith R, Currie D, Picket W, Richter M, Morgan A, Barnekow V (2008) Inequalities in young people's health. HSBC International Report from the 2005/200 survey. World Health Organisation Regional Office for Europe, Copenhagen.

http://www.euro.who.int/ data/assets/pdf file/0005/53852/E91416 .pdf (Accessed 9.3.15)

European Commission (2015).Public Health / Indicators / International Classification.

http:/ / ec.europa.eu/health/indicators/international_classification/inde x_en.htm. (Accessed 24.3.15)

European Commission (2011) Staff working document: On EU indicators in the field of youth. Brussels. 25.03.2011 SEC(2011) 401 final. 
EUROSTAT (2015) Comparing Apples with Apples. http://ec.europa.eu/eurostat/about/overview. (Accessed 18.3.15).

Gagnon AJ, Zimbeck M, Zeitlin J. (2010) Migration and perinatal health surveillance: an international Delphi survey. European Journal of Obstetrics, Gynaecology and Reproductive Biology. 149(1) 37-43.

Gilbert R, Kemp A, Thoburn J, Sidebotham P, Radford L, Glaser D, MacMillan HL (2009) Recognising and responding to child maltreatment. Lancet 373 pp167-80

Gissler M, Mohangoo AD, Blondel B, Chalmers J, Macfarlane A, Gaizauskiene A, Gatt M, Lack N, Sakkeus L, Zeitlin J. (2010) Perinatal health monitoring in Europe: results from the EURO-PERISTAT project. Informatics for Health and Social Care. 35(2) pp64-79.

Godinet MT, Li F, Berg T (2014) Early childhood maltreatment and trajectories of behavioural problems: Exploring gender and racial differences. Child Abuse and Neglect. 38(3) pp544-556.

Gustafsson PE, San Sebastian M, Janlert U, Theorell T, Westerlund H, Hammarström A. (2014) Life-course accumulation of neighborhood disadvantage and allostatic load: empirical integration of three social determinants of health frameworks. Am J Public Health. 104(5):904-10. doi: 10.2105/AJPH.2013.301707. Epub 2014 Mar 13.

Hjern A. (2012) Quality issues in international comparisons of child health based on administrative data. RICHE work package 2 . www.childhealthresearch.eu. (Accessed 9.3.15)

Hjern A. (Ed.) (2011) Child health measurement and indicators - an update in a gaps perspective. RICHE Work Package 2. www.childhealthresearch.eu (Accessed 9.3.15)

Institute of health metrics and evaluation (2015). About Global burden of disease: the global burden of disease a critical resource for informed policymaking http://www.healthdata.org/gbd/about. (Accessed 9.3.15)

Institute of Medicine (2011) Child and Adolescent Health and Health Care Quality: Measuring what matters. Committee on Pediatric Health and Health Care Quality Measures; Institute of Medicine and National 
Research Council. www.iom.edu/Reports/2011/Child-and-AdolescentHealth-and-Health-Care-Quality.aspx (Accessed 14.4.15)

Janevic T, Petrovic O, Bjelic I, Kubera A. (2010) Risk factors for childhood malnutrition in Roma Settlements in Serbia. BMC Public Health. Aug 22; 10:509.

Kärtner J, Keller H, Chaudhary N. (2010) Cognitive and social influences on early prosocial behaviour in two sociocultural contexts. Developmental Psychology. Jul 46(4) pp905-14.

Kipeläinan K, Aromaa A and the ECHIM Core Group (editors) (2008) European health indicators development and initial implementation. Final report of the ECHIM project. National Public Health Institute, Helsinki. http://www.echim.org/docs/ECHIM_final_report.pdf (Accessed 9.3.15)

Kubzansky LD (2014) Childhood social disadvantage, cardiometabolic risk, and chronic disease in adulthood. Am J Epidemiol. 180(3):263-71. doi: 10.1093/aje/kwu127. Epub 2014 Jun 26.

Kuh D, \& Shlomo, YB (Eds) (2004). A Life Course Approach to Chronic Diseases Epidemiology (2 ed.). Oxford University Press, Oxford, UK:

Lê-Scherban F, Diez Roux AV, Li Y, Morgenstern H (2014) Does academic achievement during childhood and adolescence benefit later health? Ann Epidemiol. 24(5):344-55. doi: 10.1016/j.annepidem.2014.02.008. Epub 2014 Mar 3.

Lindström M, Fridh M, Rosvall M (2014) Economic stress in childhood and adulthood, and poor psychological health: three life course hypotheses. Psychiatry Res. 215(2):386-93. doi: 10.1016/j.psychres.2013.11.018. Epub 2013 Nov 26.

MacDorman MF, Mathews TJ. (2009) Behind international rankings of infant mortality: how the United States compares with Europe. NCHS Data Brief. Nov (23) p1-8.

Marmot M (Chair). (2010) Interim first report on social determinants of health and the health divide in the World Health Organisation Europe 
Region. WHO Regional Office for Europe, Copenhagen, Denmark. http://www.euro.who.int/_data/assets/pdf_file/0003/124464/E9437 0.pdf (Accessed 14.4.15)

Morton PM, Mustillo SA, Ferraro KF (2014) Does childhood misfortune raise the risk of acute myocardial infarction in adulthood? Soc Sci Med. 104:133-41. doi: 10.1016/j.socscimed.2013.11.026. Epub 2013 Dec 3.

Non AL, Rewak M, Kawachi I, Gilman SE, Loucks EB, Appleton AA, Román JC, Buka SL,

Organisation for Economic Co-operation and Development (OECD) (2015) www.oecd.org (Accessed 9.3.15)

Peiris D, Mohsin, M, Jenkins A, Hughes C, Cass A. (2010) Robust data to close the gap: current vascular and maternal/newborn indicators as measures of progress in Aboriginal health in New South Wales. Australian and New Zealand Journal of Public Health. 34(6) pp563-71.

Rigby M and Köhler L (2002) Child Health Indicators of Life and Development (CHILD): Report to the European Commission. http:/ / ec.europa.eu/health/ph_projects/2000/monitoring/fp_monitori ng_2000_frep_08_en.pdf (Accessed 14.4.15)

Rigby M, Kohler L, Blair ME, Metchler R. (2002) Child Health Indicators for Europe: a priority for a caring society. European Journal of Public Health 13(3 Suppl) pp38-46.

Roy K, Haddix AC, Ikeda RM, Curry CW, Truman BI, Thacker SB. (2009) Monitoring progress toward CDC's health protection goals: health outcome measures by life stage. Public Health Reports. 124(2) pp304-16.

Saks M and Allsop J. (2007) Researching Health: qualitative, quantitative and mixed methods. Sage Publications, London.

Shepherd J (2014) How to achieve more effective services: the evidence ecosystem. What Works Network Cabinet Office / Cardiff University, UK. 
Smith CA, Ireland TO, Thornberry TP, Elwyn L (2008) Childhood maltreatment and antisocial behaviour: Comparison of self-reported and substantiated maltreatment. American Journal of Orthopsychiatry 78(2) pp173-186.

Steenkamp M, Bar-Zeev S, Rumbold A, Barclay L, Kildea S. (2010) Pragmatic indicators for remote Aboriginal maternal and infant health care: why it matters and where to start. Australian and New Zealand Journal of Public Health. 34 suppl 1 s5-8.

Stronks K, Kulu-Glasgow I, Agyemang C. (2009) The utility of 'country of birth' for the classification of ethnic groups in health research: the Dutch experience. Ethnic Health. 14(3) pp255-69.

Temmerman M, Foster LB, Hannaford P, Cattaneo A, Olsen J, Bloemenkamp KW, Jahn A, da Silva MO. (2006) Reproductive health indicators in the European Union: The REPROSTAT report. European Journal of Obstetrics, Gynaecology and Reproductive Biology. 126(1) pp3-10.

UNICEF (2015) State of the World's Children 2015: Summary and tables.

http://data.unicef.org/corecode/uploads/document6/uploaded_pdfs/c orecode/SOWC_2015_Summary_and_Tables_210.pdf (Accessed 9.3.15)

UNICEF data: monitoring the situation of children and women (2015). www.unicef.org/resources. (Accessed 9.3.15)

United Nations Office of the High Commissioner for Human Rights (1989) Convention on the Rights of the Child. United Nations, Geneva

World Health Organisation Regional Office for Europe. (2013) Core Health Indicators in the WHO European Region 2013 World Health Organisation, Copenhagen. http://www.euro.who.int/_data/assets/pdf_file/0019/216703/RC63Core-Health-Indicators-in-the-WHO-EURO-Eng.pdf?ua=1 (accessed 14.4.15) 
World Health Organisation Regional Office for Europe (2013) Health 2020: A European policy framework and strategy for the $21^{\text {st }}$ century. World Health Organisation, Copenhagen

World Health Organisation Regional Office for Europe (2012) ENHIS Second Extraordinary Meeting of the European Environment and Health Task Force (EHTF) Meeting report The Hague, the Netherlands 31 May - 1 June 2012 Copenhagen http://www.euro.who.int/_data/assets/pdf_file/0006/186027/e9682 0.pdf?ua $=1$ (Accessed 9.3.15)

World Health Organisation Regional Office for Europe (2005) European Health Report 2005: Public Health Action for healthier children and populations. www.euro.who.int/_data/assets/pdf_file/0004/82435/E87325.pdf. (Accessed 9.3.15)

World Health Organisation Regional Office for Europe (2002) Children's Environment and Health Indicators (workshop), World Health Organisation, Copenhagen. http://www.euro.who.int/ data/assets/pdf file/0003/134895/E8060 4.pdf. (Accessed 7.5.15)

World Health Organisation European Ministerial Conference on Counteracting Obesity. (2006) Diet and physical activity for health. Comparative Analysis of Nutrition Policies in the WHO European region. World Health Organisation Regional office for Europe, Copenhagen

http://www.euro.who.int/_data/assets/pdf_file/0004/149782/instan bul_conf_20ebd02.pdf (Accessed 9.3.15)

World health Organisation Europe Regional Committee for Europe $64^{\text {th }}$ Session. (2014) Copenhagen, Denmark, 15-18 September 2014. Investing in children: the European child maltreatment prevention action plan 2015-2020

World Health Organisation (2015) About WHO: Regional Office for Europe. http://www.who.int/about/regions/euro/en/ (Accessed 14.4.15) 
World Health Organisation (2011) Indicator and Measurement Registry http://apps.who.int/gho/indicatorregistry/App_Main/browse_indicato rs.aspx . (Accessed 9.3.15)

World Health Organisation (2011) World Health Statistics 2011. www.who.int/whosis/whostat/2011/en/index.html (Accessed 9.3.15)

World Health Organisation (1948) Definition of Health http://www.who.int/about/definition/en/print.html (Accessed 7.5.15)

World Health Organisation in the Global Health Observatory (2015) www.who.int/gho/en/. (Accessed 9.3.15)

Zeitlin J Mohangoo A,Delnord M (2010) European Perinatal Health Report: Health and Care of Pregnant Women and Babies in Europe in 2010

http:/ /www.europeristat.com/images/doc/Peristat\%202013\%20V2.pdf (Accessed 9.3.15) 


\section{Chapter 9}

\section{Valorisation}

Children make up around a fifth of the population of Europe, and as such, deserve much greater attention in terms of health surveillance than is currently apportioned to them. Related to this is the need for evidence-based policies to ensure that optimum health is within the reach of every child across the continent.

The child population is unique in its vulnerability. Children have the least autonomy of any population group. Young children are entirely dependent upon the actions of adults for their health and wellbeing, and although children become more empowered in terms of their health behaviour as they grow up, they remain deeply influenced by their family, social, cultural, educational, policy and structural environment. Thus, it is important that the child population is subjected to specific attention for its health needs and the measurement of its health.

Measurement of the behavioural determinants of health can give us a more accurate picture of the most important influences of the health on this generally well population. Health of children encompasses is so much more than simply the "absence of disease" (World Health Organisation 1948) but contains the promises of the future within - in personal, social and economic terms that will influence the future of Europe. Of course, health outcomes are important to measure, but where children are concerned, the contextual influences and upstream behavioural determinants are equally important to focus upon.

\section{Relevance}

Children are a valuable resource that must be protected and nurtured. Investing public health energy into children means we will reap rewards from good child health long into the future, and provide great benefits to the future European health, wealth and happiness. Conversely, allowing inequalities in health opportunities for children to continue, and not investing in protecting the good health of our child population will lead to long-term health, social and economic adverse consequences (World Health Organisation Regional Office for Europe, 2002).

Focusing on measuring behavioural determinants of health will allow countries and communities to see how well children are doing in their 
regions, where things need to change and what is working well. Being able to use behavioural determinants of children's health as part of the evidence base for policy making means that good practice can be identified, and adopted; interventions can be put in place in a timely manner, so that they have the potential to prevent poor outcomes, rather than treat outcomes that have already begun to impact on children, families and their communities.

In addition to this, a focus on measuring upstream behavioural determinants of health will reaffirm to the wider population the importance of lifestyle decisions upon present and future health. Collecting data to indicators of good health will subtly (and sometimes not so subtly) underline their importance and prominence in people's lives. This may have the potential to improve overall health.

\section{Target groups}

There are a number of target groups to which this work is relevant and of interest. These groups are very different in their needs, but all of whom have, or should have, the interests of the child as a central focus of their actions. Policy makers need to have clear and understandable evidence to inform the decisions that are made which concern children. Implicit in this statement is the fact that almost every policy has the potential to impact upon this population because of their vulnerability to changes in their environment. From town planning or economics to education policy or changes to social security, these affect families and children and the ease at which they can make positive decisions about their health and protecting their health. Decision-makers in health surveillance will also benefit from this research. Many of these data already exist, as do many of the indicators suggested by the projects that make up this thesis. However, the child is not yet placed in a focal position, and the data is not available, or analysed in a manner that is useful for evidencebased decisions. National and Local Governments have also the potential to see how they can improve child health surveillance as a result of this work, simply by looking further upstream in terms of indicators of children's health and wellbeing. Parents and children will also benefit, as they see investment in healthy community, lifestyles and in children's futures. Making healthy decisions and adopting lifestyle habits that benefit health should become easier if this is made a priority in overall health surveillance. For example, if it becomes easier and cheaper to buy 
and cook healthy food; or there are fewer barriers to living an active lifestyle - such as traffic-free routes to walk or cycle to work and school.

\section{Activities / products}

As mentioned earlier, many data exist already, but are not analysed in a child-focused manner. If this research could inspire the availability of better data about the behavioural determinants of children's health, and the promotion and use of indicators that describe children's lives it would contribute to improving health determinants of millions of children in Europe.

Using indicators in specific combinations that focus on upstream influences, as achieved by the Lifestyle Determinants project described in chapters 2, 3 and 4 is not impossible, and not particularly prohibitive in terms of effort or cost implications. This method is also suggested for difficult subjects such as child maltreatment described in Chapter 5.

A consensus and a debate about how to use existing indicators in a new way that is beneficial and focused on children would be of great use, in a similar fashion to the "Bellagio consensus" on breastfeeding and contraception achieved in 1988 on contraception. In terms of behavioural indicators of children's health, it would mean that research efforts could by focused upon using these indicators, and evaluating their utility in practice in improving health outcomes and the overall health of the child population in Europe.

\section{Innovation}

The results of this research are innovative in that they place an overall emphasis on the importance of the child, and how data upon children is not only patchy, but it is also very difficult to compare between nations, and difficult to ascertain the true health status of a large proportion of Europe's population.

In addition to this, scientifically based solutions to these measurement difficulties are suggested using many tools and indicators that already exist, but are not currently widely adopted.

\section{Schedule and implementation}

The results of these studies will be disseminated to interested stakeholders. These include children, families, decision-makers on many 
levels and policy makers. Highlighting the unique needs of children in terms of overall surveillance is a task that has been attempted for many years, but will continue because of its vital contribution to the present and future health of the European population.

The results of the RICHE project, which was an important part of this research, will feed into future decision-making in terms of funding and coordinating children's health. Children's health is many faceted, but the upstream determinants have the potential to influence many of the health outcomes. Measuring these determinants, and as a complementary activity, strengthening these determinants in society will impact upon many health outcomes and benefit many children.

Most European countries profess to focus on children's health; but in real terms this is not demonstrated in actions, data or in policy decisions. Children's lives are marginalised in terms of specific indicators that describe them, and financial, academic and scientific energy is not dedicated to child health in many government decisions. This is not difficult to change in practical or economic terms, but requires a perspective shift for it to occur. For effective policies that truly benefit child health to be created and adopted; a functional, informative and long-term evidence stream is required (Shepherd 2014). It remains to be seen whether this is the direction that Europe will take in the future. 


\section{Summary}

\section{Background, aim and research questions}

Behavioural determinants in health are becoming increasingly important to public health, as we appreciate the holistic influence on health. This is particularly pertinent to children, who make up around a fifth of Europe's population. Children's lack of autonomy make them vulnerable to environmental and cultural influences, and are dependent to a large degree on decisions made on their behalf by the adults in their lives.

Measurement is an important aspect of public health. Without it we cannot know where to focus our efforts, what actions to take and if any interventions are successful. By knowing the size and severity of any issue, we can act accordingly to improve health, prevent poor health outcomes and treat conditions that arise.

Upstream measurements, which measure the elements that occur before the immediate causes of any health outcome, are very important when measuring children, who are essentially a well population. Nonetheless, it is important to take a long-term view, as habits of behaviour established by children can potentially last until adulthood, and as such, behavioural determinants of health that impact on children themselves, adults, and the societies that children live within are worthy of scientific scrutiny.

This thesis hypothesises that such measurement can be largely achieved using existing indicators in new combinations. It also hypothesises that the data to populate such indicators do not, at present, exist consistently across the European region.

\section{Methods}

To navigate the enormous variety of influences and determinants on children's health; this project chooses public health topics that are particularly relevant to children living in Europe in the early $21^{\text {st }}$ Century. These were all the focus of recent EU-funded projects.

Childhood obesity - the behavioural determinants of nutrition and physical activity behaviour at different points in a child's life course were 
explored using different groups of indicators. The research aimed to establish if these indicators were collected by 31 countries in the European Union, the EEA, Turkey, Croatia and Macedonia (2007). The concept of developing specific measurements of children's obesity emerged from the work of a large-scale EU project (The Scientific Platform Project on Lifestyle Determinants of Obesity), which involved many experts in the field of children's physical activity and nutrition. The literature and emerging discussion was analysed and indicators selected to form the resulting discussion about the use of indicators, and the challenges in developing them and obtaining the relevant data.

Child maltreatment - a group of existing indicators designed to measure the risk factors for child maltreatment as well as preventive and help to children affected factors was drawn up. This work follows on from a World Health Organisation call for greater prevention of child maltreatment, and more accurate and comparative measurement in the European Region. The paper calls for a consensus about establishing consistent indicators internationally. Many of the indicators were drawn from the Public Health Action for a Safer Europe (PHASE) EU-project; which investigated how physical child maltreatment is measured and what prevention methods exist in the countries of the European Union. This work was analysed and expanded to create this measurement concept that has the potential to all forms of maltreatment, its prevention and actions to help maltreated children.

Injury is the biggest killer of children in Europe, and is a massive cause of disability and misery for children and their families across the continent. There has been important work on injury carried out in Europe recently, by the European Child Safety Alliance, which has created national indicators and national report cards allowing countries to compare the safety of their children and the risks of injury. Injury is a challenging subject to measure, as it does not affect children equally and the national indicator project was unable to measure this important subject adequately. A large EU-project Tools to Address Childhood Trauma, Injury and Children's Safety (TACTICS) hoped to explore the causes of injury, and means of prevention further. There seems to be a socioeconomic gradient in the incidence and prevalence of injury. This is seen nationally, with those in poorer countries suffering more acutely than those in affluent countries. In addition to this, the data that describe injury are inadequate and therefore upstream measures of safety and risk 
are potentially valuable. This work explored whether safety and upstream injury indicators could be used effectively on a sub-national scale, but would also work internationally in the form of an index. It was hoped that a region in Spain, for example could compare itself with a similar area in Hungary and learn from the experience. To do this, the national indicators already used successfully by the European Child Safety Alliance were analysed as to their suitability for sub-national use; and where there were gaps, alternative indicators were sourced and assessed. However, once the indicator list was drawn up, the final feasibility study of whether the index could succeed, however, faltered primarily because of the lack of data available.

Finally, this thesis moves to itself take an upstream approach, moving from specific, micro-level subjects to take a macro view. The final paper investigates how attempts have been made to make sense of the vast numbers of research projects and indicators that are carried out across Europe. This is work that has not been done before. The paper from this project describes the disparate sources of research and indicators, and the many topics that impact upon children's lives and health; and aims to find a means of navigating this to find and use appropriate indicators and upstream knowledge. This was part of the Research Inventory of Child Health in Europe (RICHE) project, which was an attempt to facilitate greater communication and connections between researchers and in highlighting research findings for policy-makers among other users. As part of the RICHE project, a taxonomy was developed in order to make sense of the many influences on children's health and life experiences. This taxonomy drew upon the concepts of upstream measures of health, and placed the needs of the child at the centre of the taxonomic organisation.

\section{Results and discussion}

It is feasible to measure children in this upstream manner, and it has the potential to give us good and robust information about what influences children's health choices and the choices that are made on their behalf while being unobtrusive on children's lives.

However, at present lack of data and a lack of focus on the specific needs of children provide a barrier to the adoption of such an upstream approach. This prevents further exploration and 'real life' testing of the hypotheses in this thesis. 
All the research exercises described in this thesis show how children's health is influenced by wider environmental influences, in every sense and that measuring just the immediate causes of any health condition that affects children is inadequate to measure this population. In this respect, it underlines a central tenet of public health. 


\section{Samenvatting}

\section{Achtergrond, doel en onderzoeksvragen}

Gedragsdeterminanten in gezondheid worden steeds belangrijker voor de volksgezondheid aangezien een holistische invloed op de gezondheid toeneemt. Dit is in het bijzonder relevant voor kinderen die immers voor een vijfde deel uit maken van de bevolking van Europa. Het gebrek aan autonomie bij kinderen makkt hen kwetsbaar voor culturele en omgevingsinvloeden. Ze zijn voor een groot deel afhankelijk van beslissingen die volwassenen voor hen nemen.

Meten is een belangrijk aspect van volksgezondheid. Zonder dit weten we niet waar we onze inspanningen op moeten richten, welke acties ondernomen moeten worden en welke interventies succesvol zijn. Als we weten hoe groot en zwaar een probleem is, kunnen we op gepaste wijze handelen om gezondheid te bevorderen, slechte gezondheidsresultaten voorkomen en aandoeningen die ontstaan, behandelen.

Upstream measurements, die letten op factoren die er zijn vóór de directe oorzaak van welk gezondheidsresultaat dan ook, zijn erg belangrijk bij het beoordelen van kinderen, die in essentie een gezonde populatie zijn. Desalniettemin is het belangrijk om een lange termijnvisie te hebben, aangezien gedragsgewoontes die kinderen hebben aangenomen, mogelijk kunnen duren totdat ze volwassen zijn, en als zodanig, zijn gedragsdeterminanten in gezondheid, de impact op kinderen, volwassenen en de samenleving waarin de kinderen leven, wetenschappelijk onderzoek waard.

Deze dissertatie gaat ervan uit dat zulke metingen in ruime mate verkregen kunnen worden door het gebruik van bestaande indicatoren in nieuwe combinaties. Er wordt ook als hypothese aangenomen dat de data, om zulke indicatoren te verkrijgen, momenteel, niet consistent voorkomen binnen het Europees gebied.

\section{Methodes}

Om door de enorme variatie van invloeden en bepalende factoren met betrekking tot de gezondheid van kinderen te kunnen loodsen, heeft dit project gekozen voor volksgezondheidsonderwerpen die specifiek zijn 
voor kinderen die in Europa leven in het begin van de $21^{\mathrm{e}}$ eeuw. Ze waren alle aandachtsgebied van recente EU-gesubsidieerde projecten.

\section{Obesitas bij kinderen}

De gedragsfactoren met betrekking tot voeding en fysieke activiteit op diverse momenten gedurende het leven van een kind zijn onderzocht door verschillende groepen van indicatoren te gebruiken. Het onderzoek had tot doel om vast te stellen of deze indicatoren door 31 landen in de Europese unie, het Europees vrijhandelsgebied (EEA), Turkije, Kroatië en Macedonië (2007) verzameld zijn. Het idee om specifieke maatregelen te ontwikkelen voor obesitas bij kinderen kwam voort uit het werk van een grootschalig EU-project project (The Scientific Platform Project on Lifestyle Determinants of Obesity), waarbij veel experts op het gebied van fysieke activiteit van kinderen en voeding betrokken waren. De literatuur en de daaruit voortkomende discussie werd geanalyseerd en indicatoren geselecteerd waardoor de daaruit voortvloeiende discussie over het gebruik van de indicatoren en de uitdagingen in het ontwikkelen daarvan, alsmede om relevante data te verkrijgen, kon worden gevoerd.

\section{Kindermishandeling}

Een verzameling van bestaande indicatoren, bedoeld om de risicofactoren voor kindermishandeling te beoordelen alsook preventie en hulp voor de betreffende kinderen, werd samengesteld. Dit werk is een vervolg van een WHO-oproep om meer preventie van kindermishandeling en nauwkeurigere en een beter vergelijkbare meting in het Europees gebied. Het document vraagt een consensus over het vaststellen van internationale consistente indicatoren. Veel van de indicatoren zijn overgenomen uit het EU-project Public Health Action for a Safer Europe (PHASE). Dit project onderzocht hoe fysieke kindermishandeling wordt gemeten en welke preventieve methodes er bestaan in de landen van de Europese Unie. Dit werk is geanalyseerd en uitgebreid om dit concept van meting, dat toegepast kan worden op alle vormen van mishandeling, preventie en acties om mishandelde kinderen te helpen, tot stand te brengen.

\section{Letsel}

Verwondingen zijn de grootste veroorzaker van kindersterfte en ze zijn een belangrijke oorzaak van handicaps, ziekte en ellende van kinderen en hun families op het hele continent. The European Child Safety Alliance 
heeft recentelijk belangrijk werk uitgevoerd met betrekking tot letsel. Ze heeft ook nationale indicatoren vastgesteld en nationale rapporten waarmee landen de veiligheid van hun kinderen en het risico op verwondingen, kunnen vergelijken. Letsel is lastig te meten, de uitwerking is niet altijd bij elk kind hetzelfde en het nationale indicatoren project kon dit belangrijke aspect niet adequaat meten.

Een groot EU-project Tools to Address Childhood Trauma, Injury and Children's Safety (TACTICS) wilde erachter komen wat de oorzaak van verwondingen is en onderzocht verdere mogelijkheden van preventie. Het lijkt erop dat een sociaal-economische component meespeelt in de mate waarin letsel voorkomt en het aantal gevallen van ziekte op één tijdstip. Dit is nationaal bezien, met dien verstande dat zij die in armere landen wonen meer lijden aan acute ziektes dan zij die in welvarendere landen leven. Bovendien waren de gegevens, die de verwonding beschrijven, ontoereikend en derhalve is het wellicht waardevol om te kijken naar de oorzaken die als basis dienen voor veiligheid en risico. Onderzocht werd of veiligheid en indicatoren die aan letsel ten grondslag liggen effectief gebruikt konden worden op een sub-nationale schaal, maar ook internationaal toegepast zouden kunnen worden in de vorm van een index.

Het ware gunstig geweest als een regio in Spanje, bijvoorbeeld, te vergelijken was geweest met een gelijkwaardige regio in Hongarije en om van die ervaringen te kunnen leren. Om dit te doen werden de nationale indicatoren, die al met succes waren gebruikt bij de European Child Safety Alliance, geanalyseerd om te bezien of ze geschikt waren voor sub-nationaal gebruik en daar waar onvolledigheden waren werden alternatieve indicatoren gezocht en vastgesteld. Echter, toen de indicatorenlijst klaar was, de finale haalbaarheidsstudie waarbij werd bezien of de index kans van slagen had, wankelde deze al primair vanwege het gebrek aan beschikbare data.

Ten slotte; deze dissertatie heeft zelf een upstream approach die gaat van specifieke onderwerpen op micro-niveau om vervolgens een macro view te krijgen. In het einddocument wordt onderzocht welke pogingen zijn ondernomen om de enorme hoeveelheid van onderzoeksprojecten en indicatoren die over heel Europa zijn uitgevoerd, te kunnen doorgronden. Dit soort werk is nog niet eerder verricht. Het document van dit project beschrijft de ongelijksoortige bronnen van onderzoek en 
indicatoren en de vele onderwerpen die impact hebben op het leven en de gezondheid van kinderen. Het tracht een weg te vinden om dit te navigeren om gepaste indicatoren en upstream kennis te vinden. Dit maakte deel uit van het Research Inventory of Child Health in Europe (RICHE) project dat een poging deed om bredere communicatie en connecties tussen onderzoekers te faciliteren alsmede het markeren van onderzoeksbevindingen voor o.a. beleidsmakers.

Als onderdeel van het RICHE project werd een taxonomie ontwikkeld om wijs te kunnen worden uit de vele invloeden op de gezondheid en levenservaring van kinderen. De taxonomie maakte gebruik van het concept van upstream measures met betrekking tot gezondheid en plaatste de behoeften van de kinderen in het centrum van de taxonomische organisatie.

\section{Resultaat en discussie}

Het is mogelijk om kinderen te meten op deze upstream manier en het heeft de potentie om ons goede en solide informatie over de invloeden van gezondheidskeuzes van kinderen en de keuzes die voor hen op indiscrete wijze worden gemaakt over hun leven.

Echter, op dit moment vormt het gebrek aan gegevens en het gebrek aan focus inzake de specifieke behoeften van kinderen een barrière voor het toepassen van zo'n upstream aanpak. Dit verhindert verder onderzoek en 'levensecht' testen van de hypothesen in deze dissertatie.

Alle in deze dissertatie beschreven onderzoekspraktijken laten zien hoe de gezondheid van kinderen is beïnvloed door omvangrijke omgevingsinvloeden in elk aspect en dat het meten van slechts de directe oorzaken, van welke gezondheidsaandoening dan ook die kinderen beïnvloeden, onvoldoende is om deze populatie te meten. In dit opzicht benadrukt het een van de belangrijkste grondbeginselen van volksgezondheid. 


\section{Acknowledgements}

The European projects that form the backbone of this doctoral research are the Scientific Platform Project on Lifestyle Determinants of Obesity (project No; 2005111), the Tools to Address Childhood Trauma, Injury and Children's Safety (TACTICS) project, (EU Health Programme No: 20101212); the Public Health Action for a Safer Europe, (PHASE) project (EC Grant Agreement number 2006123); and Research Inventory of Child Health In Europe (RICHE) project (DG Research Framework 7 (public health): No: 242181).

Many thanks go to Professor Michael Rigby for support and mentorship over many years during all of these projects, and as supervisor for this research. Thanks also to Professor Lennart Köhler and Professor Mika Gissler for continued and unfailing encouragement at the Nordic School of Public Health, and to Professor Helmut Brand and Dr Peter Schröder-Back for their support and excellent supervision at Maastricht University.

As a working mother, none of this work would be possible without family support and a healthy environment in which to conduct this research. My husband Steve and two wonderful daughters Jennifer and Elizabeth are as much part of this work as I am. In addition, credit goes to my mother Ann Jenkins, for childcare, reading, encouragement and faith in my abilities, and to Rosaleen Edwards for her enduring practical help, positive outlook and childcare.

Finally, I would like to remember my late father Dr Chris Alexander, the original Doc Alex; and my late father-in-law Tony Edwards. It's such a shame neither of you ever read a word of this as I'm sure you would have thoroughly enjoyed being part of this experience. 


\begin{abstract}
About the Author
Denise Alexander was born in Australia in 1970, but moved to the United Kingdom as a young child. She studied English literature at Queen Mary College, University of London and worked as an editor in popular health publishing for many years. She moved into public health research with an increasing desire to contribute to scientific knowledge, having developed a passion for preventive health, particularly in relation to children. In 2002, she studied for a Masters in Health Research at the University of Manchester, while working as a public health scientist for North Wales Health Authority. While bringing up her two children, she has worked as a freelance researcher and writer on a number of European Commission public health projects forging relationships and collaborations with institutions and researchers across Europe. She began her journey towards her doctorate at the Nordic School of Public Health in 2010; and after the Nordic School ceased to exist in 2013, she became an external $\mathrm{PhD}$ student at Maastricht University in the Netherlands. Denise Alexander has recently started working as Research Coordinator on the Horizon 2020 Models of Child Health Appraised (MOCHA) project as part of a research team at Imperial College, University of London. This work furthers her interest in preventive health actions and primary care in terms of children's health in Europe.
\end{abstract}




\section{List of publications}

Alexander D, Rigby M, Sjöström M, Frazzica RG, Hillger C, Neumann G, Kirch W. (2010) Challenges and findings in measuring the behavioural determinants of obesity in children in Europe. Huber, Bern.

Alexander D, Rigby MJ, Di Mattia P, Zscheppang A (2015) Challenges in finding and measuring behavioural determinants of childhood obesity in Europe. Journal of Public Health: Volume 23 (2) pp 87-94. doi: 10.1007/s10389-015-0657-8

Alexander D, Rigby M, Minicuci N. (in draft) Measuring behavioural determinants of child maltreatment - an alternative approach focusing on preventive and risk factors. (Submitted to Central European Journal of Public Health, May 2015).

Alexander D, Rigby M, Gissler M, Kohler L, MacKay M. (2015) The challenges of compiling data profiles to stimulate local preventive health action - a European case study from child safety. International Journal of Public Health 60(4) 449-56. doi: 10.1007/s00038-015-0665-z

Alexander D, Bourek A, Kilroe J, Rigby M, Staines A. (2013) The RICHE taxonomy - an innovative means of classification of child health research. Child: Care, Health and Development 40(5) 632-9. doi: 10.1111.ccj.12119 


\section{List of EU Projects}

The following European Union-funded projects were integral to the research in this thesis:

The Scientific Platform Project on Lifestyle Determinants of Obesity (project No; 2005111) (2007)

http:/ / ec.europa.eu/health/ph_projects/2005/action1/docs/action1_2 005_frep_05_en.pdf

\section{Selected publications:}

Alexander D, Rigby M, Sjöström M, Frazzica RG, Hillger C, Neumann G, Kirch W. (2010) Challenges and findings in measuring the behavioural determinants of obesity in children in Europe. Huber, Bern.

Alexander D, Rigby MJ, Di Mattia P, Zscheppang A (2015) Challenges in finding and measuring behavioural determinants of childhood obesity in Europe. Journal of Public Health: Volume 23 (2) pp 87-94. doi: $10.1007 / \mathrm{s} 10389-015-0657-8$

Tools to Address Childhood Trauma, Injury and Children's Safety (TACTICS) project, (EU Health Programme No: 20101212) (2013) http://www.childsafetyeurope.org/tactics/

\section{Selected publications:}

Alexander D, Rigby M, Gissler M, Kohler L, MacKay M. (2015) The challenges of compiling data profiles to stimulate local preventive health action - a European case study from child safety. International Journal of Public Health 60(4) 449-56. doi: 10.1007/s00038-015-0665-z

Final project report:

http://www.childsafetyeurope.org/tactics/info/tactics-publicreport.pdf

Public Health Action for a Safer Europe, (PHASE) project (EC Grant Agreement number 2006123).

http://internazionali.ulss20.verona.it/phase_en.html

\section{Selected publications}

European Commission. (2008) PHASE - Public Health Action for a Safer Europe Final report including an Inventory of interventions in violence prevention and tools for capacity building in view of making 
violence prevention part of formal public health education and training. Regione Veneto ULSS 20 Verona, Italy. EC Grant Agreement No.: 2006123.

European Commission. (2008) PHASE - Public Health Action for a Safer Europe Report on methodological issues, deficiencies and recommendations. Regione Veneto ULSS 20 Verona, Italy. EC Grant Agreement No.:2006123.

\section{Research Inventory of Child Health in Europe (RICHE) project (DG Research Framework 7 (public health): No: 242181).}

www.childhealthresearch.eu

\section{Selected publications:}

Alexander D, Bourek A, Kilroe J, Rigby M, Staines A. (2013) The RICHE taxonomy - an innovative means of classification of child health research. Child: Care, Health and Development 40(5) 632-9. doi: 10.1111.ccj.12119

Report Summary:

http://cordis.europa.eu/docs/results/242181/periodic2-revisedpublishable-summary-period-2.pdf

RICHE Roadmaps report:

http://doras.dcu.ie/19732/1/WP4_D8_RICHE_Roadmap.pdf 


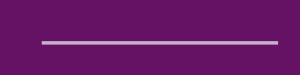

